\title{
Medical technology assessment of endoscopic surgery
}

Citation for published version (APA):

Dirksen, C. D. (1998). Medical technology assessment of endoscopic surgery. [Doctoral Thesis, Maastricht University]. Universiteit Maastricht. https://doi.org/10.26481/dis.19980619cd

Document status and date:

Published: 01/01/1998

DOI:

10.26481/dis.19980619cd

Document Version:

Publisher's PDF, also known as Version of record

\section{Please check the document version of this publication:}

- A submitted manuscript is the version of the article upon submission and before peer-review. There can be important differences between the submitted version and the official published version of record.

People interested in the research are advised to contact the author for the final version of the publication, or visit the DOI to the publisher's website.

- The final author version and the galley proof are versions of the publication after peer review.

- The final published version features the final layout of the paper including the volume, issue and page numbers.

Link to publication

\footnotetext{
General rights rights.

- You may freely distribute the URL identifying the publication in the public portal. please follow below link for the End User Agreement:

www.umlib.nl/taverne-license

Take down policy

If you believe that this document breaches copyright please contact us at:

repository@maastrichtuniversity.nl

providing details and we will investigate your claim.
}

Copyright and moral rights for the publications made accessible in the public portal are retained by the authors and/or other copyright owners and it is a condition of accessing publications that users recognise and abide by the legal requirements associated with these

- Users may download and print one copy of any publication from the public portal for the purpose of private study or research.

- You may not further distribute the material or use it for any profit-making activity or commercial gain

If the publication is distributed under the terms of Article $25 \mathrm{fa}$ of the Dutch Copyright Act, indicated by the "Taverne" license above, 
Medical Technology Assessment of Endoscopic Surgery 
(C) C. D. Dirksen, Maastricht 1998 ISBN 90-9011781-4

Grafische verzorging Drukkerij Schrijen-Lippertz Voerendaal 


\section{MEDICAL TECHNOLOGY ASSESSMENT OF ENDOSCOPIC SURGERY}

Costs, effects and diffusion of laparoscopic cholecystectomy and laparoscopic inguinal hernia repair

\section{PROEFSCHRIFT}

ter verkrijging van de graad van doctor aan de Universiteit Maastricht op gezag van de Rector Magnificus

Prof. dr. A.C. Nieuwenhuijzen Kruseman, volgens het besluit van het College van Decanen,

in het openbaar te verdedigen op vrijdag 19 juni 1998 om 12.00 uur

door

Carmen Desirée Dirksen

geboren te Sneek op 8 december 1967 


\section{Promotor:}

Prof. dr. G. Kootstra

\section{Co-promotores:}

Dr. P.M.N.Y.H. Go (Sint Antonius Ziekenhuis, Nieuwegein)

Dr. A.J.H.A. Ament

\section{Beoordelingscommissie:}

Prof. dr. J.A.M. Maarse (voorzitter)

Prof. dr. J de Haan

Prof. dr. K. Kesteloot (Katholieke Universiteit Leuven, België)

Prof. dr. F.F.H. Rutten (Erasmus Universiteit Rotterdam)

Prof. dr. R. W. Stockbritigger 
"Verlangen is voor de geest wat ademen voor het lichaam is. Als men alles zou bezitten, zou men ontgoocheld en onteveden zijn. Zelfs voor het verstand moet er steeds iets overbliven om te leren, waardoor de nieuwsgierigheid wordt gevoed. Hoop doet leven; oververzadiging van geluk is dodelijk. Bij het belonern doet men er verstandig aan nooit alles te geven. Als er niets meer te wensen valt, moet men voor alles bedacht zijn: onzalige gelukzaligheid. Waar het verlangen ophoudt, begint de vrees."

Baltasar Gracián (1647) 



\section{Contents}

1. Introduction and aim of the thesis 9

2. Introduction of laparoscopic cholecystectomy in The Netherlands.

A retrospective comparison with Extracorporeal Shock-Wave

Lithotripsy and conventional cholecystectomy.

3. Bassini repair compared with laparoscopic repair for primary inguinal hernia. A randomized controlled trial.

4. Cost-effectiveness of open versus laparoscopic repair for primary inguinal hernia.

5. Open or laparoscopic preperitoneal mesh repair for recurrent inguinal hernia. A randomized controlled trial.

6. Diffusion of six surgical endoscopic procedures in The Netherlands.

Stimulating and restraining factors.

7. Discussion, conclusions and recommendations.

Summary

Samenvatting

Dankwoord

List of Publications

Curriculum Vitae 

1

\section{INTRODUCTION AND AIM OF THE THESIS}

Part of this chapter has been published in:

- Adang E.M.M., Dirksen C.D., Baeten C.G.M.I. Medical Technology Assessment: economic evaluation of new technologies. British Journal of Hospital Medicine 1995: 53: 562-566. 


\section{Introduction}

Since the end of World War II, expenditure on health care has been growing. Health care costs have risen in both relative and absolute terms. Since 1970, government spending in Western Europe has risen from $36,5 \%$ of the gross domestic product (DGP) to almost $51 \%$ (1). Medical costs in 10 western European countries rose by an average $4,1 \%$ in real terms each year between 1970 and 1990 , while real economic growth during the same period increased by only $2,7 \%$ annually (2). The rise in health care spending is particularly worrying because it is mostly caused by factors beyond governmental control. Important reasons for these growing expenditures are rising prices, ageing of the population, increasing demands with regard to quality of care and a continuous growth in technological possibilities.

Over the last two decades, health care policy makers have become strongly interested in controlling the expenditure precipitated by the constant development and availability of new medical technologies. Employing all of these new technologies would cause growing pressure on public sector resources. Therefore, choices among medical technologies have to be made. Making choices in health care however is difficult. Without a careful consideration of the implications of choice, some groups can be partially or wholly excluded from access to health care.

\section{Medical Technology Assessment}

Health care policy decision makers have long searched for clear, unambiguous analyses to support difficult resource allocation decisions. Medical Technology Assessment (MTA) is of direct value in this context. In MTA, "technology' is not a term restricted to the description of apparatus. The Office of Technology Assessment (OTA), defined technology as: The drugs, devices, medical and surgical procedures used in medical care, and the organisation and support systems within which such care is provided (3).

MTA is a technique to evaluate different aspects of medical technology, with the aim to provide comprehensive information to the government and advisors, health insurance companies, hospital boards, clinicians and general practitioners. MTA, in general, involves the following aspects: medical effectiveness, social-economic aspects (e.g. quality of life and convalescence), efficiency (cost-effectiveness) and ethical, judicial and organisational aspects (4). Depending on the technology chosen and the perspective from which the analysis is performed, each aspect can be evaluated either more or less extensively.

MTA can be a valuable tool to assist policy makers at different levels in decision making with regard to which, where and to what extent technologies should be provided. By evaluating new technologies in an early phase of their introduction, one can monitor and/or control the diffusion of these developments, based on rational 
considerations.

Diffusion can be defined as the adoption and use of technology which follows the developmental phases (5). Ideally, a new technology should not diffuse widely before there is sufficient evidence of its effectiveness and cost-effectiveness. In the real world, however, information about the value of a new technology is often imperfect or not (yet) available. Furthermore, the diffusion of a medical technology is often subject to many other factors.

\section{MTA in the Netherlands}

In the Netherlands, the field of MTA is approximately 15 years old. The Health Council (Gezondheidsraad), which advices the government on the scientific state of the art with respect to health care, public health and environmental protection in the Netherlands, has reported on medical technologies many years, even before the term 'technology assessment' was used. In a 1983 paper, the Health Insurance Council (Ziekenfondsraad) stated explicitly that in the future all new medical technologies were to be assessed for their efficacy and cost-effectiveness and that they would be admitted to the benefit package according to their priority (6).

Perhaps the most important acknowledgement of MTA has been the foundation of a National Fund for Investigational Medicine (Fonds Ontwikkelingsgeneeskunde) in 1988, by the Minister of Health, the Minister of Science and Education, and the Health Insurance Funds Council (Ziekenfondsraad). Through this Fund the government supports clinical research in (new) medical technologies annually. Projects that have been approved by the Standing Committee on Investigational Medicine (Commissie Ontwikkelingsgeneeskunde), receive a funding for three years, after which a report is submitted to the standing committee. Since 1989, more than 80 research projects have been funded (7).

More than 20 Dutch organisations are currently involved in the process of thealth care technology assessment. Due to the investments in MTA and the involvement of important institutions in promoting MTA, the concepts of the field are becoming increasingly familiar. Policy makers have begun to understand their need for information, and they desire explicit answers from assessments before making important technology-related decisions. Also clinicians and managers are increasingly becoming aware of the need for assessments.

\section{Endoscopic surgery: a new medical technology}

The widespread application of endoscopic procedures in general surgery started with the introduction of laparoscopic cholecystectomy in 1990. In the Netherlands the first laparoscopic cholecystectomy was performed in a general hospital in Eindhoven, which was soon followed by its introduction in the University Hospital of Maastricht. 
In the course of 1990 , several practical courses on swine models were started, which accelerated the diffusion of this technique throughout the country. The first results of laparoscopic cholecystectomy in the University Hospital of Maastricht were investigated in a comparative retrospective study. In the meanwhile, a study-protocol was submitted to the Committee on Investigational Medicine in order to receive a funding for: 1) a cost-effectiveness analysis on laparoscopic versus conventional cholecystectomy in a randomized controlled trial, and 2) an evaluation of the adoption and diffusion of laparoscopic cholecystectomy in the Netherlands. In the end of 1991 , the application was rejected, primarily because the Committee questioned the feasibility of the randomization procedure, because of the expected patient preference for the laparoscopic technique. Furthermore, the diffusion study was considered to fall beyond the scope of Investigational Medicine.

The fast and widespread adoption and use of laparoscopic cholecystectomy stimulated many surgeons to explore other endoscopic applications, among which laparoscopic inguinal hernia repair. This technique was introduced in the University Hospital of Maastricht in early 1992. In the course of 1992, a study-protocol was written, comparing the costs and effects of laparoscopic repair with Bassini repair and Giant Prosthetic Reinforcement of the Visceral Sac (GPRVS) for respectively primary and recurrent inguinal hernias, by means of a randomized controlled trial. After final rejection of this application by the Committee of Investigational Medicine, the project was subsequently approved by the "University Hospital of Maastricht Fund for Outstanding and Competitive Clinical Research" (Profileringsfonds azM). The study was started in November 1993.

\section{Aim of the thesis}

The aim of this thesis is twofold.

Firstly, the costs and effects of two surgical endoscopic procedures are evaluated. Laparoscopic cholecystectomy is compared to both conventional cholecystectomy and Extra Corporeal Shock-Wave Lithotripsy (ESWL). Laparoscopic inguinal hernia repair is compared to Bassini repair and to Stoppa's Giant Prosthetic Reinforcement of the Visceral Sac (GPRVS), for respectively primary and recurrent inguinal hernias.

Secondly, the intluence of several health-care related factors on the adoption of six surgical endoscopic procedures is investigated. Based on the results of this study, an ideal diffusion profile is described. 


\section{Chapter distribution}

In chapter 2 laparoscopic cholecystectomy is compared with conventional cholecystectomy and ESWL by means of a retrospective study. Objective and subjective outcomes are compared. The costs of the above therapies are calculated from the hospitall- and Sick Fund (Ziekenfonds) perspective. Indirect costs outside the health care sector are also investigated.

In chapter 3 laparoscopic repair is compared to Bassini repair for primary inguinal hernia by means of a randomized controlled trial. Recurrence rates, postoperative morbidity and complications, pain and convalescence are assessed. Based on the 1year recurrence rates after both repairs, a cost-effectiveness analysis is performed in chapter 4. Cost-effectiveness ratios are calculated from both the hospital- and societal perspective, expressed as the incremental costs per 1-year recurrence-free patient.

In chapter 5 laparoscopic repair is compared with Giant Prosthetic Reinforcement of the Visceral Sac (GPRVS) for recurrent hernias in a randomized controlled trial. Recurrence rates, postoperative morbidity and complications, pain, convalescence and hospital costs are evaluated.

In chapter 6 the diffusion of six surgical endoscopic procedures in the Netherlands is investigated, by means of a questionnaire sent to 138 laparoscopic surgeons. Surgeons are asked to indicate the influence of 13 pre-defined factors on adoption. In an ideal diffusion model, a description is given of when and how the 13 factors can influence the diffusion of an endoscopic procedure in the desired direction.

In chapter 7 a discussion and conclusions are presented. Finally, general recommendations are given with respect to MTA in relation to the diffusion of medical services.

\section{References}

1. Rubensicin. E.S. Comparative spending of Goverwments. The Right Data. National review Books, New York, 1994.

2. Betien, P. Health care Reform in Europe. Phamacoecononics 1996:10:94.99.

3. Office of Technology Assessment. Assessing the Efficacy and Safety of Medical technologies. Government printing Office, Washington $\mathrm{DC} 1978$.

4. Banta, H.D. ILace B.R. Healh Care Technology and its Assesment. Oxford University Press. Oxford, 1993.

5. Bartista, R.N. Innovation and diffusion of health-related technologies. A conceptual framework. International Journal of Technology Assessmen in Health Care 1989:5:227-248.

6. Ziekenfondsaad. Grenzen aan de groei wan het werstrekingenpakket. Eerste Advies, 1983.

7. Banta, H.D., Oortwijn. W.J., Van Beekum, W. T. Rathenau Institute. TNO, prevention and healh. The Organwation of Health care rechnology Axsessment in the Netherdands. Meboprint. Amsterdarn, 1995. 



\section{INTRODUCTION OF LAPAROSCOPIC} CHOLECYSTECTOMY IN THE NETHERLANDS

A retrospective comparison with Extracorporeal Shock-Wave Lithotripsy and conventional cholecystectomy

Parts of this chapter have been published in:

- Dirksen C.D., Ament A.J.H.A., Go P.M.N.Y.H., Hupkens van der Elst D. The diffusion of endoscopic surgery (in Dutch). Economisch Statistische Berichten 1994; 79: 82-85.

- Go P.M.N.Y.H., Stolk M.F.J., Obertop H., Dirksen C.D., Hupkens van der Elst D., Ament A.J.H.A., Erpecum van K.J., Berge Henegouwen van G.P., Gouma D.J. Cost-effectiveness of treatment with extracorporeal shock-wave Lithotripsy, conventional and laparoscopic cholecystectomy. Surgical Endoscopy 1995; 9: 37 41 . 


\section{Introduction}

In order to determine the consequences of the introduction of a new technology on health care and society, Medical Technology Assessment (MTA) can be performed. In this type of assessment the clinical effectiveness, costs, juridical, ethical, organizational and social-economical aspects of a medical technology are evaluated (1). An important component of MTA is the cost-effectiveness analysis, in which the cost and consequences of health care programmes, devices, therapies or drugs are evaluated. A cost-effectiveness analysis can be performed from the perspective of the institution in which the technology is applied, the payer (for example the health insurance agency), or from a societal perspective. The latter includes all costs in- and outside the health care sector, which is the most complete cost-effectiveness approach (2).

One of the last phases in the MTA process is implementation: the use of MTA results for decisions and actions on different levels in health care. For example, the Minister of Health can apply the results for a reimbursement decision or for the planning of medical resources; health insurance agencies may use results in their production agreements with hospitals, and physicians and their scientific organisations may use MTA knowledge to formulate guidelines or write protocols regarding the (degree of) application of that particular technology in their daily practice. The decision whether or not to adopt a medical technology and subsequently, how and when to use it, is not easily made. As outlined above, not only the preferences of the medical profession, but also those of other actors in the field, as well as organizational and financial aspects can play a role in the decision making process.

In this paper the case of laparoscopic cholecystectomy is presented. This technique for gallbladder removal in patients with symptomatic gallbladder stone disease was introduced in the Netherlands in 1990. In this technique, the diseased gallbladder is removed by means of instruments introduced through cannulas; vision of the operative field is maintined by use of a television camera-monitor system (video-laparoscope). A laparoscopic cholecystectomy leaves the patient with four $1 / 2$ to $1-\mathrm{cm}$ incisions $(3)$. The standard surgical procedure was conventional cholecystectomy, in which the gallbladder is removed by means of a subcostal uncision of about $15-20 \mathrm{~cm}$. About 17.000 cholecystectomics are performed in the Netherlands annually (4). Another non-invasive method to treat gallstones is the Extracorporeal Shock-Wave Lithotripsy (ESWL), combined with oral dissolution therapy. With ESWL, gallstones are fragmented by externally generated shockwaves, which are transmitted through a column of water to the patient's body.

Laparoscopic cholecystectomy was expected to have a major influence on the treatment of patients with symptomatic gallbladder stone disease. Soon after its introduction in the University Hospital of Maastricht, a retrospective study was performed, in which the effects and costs of the above treatment modalities were 
compared $(5,6)$. Based on the results of this study, possible consequences of the introduction of laparoscopic cholecystectomy are described for several actors in the field of health care, in the framework of the Dutch health care system.

\section{Costs and effects of treatment with Extracorporeal Shock-Wave Lithotripsy, conventional and laparoscopic cholecystectomy}

For more than 100 years, conventional cholecystectomy has been considered the "gold standard". for the treatment of symptomatic gallbladder stones (7). However, conventional cholecystectomy carries a small risk of morbidity and mortality. Therefore, Extracorporeal Shock-Wave Lithotripsy (ESWL) with adjuvant bile acid therapy to dissolve residual fragments has recently been proposed as an alternative treatment in selected patients (8). Inilial results for ESWL were cause for optimism, with more than $90 \%$ of patients stone-free after a follow up of $12-18$ months $(9)$. More recently, the Dornier National Biliary Lithotripsy Study revealed disappointing results: only $21 \%$ of patients on ursodeoxycholic acid therapy and $9 \%$ of patients on placebo were stone-free after 6 months of follow up (10). Moreover, the introduction of laparoscopic cholecystectomy has had a major impact on the treatment of gallbladder stones. Laparoscopic cholecystectomy results in less postoperative pain and less wound infection, shorter hospital stay, earlier resumption of activities, and a better cosmetic result as compared with conventional cholecystectomy per laparotomy (11-14). A point of concern may be a higher risk of bile duct lesions during the learning curve of laparoscopic cholecystectomy (15).

In order to strike the most favourable balance between health benefits and costs it is necessary to subject the three treatment modalities for gallstone disease to a careful clinical and economical examination (16). The aim of the present study is to compare the clinical effectiveness and costs of ESWL and conventional and haparoscopic cholecystectomy. The costs and effects of the techniques are considered from the perspective of the patient, the surgeon, the hospital, the medical insurance companies and society.

\section{Materials and methods}

\section{Patients}

The present study included 55 patients treated by ESWL, 45 patients who had a conventional cholecystectomy and 47 patients who hacl a laparoscopic cholecystectomy. Mean age was comparable in the three treatment groups ( 50 |range 19-77], 48 [range 20-70] and 50 [range 26-69] years respectively). Male/female ratio was also similar (18/37, 13/32 and 13/34 respectivelly). The pretreatment work up for all patients included medical history, physical examination, serum haemoglobin. leucocytes, erythrocyte sedimentation rate, liver biochemistry (ASAT, ALAT, LDH, 
bilirubin, alkaline phosphatase) and amylase, as well as ultrasonography of gallbladder and bile ducts. In the ESWL group an additional oral cholecystography, blood coagulation tests (PT, APTT, bleeding time) and urine analysis were performed.

\section{Procedures:}

The ESWL group was treated in the period 1989-1990 with a commercially rented mobile electrohydrolic lithotriptor (Dornier MPL9000) at the University Hospital of Utrecht. Patients were accepted for ESWL according to the Munich criteria $(8,9)$. Of the patients, $60 \%$ had a solitary stone and $40 \%$ had two or three stones. Rim calcification was present in nine cases. All patients received the following medication 1 hour before ESWL: oxazepam $20 \mathrm{mg}$ orally, pethidine $25 \mathrm{mg} \mathrm{im}$, and diclofenac $100 \mathrm{mg}$ supp. If necessary, midazolam was given during the ESWL procedure. In general, 1500 shock-waves were administered with the Dornier MPL9000 during the ESWL procedure. When no adequate stone fragmentation (defined as the presence of stone fragments greater than $5 \mathrm{~mm}$ at follow up ultrasound) was obtained, the ESWL treatment was repeated up to two times, in the case of patient consent. Patients were generally admitted for one night in the hospital after the ESWL procedure. Patients were treated with oral bile acids (ursodeoxycholic acid and chenodeoxycholic acid) starting 2 weeks before ESWL until complete stone dissolution. Follow up was done at 3-month intervals and included routine haematology, liver biochemistry, amylase, urine analysis and ultrasonography of the gallbladder and bille ducts. Complete stone dissolution was confirmed by at least two negative ultrasound studies.

The conventional cholecystectomy group consisted of the last consecutive patients meeting the same criteria as for laparoscopic cholecystectomy: symptomatic cholelithiasis, without evidence of common bile duct stones or cholecystitis, and no prior upper abdominal operation. They were treated in the University Hospital of Maastricht in 1990, before the introduction of laparoscopic cholecystectomy. Conventional cholecystectomy was performed through a subcostal incision.

The laparoscopic group consisted of the first consecutive patients treated in the University hospital of Maastricht after introduction of this mode of treatment. Laparoscopic cholecystectomy was performed with the four-puncture technique using a disposable clip applier to ligate the cystic duct and the cystic artery (17). All patients from both cholecystectomy groups underwent elective surgery for symptomatic gallstone disease and had no evidence of acute cholecystitis, pancreatitis, cholangitis or bile duct stones. Intra operative cholangiography was not routinely performed. Laparoscopic and conventional cholecystectomy were performed as inpatient procedures. Patients were discharged from the hospital as soon as their clinical condition permitted.

\section{Study design}

The clinical effectiveness of the different modes of gallstone treatment were 
determined by analysing objective and subjective health outcomes. Absence of stones, as an endpoint of treament, and complications that need additional treatment were considered objective health outcomes. Subjective health outcomes consisted of remaining complaints after treatment, new complaints that emerge after and possibly as a result of treatment, and patient appreciation of treatment. Objective health outcomes of the three treatment modalities (absence of stones as an endpoint of treatment, and complications) were determined by retrospective review of the patient charts. Subjective health outcomes were evaluated by means of a questionnaire sent to all patients. Remaining persistent complaints after treatment, such as abdominal pain or biliary colic, were classified as type 1 complaints. New complaints arising after, and possibly caused by the treatment, such as diarrhea related to bile acid dissolution therapy or discomfort at the site of operation (scar) were classified as type 2 complaints. In addition, the patients were asked to score their treatment appreciation on a scale from 1 (very bad) to 10 (excellent).

Costs were assessed from the hospital-, health insurance- and societal perspective. Treatment costs were divided into costs for diagnosis of gallstone disease, selection for a particular mode of gallstone treatment (for example, costs of oral cholecystography, blood coagulation tests and urine analysis when the patient is considered for ESWL), costs for treatment (for example, costs of rental of the mobile lithotriptor), costs of hospitalization, costs of follow up at the outpatient department (including costs of bile acid dissolution treatment) and costs of complications requiring additional treatment. Hospital costs consisted of personnel, equipment and material costs. Cost-prices were based on 1991 figures and were obtained from the Economic Administrative Department of the University Hospital of Mastricht. From the societal perspective, only indirect costs outside the health care sector due to productivity losses were considered besides the hospital costs. Indirect costs were expressed as the number of days to full paid (job) and unpaid (household) activities after hospital discharge. These data were obtained by specific items in the patient questionnaire.

\section{Statistical analysis}

Statistical analysis was performed by unpaired Student-t test, one-way ANOVA, or Chi-square tests when appropriate. A two-sided $P$ value below 0,05 was considered statistically significant.

\section{Results}

\section{Objective health outcones}

Of the patients in the ESWL group, 34 patients $(62 \%)$ had one treatment session, 20 patients $(36 \%)$ had two treatment sessions, and 1 patient (2\%) had three sessions; $35 \%$ of patients were free of stones, $23 \%$ had residual fragments $55 \mathrm{~mm}$ (indicating 
adequate stone fragmentation and relative high chance of becoming stone-free at longer follow-up) and $42 \%$ had fragments $>5 \mathrm{~mm}$ (indicating treatment failure) or had undergone cholecystectomy with a follow up of 1 year. Ten patients underwent cholecystectomy (nine patients conventional, one laparoscopic) because of failure of adequate stone fragmentation and/or complete stone dissolution as well as the presence of persistent type 1 complaints that necessitated additional therapy. Results were better for patients with single (60\% of all patients) as compared with multiple gailstones ( $40 \%$ of all patients). Actuarial analysis showed that $62 \%$ of the patients with a solitary stone, but only $35 \%$ of patients with multiple stones, had complete gallstone dissolution after l-year follow up. Disappointing results were found for the nine patients with rim calcification of their gallstones. None were stone-free, two had fragments $\leq 5 \mathrm{~mm}$ and seven had fragments $>5 \mathrm{~mm}$ after a follow up of 1 year. Two patients had major complications after ESWL: obstructive jaundice and acute pancreatitis by gallstone fragments migrated to the bile duct in one patient each. Both patients had an uneventful recovery after endoscopic sphincterotomy and fragment extraction. Minor complications included biliary colic (22\%), skin thaematoma (20\%), macroscopic haematuria (31\%), and bradycardia during ESWL (2\%). Recurrence of gallstones after complete stone dissolution was observed in three patients after 8,9 and 10 months of further follow up.

No complications occurred during operation in the conventional cholecystectomy group. However, one patient had to be re-operated because of an incisional hernia. This patient had a hospital stay of 10 days. All patients were free of symptomatic resiclual or recurrent bile duct stones after a follow up period of at least 1 year.

In the laparoscopic cholecystectomy group, in three of the 47 patients $(6 \%)$ a laparotomy was necessary. One laparoscopic procedure had to be converted to laparotomy because of severe adhesions. In two patients a laparotomy had to be performed within 24 hours after laparoscopic cholecystectomy because of thaemorthage (one patient) and bile leakage from the cystic duct (one patient) because of clip dislodgenent. Both complications were solved with an uneventful postoperative course. None of the patients from the laparoscopic cholecystectomy group had symptomatic residual or recurrent bile duct stones after a follow up of at least 6 months.

\section{Subjective health outcomes}

Response-rate to the questionnaire was $89 \%$ for the ESWL group, $85 \%$ for the conventional cholecystectomy group and $91 \%$ for the laparoscopic cholecystectomy group. Persistent (type 1) complaints were reported by $59 \%$ of the patients in the ESWL group, by $11 \%$ of the patients in the conventional cholecystectomy group and $14 \%$ of the patients in the laparoscopic cholecystectomy group $(\mathrm{P}<0,001$ for $\mathrm{ESWL}$ compared with both cholecystectomy groups). In the ESWL group there was a significant relation between the absence of stones and absence of persistent type 1 (but 
not type 2) complaints ( $\mathrm{P}<0,03$ ). New (type 2) compiaints arising after and possibly caused by the treatment were reported by $12 \%$ of the ESWL patients (mainly diarthea induced by bile acid treatment), $11 \%$ of the conventional cholecystectomy group (all cases: pain or tenderness of the abdominal scar) and $5 \%$ of laparoscopic cholecystectomy patients (all cases: sore umbilicus), which was not significantly different.

Patient appreciation score of the treatment results was $6,2 \pm 3,4$ (mean \pm SD) for the ESWL group, 8,3 $\pm 1,8$ for the conventional cholecystectomy group and $9,1 \pm 1,3$ for the laparoscopic cholecystectomy group $(\mathrm{P}<0.05$ for the ESWL vs both cholecystectomy groups). Patient appreciation score after ESWL was related to the efficacy of fragmentation and stone disappearance: $8,8 \pm 1,8$ in the case of absence of stones, $6,8 \pm 2,7$ in the case of fragments $\leq 5 \mathrm{~mm}$ and $3,2 \pm 2,8$ for fragments $>5 \mathrm{~mm}$ $(P<0,05)$. In addition, presence of residual type 1 symptoms had an appreciable influence on patient appreciation score in the ESWL patients $(8,4 \pm 1.8$ for asymptomatic patients, $7,5 \pm 1,7$ for patients with minor symptoms, $2,3 \pm 2,7$ for patients with severe symptoms; $\mathrm{P}<0,05)$.

\section{Hospital cost}

Operation costs were based on Operation Theatre (OT) times of 155 minutes for conventional- and 220 minutes for laparoscopic cholecystectomy (operating times were 130 and 195 minutes respectively). Mean hospital stay was $2,4 \pm 0,69$ days in the ESWL group, $10 \pm 2,49$ days in the conventional cholecystectomy group and 3,4 \pm 1,51 days in the laparoscopic cholecystectomy group $(\mathrm{P}<0,05)$. Mean costs per patient for ESWL were based on Dfl $\rfloor 1.800$ lithotriptor rental per day, during which 4 or 5 patients could be treated. In table 1, the average hospital costs per patient for ESWL, conventional and laparoscopic cholecystectomy are listed in 1991 Dutch guilders.

The costs for diagnosis and selection are the highest for ESWL as compared to both types of cholecystectomy, because of the additional oral cholangiogram and laboratory tests. The treatment costs consist of lithotriptor rental for ESWL and operative costs for both cholecystectomies. The laparoscopic cholecystectomy is more expensive than the conventional cholecystectomy, mainly due to the use of the disposable clip applier and the longer operative/OT time (which is reflected in the personnel costs). The follow up after cholecystectomy consists of a last visit at the outpatient department whereas after ESWL several visits, repeated ultrasonography, laboratory tests, and prolonged medication tor gallstone resolution are necessary.

The following costs were considered to be additional costs caused by complications in the ESWL group: 1) the costs of conventional cholecystectomy because of failure of complete stone dissolution, combined with persistent complaints $(10 / 55 \times$ costs of cholecystectomy); and 2) the costs of ERCP performed in two patients (2/55 x cosis of $\mathrm{ERCP}+$ hospital stay). The three laparotomies in the laparoscopic cholecystectomy group were performed during initial hospital stay and therefore prolonged the mean 
hospital stay of the whole group. The proportional costs of the additional laparotomies ( $3 / 47 \times$ costs of laparotomy), performed to manage the complications are added. Complication costs for the conventional cholecystectomy group include the costs of repair of an incisional hernia in one patient $(\mathbb{1} / 45 \times$ costs of incisional hernia repair + hospital stay).

Table 1. Hospitall cossiss per patient (means)

\begin{tabular}{llll}
\hline & ESWL & CC & LC \\
\hline $\begin{array}{l}\text { Diatgnosis and selection } \\
\text { Operation/treatment }\end{array}$ & 599 & 187 & 187 \\
$\quad$ personnel & n.a. & 734 & 1.050 \\
$\quad$ matterial & n.a. & 379 & 939 \\
$\quad$ equipment & $3.567^{\text {* }}$ & 99 & 115 \\
Hospital stay & 341 & 1.420 & 483 \\
Follow up & $592^{*} *$ & 18 & 18 \\
$\quad$ Subtotal & 5.099 & 2.837 & 2.792 \\
Complications & & & \\
- ERCP + hospiral stay & 24 & n.a. & n.a. \\
- Cholecystectomy + hospital stay & 515 & n.a. & n.a. \\
- Laparotomy & n.a. & n.a. & n.a. \\
- Incisional herniat + hospital stay & n.a. & 48 & 2.815 \\
$\quad$ Total & 5.638 & 2.885 & .
\end{tabular}

*) Consists of equipment, material, personnel costs and provision for the company providing the lithotriptor. *as) Costs of three outpatient department visits, costs of laboratory tests and ultrasonography.

\section{Health insurance perspective}

In table 2 the maximum tariffs are given for the three treatment modalities.

Table 2. Public bealth insurance costs per patient (means)

\begin{tabular}{|c|c|c|c|}
\hline & ESWL & $\mathrm{CC}$ & LC \\
\hline Diagnosis and selection & 299 & 193 & 193 \\
\hline Operationftreatment & 3.873 & 1.473 & 1.473 \\
\hline Hospital stay & 2.040 & 8500 & 2.890 \\
\hline Follow up & 0 & 0 & 0 \\
\hline Subtotal & 6.212 & 10.166 & 4.556 \\
\hline \multicolumn{4}{|l|}{ Complications } \\
\hline - ERCP + hospital stily* & 113 & n.a. & n.a. \\
\hline - eholecystectomy + hospital stay & 1.813 & n.a. & n.a \\
\hline 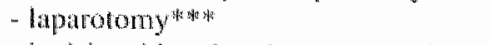 & n.a. & n.a. & 70 \\
\hline - incisional hernia + hospital stay & n.a. & 218 & n.a. \\
\hline Total & 8.138 & 10.384 & 4.626 \\
\hline
\end{tabular}

*) $2 / 55 \times$ (reimbursement ERCP + reimbursemen of 3 inpatient days)

w) $10 / 55 \times$ (reimbursement cholecystectomy + reimbursement of 10 inpatient days)

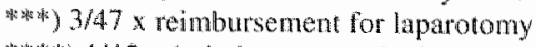

*3* $1 / 45 \times$ (rembursement for incisional hernia repair + reimbursement of 10 inpatient days) 
In case of a successful and uncomplicated treatment, conventional cholecystectomy is the most expensive procedure to reimburse for the public health insurance company. If complications and failures are included only the additional inpatient procedures and hospital days are reimbursed. Additional outpatient visits are not reimbursed: for outpatient visits hospitals receive a fixed amount per patient of Dfl 59 per year, independent of the number of visits.

\section{Indirect costs outside the health care sector}

Paid activities (job) were performed before treatment in $48 \%$ of the ESWL patients, $34 \%$ of the conventional cholecystectomy group and in $32 \%$ of the laparoscopic cholecystectomy group ( $P<0,05$ for ESWL ws both cholecystectomy groups). Paid (job) activities were completely resumed after an average of 7 days in the ESWL group, after 43 days in the conventional group, and after 19 days in the laparoscopic cholecystectomy group $(\mathrm{P}<0,05)$. Unpaid (household) activities were fully resumed on average 4 days after hospital discharge in the ESWL group, after 39 days in the conventional group, and after 13 days in the laparoscopic cholecystectony group $(\mathrm{P}<0,05)$.

\section{Discussion}

In the present study, health outcomes and costs of three treatment modalities for symptomatic gallbladder stone disease were compared. Ideally, such a comparison should be done in a prospective randomized study. However, it is very unlikely that such a prospective randomized study will ever be performed: firstly, the preference of the patient and physician for a particular treatment will preclude adequate randomization and secondly, a large proportion of patients (up to 70-80\%) is not eligible for ESWL (18). A retrospective study therefore appeared to be the 'secondbest' alternative.

\section{Effects}

The present study revealed that laparoscopic cholecystectomy is an effective treatment with a low complication rate. Although the issue has brought up possible increase of bile duct lesions during the learning curve of laparoscopic cholecystectomy (15), this was not found in the study. Most patients lost their original type 1 complaints. Type 2 complaints were reduced as compared to the conventional cholecystectomy. Patient appreciation score after laparoscopic cholecystectomy was high.

Objective health outcomes in patients treated by ESWL, determined by absence of stones and complications, lay somewhere between the best (9) and the worst (7) results reported in the literature and were comparable with more recent data $(19,20)$. Subjective health outcomes after ESWL were gathered by patient questionnaires. Up to $60 \%$ had persistent type $\|$ complaints, which was related to the presence of stones. 
Patient appreciation of the result of treatment was determined to a large degree by whether complete stone dissolution was reached. In the case of complete stone dissolution, patient appreciation was high and similar to scores after conventional and Iaparoscopic cholecystectomy. The appreciation score was low in the case of residual fragmenis.

ESWL offers some potential advantages over surgical treatment. Mortality and norbidity are probably lower for ESWL. Nevertheless, public acceptance of ESWL will depend on whether sufficienty high rates of complete stone clearance are reached, as indicated by patients" appreciation scores in the present study. In our opinion this means, with present technology, that ESWL should only be offered to patients with solitary, completely radiolucent stones, preferably with a diameter $\leq 15$ mm. An additional advantage of selecting patients with solitary stones is a much lower recurrence rate: $11 \%$ for solitary stones after 3 -year follow up as compared with up to $50 \%$ for multiple stones (2),22). Although complete stone dissolution can be reached in the case of stones with a calcified rim (23), the present study revealed that results are disappointing in this group of patients. None of the nine patients with calcified rim stone had complete clearance of gallstone fragments after 1-year follow up. The presence of significant stone calcification probably precluded complete dissolution by the ursodeox ycholic acid chenodeox ychollic acid combination.

\section{Costs}

From the hospital perspective, ESWL was the most expensive treatment modality. This was determined by the cost of patient selection, lithotriptor rental, follow up and complications or failures after ESWL. The laparoscopic cholecystectomy is the least expensive treatment modality, which is primarily caused by a short hospital stay following laparoscopic cholecystectomy. It is notable that operating cost are higher as compared to conventional cholecystectomy. This difference is largely determined by the longer operating time and the use of disposable instruments. Nevertheless, due to the longer hospital stay, conventional cholecystectomy becomes a little more costly as compared to the laparoscopic technique. Regarding costs for ESWL, a few remarks should be made. In this study, the addirional costs for stone recurrence during longterm follow up were not included. The real follow up costs of ESWL may therefore be higher than presented in our study. On the other hand, in many centres the ESWL procedure is now pertomed as a complete outpatient procedure, which may also influence the cost analysis. Another factor is the lithotriptor rental. When the device is owned by the hospital, than costs per patient depend on the initial investment, its cupacity and the possibility to use the machine for other purposes, for example kidney stones.

From the health insurance perspective, the conventional cholecystectomy is the most expensive treatment. This is caused by the number of hospital days that have to be reimbursed by the public health insurance (Sick Fund). In this respect it should be 
mentioned that differences in hospital stay are also detemined by cultural differences. In the USA, the hospital stay after conventional cholecystectomy will be very short. compared to Japan, where an average hospital stay of 3 weeks is acceptable. The present study showed an average hospital stay of 10 days for conventional cholecystectomy; if this should be reduced, our conclusions would change considerably.

From the sociatal perspective, conclusions depend on how indirect costs due to absence from work (and other activities) are quantified. Hospital costs of ESWL are about twice as high as compared to both cholecystectony groups, but revm to work is 12 days earlier as compared to laparoscopic cholecystectomy, and 36 days arlier as compared to conventional cholecystectomy. In selected patients. ESWL may therefore be a cost-effective treatment at the societal level. However, for the majority of patients undergoing the surgical procedure, laparoscopic cholecystectomy seems to be the procedure of choice. It needs to be mentioned that a significantly higher proportion of patients in the ESWL group performed work as compared to both cholecystectomy groups. This finding suggests that these patients might have preferred ESWL therapy, because they expected a shorter interuption of their paid activities.

\section{Laparoscopic cholecystectomy in the Dwch healh care system}

The results of the present study pointed out that laparoscopic cholecystectomy is preferred in patients with symptomatic gallbladder stone disease, since it appears to be the most cost-effective treatment modality. However, the use of a technology is not only determined by its cost-effectiveness, but also by the financial system in which it is introduced. In the following, the consequences of laparoscopic cholecystectomy are described from different perspectives: the hospital and physicians, the public health insurance and the society as a whole.

In the Netherlands, all hospitals receive an annual 'closed-end' budget, with which all care must be provided. If the budget is exceeded, the hospital is, in principle, financially responsible for the deficiencies. The present study revealed that ESWL is the most costly and least affective treatment modality as compared to both conventionall and laparoscopic cholecystectomy. Laparoscopic cholecystecomy and conventional cholecystectomy have comparable hospital costs. The calculation, as presented in table 1, showed that the higher operating cost of laparoscopic cholecystectomy are fully compensated by the savings due to reduction in hospital stay of about 6 days.

In the current budgeting system, however, hospitals have every incentive to stay full (24). A structural decline of inpatient days may result in a loss of beds by a ministerial decision. A reduction in hospital stay, as a result of laparoscopic cholecystectomy, may therefore indirectly lead to a greater tumover of patients. This subsequently generates higher cost per inpatient day.

To surgeons, the laparoscopic technique requires a considerable leaming curve, 
because of the different eye-hand coordination and the two-dimensional view. Even once this learning curve is passed, laparoscopic cholecystectomy will contimue to require a longer operating time. If this is not reflected in the reimbursement, both the hospital and physicians may experience a financial barrier to perform this technique. Up to 1994, the reimbursement for laparoscopic cholecystectomy was similar to conventional cholecystectomy. By now the surgeon's fee for laparoscopic cholecystectomy is about Df1 14 higher. The hospital reimbursement is still the same, despite the higher operating costs. Of course, surgical and hospital performance is not only determined by financial considerations: an improvement in quality of care surely provides an incentive for both parties to adopt Japaroscopic cholecystectomy. Another possible advantage is that a greater turnover of patients might reduce the waiting list. A reduction in the waiting list may subsequently lead to lower costs (of administration, additional outpatient department visits, etc.) per patient (25).

For public health insurance companies, laparoscopic cholecystectomy seems the most preferable treatment. As compared to ESWL, the laparoscopic treatment is both less costly and more effective. Furthermore, a decline in inpalient days of $65 \%$ as compared to conventional cholecystectomy implies a substantial saving, considering the large number of cholecystectomies performed annually. In practice, however, this potential saving will hardly be realised: the pressure of the waiting-list will constantly fill the 'empty beds'. Health insurance agencies have no incentive to stimulate the use of laparoscopic cholecystectomy when the ultimate production level increases with it (26).

Laparoscopic cholecystectomy only seems really cost-effective if viewed from a societal perspective. As compared to ESWL, laparoscopic cholecystectomy has lower hospital costs, but higher indirect costs due to a difference of 12 days in return to work. However, even when assumed that the total (direct + indirect) costs of ESWL are comparable to the total costs of laparoscopic cholecystectomy, the latter is still more effective in the majority of patients with symptomatic cholelithiasis. In addition, if waiting-lists can actually be reduced by introducing minimally invasive procedures, this might possibly lower the costs of sick-leave prior to hospitalization.

The authors conclude that the current Dutch health care system does not always provide incentives to adopt and use a promising new technique. Firstly, the higher hospital- and physicians' costs of an efficient, though more expensive procedure are not really compensated by a reduction in inpatient days; the waiting-list, as one of the production-drivers in health care, makes potential savings practically invisible to hospitals and health insurers. Secondly, the reimbursement may not always be a proper reflection of the efforts and costs made for that particular procedure. Thirdly, the potential advantage of laparoscopic cholecystectomy that appears in the social sector cannot be applied in the health care sector. 


\section{References}

1. Habbema, I.D.F. (ed.). Medische technologie assessment en gezondheidszorgheleid. Alphen an den Rijn: Samson Stafleu, 1989.

2. Drummond, M.F., Stoddard, G.L., Torrance, G.W. Methods for the economic evaluation of health care programmes. Oxford: Oxford University Press, 1987.

3. Holohan, T.V. Laparoscopic cholecystectomy. The Lancet 1991;338:801-803.

4. SIG. Health Care Information. Wageningen Veenman Drukkers, 1991.

5. Dirksen, C.D. Behandeling van symptomatische cholelithasis door midded van conventonele cholecystectomie, laparoscopische cholecystectomic of extracomorale schokgolf lithotripsie: een vergelijkend effectiviteitsonderzoek. 1992. (doctoraal scriptie, Gezondheidswetenschappen. Beleid en Beheer).

6. Hupkens wan der Elst, D. Laparoscopische cholecystectomie, conventionele cholecystectomie en extracorporale schokgolf lithotripsie; een kostenwergelijking. 1992. (doctoraal scriptic. Gezondheidswetenschappen, Beleid en Behear).

7. McSherry, C.K. Cholecystectomy: the golden standard. The American Jownat of Surgery 1989: 158:174-178.

8. Sauerbruch, T., Delius, M., Paumgartner, G., et al. Fragmentation of gallstones by extracorporal shock waves. New England Joumal of Medicine 1986,314:818-822.

9. Sackmann, M., Delius, M., Sauerbruch, T., et al. Shock-wave lithotripsy of gallbladder stones: the first 175 patients. New England Joumal of Medicine 1988;318:393-397.

10. Schoenfield, L.J., Berci, G., Camovale, R.L., et al. The effect of ursodiol on the efficacy and safety of extracorporeal shock-wave lithotripsy of gallstones: The Domier National Lithotripsy Study. New England Journal of Medicine 1990;323:1239-1245.

11. Gadacs, T.R. Talamini, M.A. Traditional versus laparoscopic cholecystectomy. The Americam Jommal of Surgery 1991;161:336-338.

12. Grace, P.A., Quereshi, A., Coleman, J., et al. Reduced postoperative hospitalization after laparoscopic cholecystectony. British Journal of Surgery 1991;78:160-162.

13. Nathanson, L.K., Shimi, S., Cuschieri, A. Laparoscopic cholecystectomy; the Dundee technique. British Journal of Surgery 1991;78:155-159.

14. Reddick. EL, Olsen, D.O. Laparoscopic laser cholecystectomy. A comparison with mini-lap cholecystectomy. Surgicat Endoscopy 1989:3:131-133.

15. Meyers, W.C., Branum, G.D., Faruk. M. et al. A prospective analysis of 1518 lapitroscopic cholecystectomies. New England Joumal of Medicine 1991:324:1073-1078.

16. Guyatt, G., Drummond, M., Feeny, D., et at. Guidelines for the clinical and economic evaluation of health care technologies. Socal Science and Medicine 1986,22:393 408 .

17. Olsen, D.O. Laparoscopic cholecystectomy. The American Journal of Surgery 1991:161:339344.

18. Erpecum van, K.J. Berge Henegouwen van, G.P., Stoelwinder, B., Stolk, M.F.J., Eggink, W.F., Govaert, W.H.A. Cholesterol and pigment gallstone disease: comparison of the reliability of three bile tests for differentiation between two stone types. Scandinawan Jourpal of Gastmenterology 1988:23:949-954.

19. Barkun, A.N.G., Ponchon, T. Extracoropreal biliary lithotripsy. Review of axperinental studies and a clinical update. Amnals of Internal Medicine 1990;112:126-137.

20. Vergunst, H., Terpstra, O.T., Brakel, K.. Lameris, J.5., Blankenstein van, M., Schroeder, $\mathbb{1} . H$. Extracorporeal shock-wave lithotripsy of gallstones. Possiblities and limilations. Annals of Surgery 1989;210:565-575.

21. Sackmann, M., Ippisch, E., Sauerbruch, T., Holl, J., Brendel, W., Paumgartner, G. Early" 
gallstone reurence after succes ful shock-wave therapy. Gastroenterology 1990,98:392-396.

22. Villanowa, N., Bazzol. F., Taron. F, et al. Gallstone recurrence after successul oral bile acil treatment: at 12-year follow up study and evaluation of long-term postdissolution treatmen. Gastroenterology 1989:97:726-731.

23. Sackmam, M., Paulekki, J.. Delius, M. et al. Nonimasive therapy of gallbadder calculi with a radiopaque rim. Gastroenterology $1992 ; 102: 988-993$.

24. Banta, H.D. Minmally Invasive Surgery. Implications for hospitals, health workers, and patients Brits Medical Joumal 1993; 307;1546-1549.

25. Jversen. T". A theory of the hosputal waing lists. Joumal of Healn Economics 1993:12:55-71.

26. Vondeling, H., Haerkens, E., Wir de, A., Bos, M., Banta, H.D. Difusion of Minimally Invasive Therapy in the Netheriands. Heath Policy 1993:23:67-81. 
BASSINI REPAIR COMPARED WITH LAPAROSCOPIC REPAIR FOR PRIMARY INGUINAL HERNIA

A randomized controlled trial

This chapter will be published in:

- Dirksen C.D., Beets G.L., Go P.M.N.Y.H., Geisler F.E.A., Baeten C.G.M.I., Kootstra G. Bassini repair compared with laparoscopic repair for primary inguinal hernia: a randomized controlled trial. European Joumal of Surgery (in pressi). 


\section{Introduction}

Inguinal hernia repair is the most common operation in The Netherlands, with approximately 24000 operations done annually (1). Modern hernia surgery started a century ago with Bassini's description of how to close the defect in the posterior wall of the inguinal canal by approximating its musculo aponeurotic edges through an inguinal incision (2). In several European countries, most inguinal hernia repairs followed Bassini's principles (3-5). In the University Hospital of Maastricht, the Bassini repair was the standard operation for primary inguinal hernia.

Another approach is to cover the abdominal wall defect with a prosthetic mesh. The mesh can be placed anteriorly on the musculo aponeurotic layer of the abdominal wall (6), or posteriorly in the preperitoneal space (7). The recurrence rates of both repairs are claimed to be low $(8,9)$.

Surgeons have started to do inguinal hernia repairs laparoscopically using various techniques. The transabdominal preperitoneal (TAPP) repair has become the most common laparoscopic approach because it is relatively simple and offers a good view of the anatomical structures (10-13). Laparoscopic inguinal hernia repair is essentially based on the principle of the open preperitoneal mesh repair. Recurrence rates ranging from $0 \%-2 \%$ have been reported $(12,14-18)$. The laparoscopic repair has the potential to combine a low recurrence rate with a reduction of the operative trauma.

Laparoscopic hernia repair was introduced in the University Hospital of Maastricht in 1992. After an initial learning period, a randomized controlled trial was started in November 1993. The aim of the study was to compare the effectiveness of the laparoscopic TAPP repair with the standard Bassini repair for primary inguinal hernias.

\section{Patients and methods}

\section{Study design and parient enrolment}

An independent mon-clinical investigator was assigned to the project by the Board of Directors of the University Hospital of Mastricht. The study was approved by the institutional ethics committee and by the scientific committee. All patients eligible for general anaesthesia (American Society of Anaesthesiologists (ASA) grades 1-III), between 20 and 80 years of age, with a primary inguinal hernia were randomly assigned to have either a Bassini or a laparoscopic inguinal hernia repair. Pregnant women, patients with coalgulation disorders, advanced carcinoma, history of lower abdominal or other pelvic surgery (except appendicectomy), and patients needing other operations simultaneously were excluded from randomisation. After obtaining a informed consent, patients were randomized at the outpatient clinic using sealed
envelopes. 


\section{Oucomes and instruments}

Postoperative morbidity, convalescence, pain, and recurrence were recorded. Hospital stay was standardized: patients were admitted the day before operation and were routinely discharged the morning after the operation, whenever possible. Operating time, operative findings, postoperative complications, and postoperative hospital stay were also recorded. A visual analogue scale (VAS) from 0 (no pain) to 10 (intolerable pain) and a verbal rating scale (VRS) with four possible responses (no pain, mild pain, moderate pain, severe pain) were used simultaneously to record pain. At discharge patients received a questionnaire to report their experience of pain, and amount and type of analgesia during the first seven postoperative days. The date of resumption of paid work and physical activities (such as sports, walking, and bicycling) was recorded. At discharge, patients were explicitly instructed that there were no restrictions governing return to routine activities, except that it should not cause discomfort or pain. Physical examinations were made at the outpatient clinic 10 days (first control visit) and six weeks (second control visit) postoperatively. Two abdominal muscle exercises were done preoperatively and one day, 10 days, and six weeks postoperatively. These exercises, a modification of a test described by Payne et al. (19), were used as an objective measure of physical performance. In the first test the patient crosses the arms on the chest and does curled sit-ups. In the second test the patient pulls up his flexed legs. These exercises were performed for 30 seconds or until the patient felt uncomfortable. Postoperative performance was expressed as a percentage of preoperative performance. To find out the recurrence rate all patients are examined once a year for five years. Recurrence is defined as a symptomatic or asymptomatic defect in the abdominal wall with herniation of abdominal contents, exacerbated by a Valsava manoeuvre.

\section{Statistical analysis}

Recurrence was the primary outcome of the study. A power analysis, based on recurrence rates of $1 \%$ for the laparoscopic repair and $12 \%$ for a Bassini repair, with $\alpha$ $=0,05$ and $\beta=0,1$, set the number of required hernias on $100 /$ treatmem group. To achieve at least the number of required hernias, the number of patients was set at 200 . To correct for possible preoperative withdrawals, 220 ( $10 \%$ extra) envelopes were prepared. Results were analysed according to "intention to treat". Work was subdivided in not-strenuous, moderate, or strenuous, according to the patient's perception. The Kolmogorov-Smirnov test was used to test for normality. The unpaired Student-t test was used to assess the significance of differences between normally distributed variables. The unpaired Mann-Whitney test was used to assess the significance of differences between skewed data or ordinal variables, and the Chisquare test was used for categorical variables. Two-sided probabilities of less than 0,05 were accepted as significant. 


\section{Chapter 3}

\section{Anciesthesia}

Premedication, anaesthesia, and postoperative pain medication were standardized so that we could compare postoperative pain. Premedication consisted of paracetamol $\mathrm{Ig}$ orally or rectally. Antibiotics were not used. All patients had a general anaesthetic consisting of thiopentone sodium $4-5 \mathrm{mg} / \mathrm{kg}$, vecuronium $0,1 \mathrm{mg} / \mathrm{kg}$ and fentanyl 1 $\mu \mathrm{g} / \mathrm{kg}$. Anaesthesia was maintained with a mixture of nitrous oxide and oxygen. Isoltorane up to 1,2 vol \% and intravenous boluses $1 \mu \mathrm{g} / \mathrm{kg}$ were used when needed. No opiate antagonists were used at the end of anaesthesia. Postoperative pain management consisted of paracetamol Ig up to three times daily when needed.

\section{Surgical techniques}

Bassini repair - the inguinal canal is opened and inspected. An indirect sac is dissected off the spermatic cord, ligated, and transected at the level of the internal ring. A direct sac is inverted. The conjoined tendon (intermal oblique muscle, transversus abdominis aponeurosis and transwersalis fascia) is sutured to the inguinal ligament using interrupted absorbable (polyglactin 910 ) surures. The external oblique fascia is closed over the cord.

Laparoscopic repair (TAPP) - a carbon dioxide pneumoperitoneum is established with a Verres needle. Three cannulas are used for access to the abdominal cavity. The peritoneum is opened at the upper border of the inguinal hernia defect from the medial umbilical ligament to the level of the iliac spine. A direct sac is reduced, and an indirect sac is reduced and dissected off the vas deferens and the testicular vessels. If the indirect sac is large it is transected. A polypropylene mesh $10 \times 15 \mathrm{~cm}$ with rounded edges is positioned over the inguino-femoral area and the defect, so that is widely overlapping the edges. The mesh is not anchored by staples or sutures. The peritoneum is closed with a running absorbable suture. If a hernia on the other side is discovered incidentally it is repaired at the same time.

Bassini repairs were performed by all surgeons, or by surgical residents assisted by a surgeon. Laparoscopic repairs were done by three laparoscopic surgeons, or by residents assisted by a laparoscopic surgeon. All laparoscopic surgeons had performed at least 20 laparoscopic repairs before they entered the study.

\section{Results}

Between 15 November 1993 and 31 Jully 1995, 210 patients were randomized to have either a Bassini or laparoscopic repair. A total of 175 patients participated in the trial (rables 1 and 2). More patients had a bilateral hernia repair in the laparoscopic group (because of the incidentally found contralateral hernias) but the difference was not 
Table 1. Randomization and participation in the trial

\begin{tabular}{llll}
\hline & Bassini & Laparoscopic repair & Total \\
\hline Patients randomized & 109 & 101 & 210 \\
Withdrawals preoperatively & 22 & 13 & 35 \\
Patients in trial & 87 & 88 & 175 \\
Patients not randomized because of: & $\ldots$ & $\ldots$ & 159 \\
Exclusion criteria & $\ldots$ & $\ldots$. & 47 \\
Outpatient treatment / regional anaesthesia & $\ldots-$ & $\ldots$ & 58 \\
Patient refused & $\ldots$ & $\ldots$ & 32 \\
Reason not recorded & $\ldots$ & $\ldots$ & 22 \\
\hline
\end{tabular}

\#Because of long waiting-list period or need for regionat anaesthesia.

Table 2. Comparability of groups

\begin{tabular}{|c|c|c|c|}
\hline & & $\begin{array}{l}\text { Bassini } \\
(n=87)\end{array}$ & $\begin{array}{l}\text { Laparoscopic repair } \\
(\mathrm{n}=88)\end{array}$ \\
\hline \multicolumn{2}{|c|}{ Men } & $85(98)$ & $88(100)$ \\
\hline \multicolumn{2}{|l|}{ Mean age (years) $\pm S D$} & $54 \pm 13$ & $53 \pm 15$ \\
\hline \multicolumn{2}{|c|}{ Mean Body Mass Index $\pm 5 D$} & $25 \pm 3$ & $25 \pm 3$ \\
\hline \multicolumn{2}{|c|}{ No of hernias } & 103 & 114 \\
\hline \multicolumn{2}{|l|}{ Unilateral hernia } & $71(82)$ & $62(70)$ \\
\hline \multicolumn{2}{|l|}{ Bilateral hernia } & $16(18)$ & $26(30)$ \\
\hline \multicolumn{2}{|l|}{ Employed patients } & $46(53)$ & $57(65)$ \\
\hline \multirow[t]{3}{*}{ Type of work: } & Not-strenuous & $13(28)$ & $19(33)$ \\
\hline & Moderate & $20(43)$ & $25(44)$ \\
\hline & Strenuous & $13(28)$ & $13(23)$ \\
\hline \multicolumn{2}{|c|}{ Physically active patients } & $70(80)$ & $73(83)$ \\
\hline
\end{tabular}

Figures are number (\%) of patients unless otherwise stated

Operative results (table 3 ).

Eighty-five Bassini repairs (83\%), and 32 laparoscopic repairs (28\%) were done by surgical residents assisted by surgeons. The other operations were done by surgeons. Operating time was significantly longer for laparoscopic compared with Bassini repairs. The mean operating times for unilateral repairs by residents were slightly but not significantly longer than those done by senior surgeons.

There was one injury to the vas deferens during a Bassini repair. One laparoscopic repair was converted to an open anterior repair because the equipment failed. In the laparoscopic group there was one puncture of the stomach by a Verres needle without further consequences, and one testicular vessel injury without subsequent testicular atrophy. 
Table 3. Results and duration of hospital stay

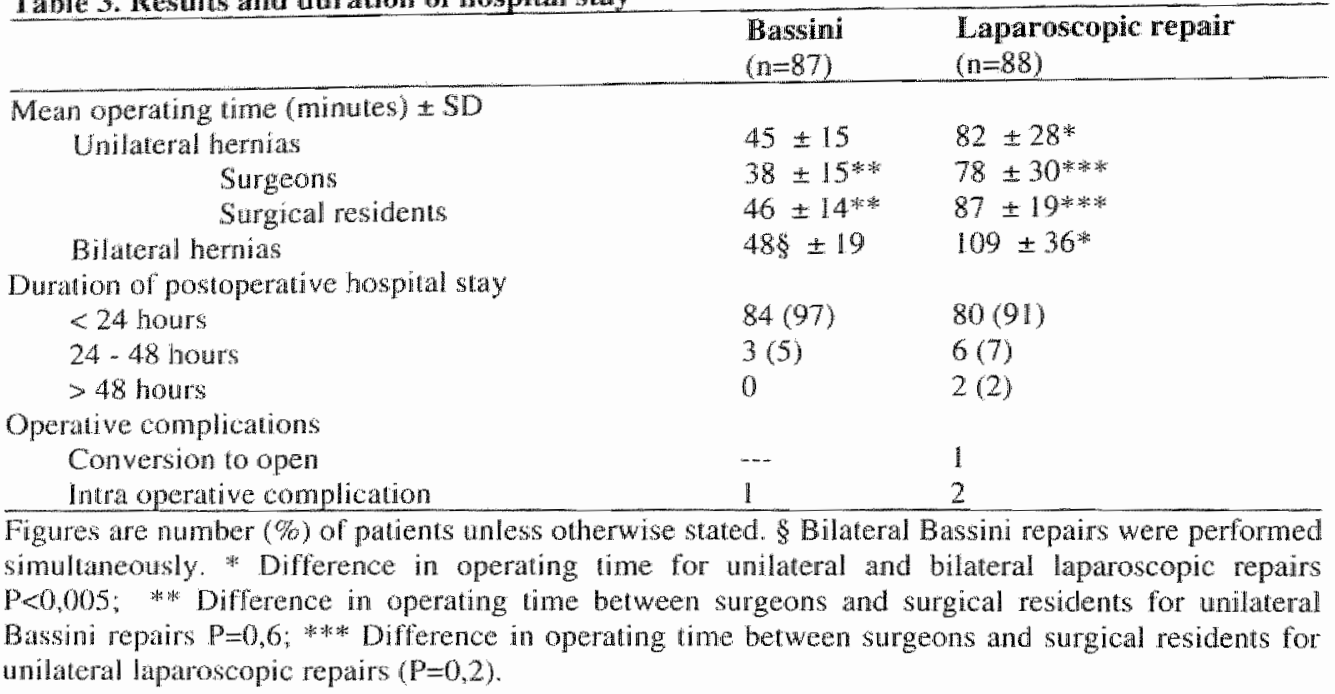

Postoperative morbidity (table 4).

After a Bassini repair half the patients had inguinal hypaesthesia. In the laparoscopic group there were more inguino-femoral ecchymoses and two patients were operated on for painful haematomas. After laparoscopic repair, two patients developed urinary tract infections and one patient urinary retention.

Table 4. Postoperative morbidity and complications

\begin{tabular}{|c|c|c|}
\hline & $\begin{array}{l}\text { Bassini } \\
(n=87)\end{array}$ & $\begin{array}{l}\text { Laparoscopic repain } \\
(n=88)\end{array}$ \\
\hline No. of hernias: & 103 & 114 \\
\hline Inguinal hypacsthesiathernia & $54(52)$ & 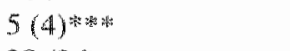 \\
\hline Groin swellinghenta & $25(24)$ & $30(26)$ \\
\hline Inguino lemoral ectymosis/hemial & $16(16)$ & $33(29)^{*}$ \\
\hline Wound inloction/patient & $1(1)$ & $2(2)$ \\
\hline Urinary complications/patient & 0 & $3(3)$ \\
\hline Pulmonary complications/patient & $1(\mathbb{1})$ & 0 \\
\hline \multicolumn{3}{|l|}{ Re-operation tor: } \\
\hline Recurrence & 0 & $2(2)$ \\
\hline Haematoma & 0 & $2(2)$ \\
\hline
\end{tabular}

\section{Pain and use of analgesics (figure 1)}

The preoperative VAS scores and the VAS scores at 6 weeks did not differ significantly between the Bassini and laparoscopic repairs. The mean (SD) VAS scores were $2,9(1,6)$ compared with $2,0(1,6)(\mathrm{P}=0,002)$ during the first postoperative 
week (day 1-day 7 ). Ten days postoperatively VAS scores were $0,9(1,4)$ compared with $0,4(0,9)(\mathrm{P}=0,045)$ for the Bassini and laparoscopic repairs respectively. The VAS correlated positively with the VRS ( $\mathrm{P}<0,001)$. The median total analgesic intake after seven days of 2 (mean 6,4; range 0-54) tablets in the Bassini group was significantly different from the median of 0 (mean 3,0; range 0-42) tablets in the laparoscopic group $(\mathrm{P}=0,008)$.

Figure 1. Visual analogue score betore and after repar by Bassini (solid bars) and laparoscopic (shaded bars) techniques.

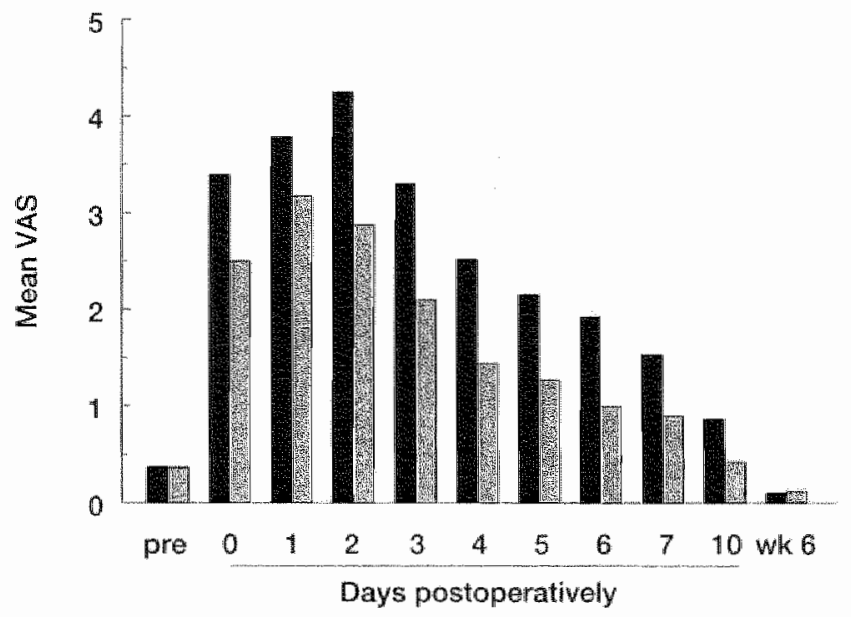

\section{Resumption of acrivities}

The mean period of disability 22 (SD 11,2; range 1-44) was days in the Bassini group and 14 (SD 10,1; range 1-42) days in the laparoscopic group $(P<0,001)$. Figure 2 presents results for people with not-strenuous, moderate, or strenuous work. Return to physical activities was 27 (SD 12,6; range 1-57) days after a Bassini repair and 17 (SD 12,2 ; range 1-43) days after a laparoscopic repair $(\mathrm{P}<0,001)$. The aggregated percentages of patients that had returned to unrestricted duties and physical activities at time of their second control visit are shown in figures 3 and 4. 
Chapter 3

Figwre 2. Days before return to work stratified by type of work after Bassini (solid bars) and laparoscopic (shaded bars) hemia repalirs, * $\mathrm{P}<0,05$; * $\mathrm{P}<0,005$ (Student-t test). Numbers above bars are number of days (number of patients).

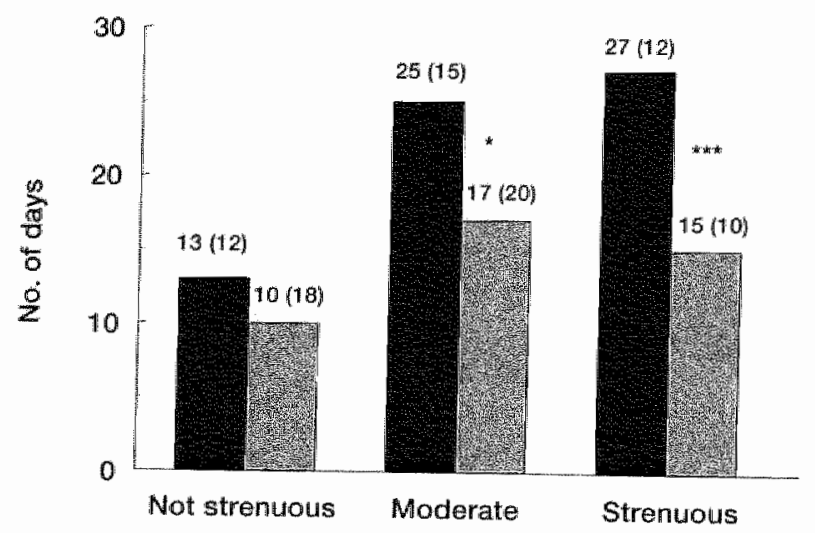

Figure 3. Aggregate return to work after Bassini (solid bars) and laparoscopic (shaded bars) hernia repairs. *** $P=0,005$ (Chi-square test).

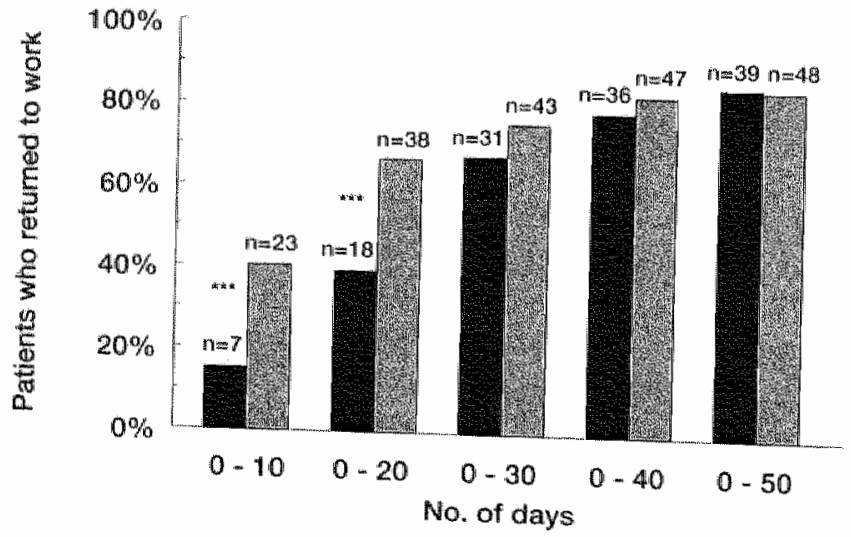


Figure 4. Aggregate resumption of physical activities after Bassini (solid bars) and laparoscopic (shided bars) repairs. * $\mathrm{P}<0,01$; * $\mathrm{P}<0,005$ (Chi-square test).

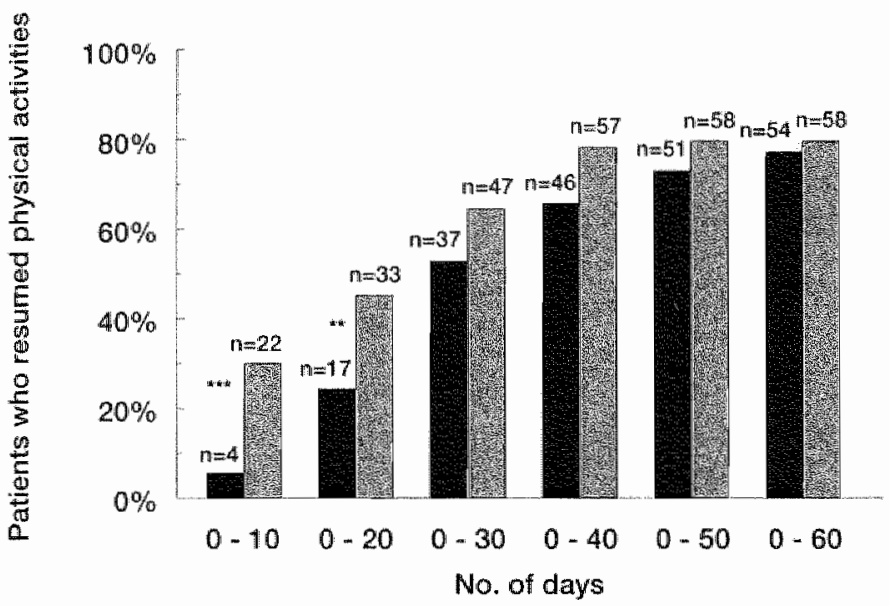

\section{Abdominal muscle tests}

Preoperative scores for patients from the Bassini and laparoscopic group were comparable for both exercises. Only the "legs pull up" test was significantly different one day postoperatively in favour of the laparoscopic repair. Ten days and six weeks postoperatively Bassini and laparoscopy had comparable results for both exercises.

\section{Follow up}

Mean follow up until October 1996 was 24 months (range 15-36). Of the Bassini group, $85(98 \%)$ patients have been evaluated by physical examination and two patients by telephone interview one year postoperatively. The two-year follow up has been completed in 38 patients (44\%). Of the laparoscopic group, 82 patients $(93 \%)$ have been evaluated by physical examination and four patients by telephone interview one year postoperatively. Two patients were not seen because they could not be contacted. The two-year follow up had been completed in 34 patients (39\%).

In the Bassini group there have been a total of 22 recurrences in 22 patients. Nineteen of the 85 repairs (22\%) done by surgical residents, and three of the 18 repairs (17\%) done by senior surgeons resulted in a recurrent hernia. Recurrence rates between surgical residents and surgeons did not differ significantly $(P=0,6)$. At the time of diagnosis, eight recurrences were asymptomatic, two of which later became symptomatic. So far, nine recurrences have been repaired. 
In the laparoscopic group there have been seven recurrences in seven patients. Three of 32 repairs ( $9 \%$ ) done by surgical residents, and 4 of 82 repairs ( $5 \%$ ) done by senior surgeons resulted in a recurrent hernia. This difference is not significant $(\mathrm{P}=0,08)$. Two recurrences were immediate and repaired within 24 hours of the primary operation. Four recurrences were asymptomatic. So far, four recurrences have been repained. Recurrence rates so far are $21 \%$ (22/103) after a Bassini repair and $6 \%$ (7/14) after a laparoscopic repair ( $\mathrm{P}=0,001)$.

One year after a Bassini repair there were eight cases (8\%) of inguinal hypaesthesia and $12(12 \%)$ of chronic wound pain. In nine patients this was described as minor discomfort, in two as moderate pain, and in one as severe pain. This last patient suffered from severe neuralgia that was not relieved by nerve infiltration and exploration of the groin. One year after a laparoscopic repair, the only patient with persistent hypaesthesia was the one who required conversion to an open anterior approach. In the laparoscopic group there were 17 cases of chronic wound pain (15\%). In all but one this was described as minor discomfort. One patient with moderate chronic pain had a small painful lump near the pubic tubercle. His groin was explored and a small piece of folded mesh removed.

\section{Discussion}

To decide the procedure of choice for inguinal hernia repair several issues need to be evaluated: safety, technical difficulty, postoperative discomfort, convalescence, recurrence rate, and cost (21,21). Although the cost of laparoscopic hernia repair compared with the Bassini repair is important in deciding the most "cost-effective" treatment, this question was not the issue in this study and therefore will not be discussed extensively.

The rate and severity of complications was similar in the two groups. Severe laparoscopy-related complications such as small bowel obstruction, bowel or bladder perforation, or major vascular injury did not occur (22-26). After a Bassini repair, hall the patients experienced some form of inguinal hypaesthesia. In $8 \%$ this was still present after a year, and in one patient it was accompanied by disabling neuralgic groin pain. No patients developed persistent neuralgic pain after a laparoscopic repair. The reported incidence of neuralgia after laparoscopic hernia repair is $2 \%-3 \%$ $(24,26)$. This is usually caused by nerve entrapment and can be prevented by avoiding
the use of staplers, as in this study. A disadvantage of the laparoscopic hernia repair is the longer operating time compared with the Bassini repair. This is confirmed by other reports in which laparoscopic was compared with open repair $(19,27,28)$. As well as showing different anatomy, the laparoscopic repair requires considerable laparoscopic skills. Operating time will decrease as experience grows, as has been stated by others (29-32). Resumption of acivities is significantly quicker after laparoscopic repair. The greatest 
difference in return to work was found in patients with a strenuous job, a result supported by Payne et al (19). A shorter recuperation period after laparoscopic repair has been reported in several comparative studies $(19,27-29,33,34)$. This result was also widely found in sudies of laparoscopic cholecystectony. It supports the assumption that laparoscopic surgery reduces the cost to society by reducing "productivity losses".

After a laparoscopic repair patients experienced less pain and used hall the amount of analgesics than those in the Bassini group. Our results resemble those of other authors $(19,28,35)$. Although the overall difference in postoperative pain is modest, it is apparently associated with a difference in the recuperation period.

A disadvantage of the laparoscopic repair is that general anaesthesia is preferred for the patients" comfort and safery. Patients who prefer or need local or regional anaesthesia cannot be managed laparoscopically. Most conventional repairs can be done under local or regional anaesthesia.

Our choice of the conventional procedure may be controversial. We chose a Bassini repair with absorbable sutures for two reasons: firstly, it was our standard repair for inguinal hernia, and secondly, a recent Dutch survey has shown that a Bassini-type of procedure is still the most popular repair, and absorbable suture material is used most often (5). Our choice of conventional procedure may have influenced the high recurrence rate, but the results with regard to pain and resumption of activicies are valid for all 'anterior tension repairs'.

The results with respect to recurrence rates favour the laparoscopic repair. However, it needs to be mentioned that the $6 \%$ recurrence rate is higher than the expected $1 \%$. The $6 \%$ short-term recurrence rate for laparoscopy is slightly higher than the $4,5 \%$ reported in a large non-randomized multi centre trial (26). Other series report recurrence rates of $0 \%-2 \% \quad(30,31,36-38)$, but these include results of personal experiences in non-randomized patients. Because a laparoscopic repair aims to reinforce the whole inguno-femoral area with a prosthetic mesh all recurrences must be considered as technical errors and therefore preventable. Four of the seven recurrences occurred within six weeks, and wo within 24 hours. The recurrences that have been repaired had all been medial to the mesh and probably result from incorrect positioning of the mesh, or not stapling the mesh, or both. The learning curve effect may have been underestimated. We now pay special attention during dissection to placing the mesh medially enough to cover any potential medial defect. We occasionally use staplers to secure the medial mesh in position.

The $21 \%$ recurrence rate after the Bassini repair is excessively high. There are several possible reasons for this. We have already mentioned the use of absorbable suture material. Although results of randomized trials comparing absorbable with nonabsorbable suture materials are conflicting (39-44), most experts in hernia surgery recommend the use of non-absorbable sutures $(45,46)$. Our data may indicate the insufficiency of absorbable (polyglactin 910) sutures, as our own one-year recurrence 
rate of conventional repair with nylon was $5 \%-10 \%$ in the early $1980 \mathrm{~s}(47)$.

1t has often been said that success of inguinal hernia repair is highly dependent on meticulous surgical technique. Although difficult to prove, it is reasonable to assume that specialisation in inguinal hernia repair will lower the recurrence rates (48). In our study, Bussin repairs were done either by residents assisted by a surgeon, or by senior surgeons, none of whom is specialised in hernia repair.

Abother possible reason for the high short term recurrence rate is our meticulous follow up and our definition of recurrence, which includes asymptomatic hemias. Almost half of the recurrences were asymptomatic and detected at the additional control visits. In normal practise (no trial) these recurrences might have remained unnoticed for a long time.

The recurrence rates after conventional repairs such as the Bassini or the Shouldice repair rise with lengthening follow up $(46,47)$, probably as a result of further deterioration of the supporting structures of the groin. In laparoscopic hemia repair the whole inguinofemoral area is reinforced by a non-absorbable prosthesis. Apart from technical errors that give rise to early recurrences it is difficult to imagine late recurrences. Whether or not this theoretical advantage is true will be noted with continuing follow up of randomized trials.

We conclude that laparoscopic transabdominal preperitoneal hernia repair is a safe operation with only a few, minor complications. Laparoscopic hernia repair has obvious advantages over the Bassini operation as far as postoperative pain, use of analgesics, and resumption of activities are concerned. Our present recurrence rates show that the laparoscopic hernia repair is superior to the Bassini repair. Because of the unacceptably high recurrence rate, we no longer do Bassini repairs. The laparoscopic repair is a technically difficult operation and requires a longer operating time. In addition, our recurrence rate for laparoscopic repair was higher than anticipated. We therefore hesitate to accept the laparoscopic technique as the new standard repair for primary inguinal hernia. It is, however, a good option for a laparoscopically skilled surgeon.

\section{References}

1. Health Cure lnformation (SIG). Trends in Sumgery 1984-1993. Apeldoon 1995.

2. Bassini, E. Ueber die Behandlung des Leistenbruches. Arch Klin Chir 1890;40:429-476.

3. Britton, B.J. Inguinal hemia tepair in England. International Surgery 1986:71:144-145.

4. Moschinski, D., Linke, R. Inguinal hernia operations in Germany. International Surgery

5. Simons, M.P. Hoitsma, H.F.W., Mullan, F.J. Primary inguinal herna repair in The Netherlands. European Jowmal of Surgery 1995; $161: 345-348$

6. Lichtenstein, I.L. Schulman, A.G., Amid, P.K., Montllor, M.M. The tension free hemioplasty. American Joumal of Surgery 1989:157:188-193.

7. Stoppa, R.E., Rives, J.L., Warlaumont, C.R., Palot, J.P., Verhaeghe, P.J, Delattre, J.F... The use of Dacron in the repair of hemias of the groin. Surgical Clinics North America 
$1984 ; 64: 269 m 285$

8. Beets, G.L., Van Geldere, D., Baeten, C.G.M.. Go, P.M.N.Y.H. Long term results of the giant prosthetic reinforcement of the visceral sac for complex recurrent inguinal hemiat. British Joumal of Surgery 1996;83:203-206.

9. Lichtenstein, I.L., Shulman, A.G., Amid, P.K.. The cause, prevention and treatment of recur" rent groin hemia. Surgical Clinics North America 1993; 73:529-544.

10. Arregui, M.E., Davis, C.D., Yucel, O. Laparoscopic mesh repair of inguinal hernia using a preperitoneal approach: a preliminary report. Sidgical Laparoscopy and Endoscopy $1992 ; 2: 53-58$.

11. Arregui, M.E., Navarette, J., Davis, C.J., Castro, D., Nagan, R.F. Laparoscopic inguinal herniormaphy. Techniques and controversies. Surgical Clinics North America 1993;73:513-527.

12. Corbitt, J.D. Transabdominal preperitoneal herniorthaphy, Surgical Laparoscopy and Endoscopy 1993;3:328-332.

13. Hanafy, M. Laparoscopic hernia repair: a review. Miminally lnasive Therapy 19932229 236.

14. Dion, Y.M., Morin, J. Laparoscopic inguinal herniorrhaphy, Canadian Jounat of Surgery 1992;35:209-212.

15. Geis, W.P., Cratton, W.B., Novak, M.J., Malago, M. Laparoscopic hermiorthaphy: results and technical aspects in 450 consecutive procedures. Surgery 1993:114:765-774.

16. Milkins, R.C., Landsdown, M.J.R., Wedgwood, K.R., Brough, W.A., Royston, M.S. Laparoscopic hernia repair: a prospective study of 409 cases. Minmaly Inwasive Therapy $1993 ; 2: 237-242$.

17. Voeller, G.R., Mangiante, E.C., Britt, L.G. Preliminary evaluation of laparoscopic hemiormaphy. Surgical Laparoscopy and Endoscopy 1993;3:100-105.

18. Winchester, D.J., Dawes, L.G., Modelski, D.D., et al. Laparoscopic inguninal hernia repair. A preliminary experience. Archives of Surgery 1993;128:781-784.

19. Payne, J.H., Grininger, L.M., Izawa, M.T., Podoll, E.F., LindahI, P.J., Balfour, J. Laparoscopic or open inguinal hemiorrhaphy? A randomized prospective trial. Archives of Surgery 1994:129:973-981.

20. Rutkow, I.M. The recurrence rate in hermia surgery. How important is it? Archives of Surgery 1995; 130:575-576.

21. Schumpelick, V., Treutner, K.H., Arlt, G. Inguinal hernia repair in adults. Lancet 1994:344:375-379.

22. Hendrickse, C.W., Evans, D.S. Intestinal obstruction following laparoscopic inguinal herniat repair. British Joupnal of Surgery 1993;80:1432.

23. MacFadyen, B.V., Arregui, M.E., Corbit, J.D., et al. Complications of laparoscopic hemiorrhaphy, Surgical Endoscopy 1993;7:155-158.

24. Phillips, E.H., Arregui, M., Caroll, B.J., et al. Incidence of complications following laparo. scopic hernioplasty. Surgical Endoscopy 1995;9:16-21.

25. Tsang, S., Normand, R., Karlin, R. Small bowel obstruction: a morbid complication after laparoscopic herniorrhaphy. American Surgeon 1994;60:332-334.

26. Fitzgibbons, R.J., Camps, I., Comet, D.A., et al. Laparoscopic inguinal herniorthaphy. Results of a multicenter trial. Annals of Surgery 1995;22:3:3 13.

27. Cornell, R.B., Kerlakian, G.M. Early complications and outcomes of the curreme technique of transperitoneal laparoscopic herniorrhaphy and a comparison to the traditional open approach. American Joumal of Surgery 1994;168:275-279.

28. Stoker, D.L.. Spiegelhalter, D.J., Singh, R., Wellwood, J.M. Laparoscopic versus open inguinal hemia repair: randomized prospective trial. Lancel 1994;343:1243-1245.

29. Dunn, D.C., Wijesinghe, L.D., Pollard, S.G., Collier, D. St. J. Postoperative rehabilitation 
following laparoscopic inguinal hemia repair. Minimally Inasive Therapy 1994;3:159-162.

30. Ferzli, G., Tiel, T. Ewolwng techniques in endoscopic extraperitoneal hemiomaphy. Surgical Endoscopy 1995,9:928-930.

31. Kavio, MS. Laparoscopic hernia repair. Three-year expenience. Surgical Endoscopy 1995:9:12-15.

32. Quilici, P. ., Greany, E.M. jr, Quilici, J., Anderson, S. Laparoscopic hernia repair results: 131 cases. Anerican Surgeon 1993;59:824-830.

33. Brooks, D.C. A prospective comparison of laparoscopic and tension-free open herniormaphy. Archives of Surgery 1994:129:361 -366.

34. Vogt, D.M., Curet, M.J., Pitcher, D.E., Marin, D.T., Zucker, K.A. Preliminary results of a prospective randomized trial of laparoscopic onlaty versus conventional inguinal herniortha. phy. American Journal of Surgery 1995; 169:84-90.

35. Newman, L., Eubanks, S., Mason, E., Duncan, T.D. Is laparoscopic herniormaphy an effective alfermative to open hernia repair? Joumat of Laparoendoscopic Surgery 1993:3:121-128.

36. Puget, G.W. Laparoscopic inguinal herniorthaphy. A personal audit of 222 hernia repairs. Medical Jommat of Alstratia 1994:161:249-253.

37. Tucker, J.G., Wilson, R.A., Ramshaw, B.J., Mason, E.M., Duncan, T.D. Lucas, G.W. Laparoscopic hemiorhaphy: technical concerns in prevention of complications and early recurrence. American Surgeon 1995;61:36-39.

38. Wheeler, K.H. Laparoscopic inguinal berniornaphy with mesh: an 18-month experience. Jownal of Laparoendoscopic Surgery 1993;3:345-350.

39. Baltazat, $\mathrm{N}$. Dexon versus conventional sutures in hernia repair. Canadian Journal of Surgery $1976 ; 19: 341-342$

40. Burchart, F., Hahn-Pedersen, J., Andersen, B., Andersen, J.R. Inguinal hemia repair with silk or polyglycolic acid sutures: a controlled trial with 5-years" follow-up. World Journal of Surgery 1983;7:416418.

41. Dorflinger, $T$., Kiil, J. Absorbable suture in hernia repair. Acta Chintrgica Scandinava 1984:150:41-43.

42. Fuchsjüger, N., Feigter, A., Hirbawi, A., Kux, M. Bassini-operation mit polyglycolsătune oder polyester. Der Chirurg 1989;60:273-276.

43. Kux, M., Fuchsjager, N., Schemper, M. Shouldice is superior to Bassini inguinal heriomaphy. American Joumal of Surgery 1994;168:15-18.

44. Solhung, J.H. Polyglycolic acid (Dexon) versus mersilene in tepair of inguinal hernia. Acta Chirargica Scandinavia 1984; 150:385-387.

45. Devlin, H.B. Gillen, P.H.A., Waxman, B.P., MacNay, R.A. Short Stay surgery for inguinal hemiat: experience of the Shouldice operation, 1970-1982. British Jourmal of Surgery
1986:73:123-124.

46. Welsh. D.R.J., Alexander, M.A.J. The Shouldice repair. Surgical Chinies North America 1993:73:451-469.

47. Beets, G.L.. Oostethuis, K.J., Go, P.M.N.Y.H. Baeten, C.G.M.I, Kootstra, G. Long-term follow up (12-15 years) of a randomized controlled trial comparing Bassini-Stetten, Shouldice and high ligation with narrowing of the internal ring for primary inguinal hemia repair. Jotwat of the American College of Surgeons 1997; 185:352-357.

48. Deysine. M. Soroff. H.S.. Must we specialize hemiorhaphy for better results? American downt of Sugen $1990 ; 160239-240$. 
4

\section{COST-EFFECTIVENESS OF OPEN VERSUS} LAPAROSCOPIC REPAIR FOR PRIMARY INGUINAL HERNIA

This chapter will be published in:

- Dirksen C.D., Ament A.J.H.A., Beets G.L., Go P.M.N.Y.H., Baeten C.G.M.I, Kootstra $G$. Cost-effectiveness of open versus laparoscopic repair for primary inguinal hernia. International Joumal of Technology Assessment in Health Care (in press). 


\section{Introduction}

Inguinal hernia repair is one of the most frequently performed procedures in genera surgery. In the Netherlands, about 25.000 repairs are performed annually (1). In the United States and the United Kingdom, respectively 500.000 (2) and 80.000 (3) repairs are performed annually.

The most commonly performed operation for primary inguinal hernia in the Netherlands and some other European countries is the musculo-aponeurotic technique $(4,5)$. One of these repairs is referred to as the Bassini operation (6). In 1993 the Bassini operation was performed by $64 \%$ of the surgeons in the Netheriands (5) and was also the standard surgical therapy for primary inguinal hemias at the University Hospital of Maastricht. A disadvantage of the Bassini repair is the high recurrence rate, which waries from $7,5 \%$ to $10 \%(7-9)$.

Inguinal hernias can also be managed by laparoscope. In the laparoscopic repair, the abdominal wall is reinforced 'from the inside' with a prosthetic mesh (10). Early reported recurrence rates of this technique varied between 0 and $2 \%$ (11-16). Laparoscopic inguinal hernia repair was introduced at the University Hospital of Maastricht in 1992.

A cost-effectiveness analysis was performed alongside a randomized controlled trial (RCT), comparing the Bassini technique with the laparoscopic repair for primary inguinal hernia. A specific Dutch study was considered useful for two reasons. Firstly, Bassini repair was the most performed technique for inguinal hernia in the Netherlands. Secondly, no cost-effectiveness analysis has yet been reported comparing Bassini with laparoscopic repair. Most RCT's on laparoscopic inguinal hernia repair have primarily focused on effectiveness measures, in which costs are either not calculated $(17-19)$ or only partly calculated $(2,20,21)$.

Since recurrence rates were expected to differ significantly between Bassini- and laparoscopic repair, this outcome served as the main measure of effectiveness (22). The cost-elfectiveness analysis was performed from both the hospital- and societal point of view. The incremental cost-effectiveness ratio was based on the average cost per 1-year recurrence-free patient.

\section{Patients and methods}

\section{Designt}

All patients eligible for general anaesthesia, between 20 and 80 years of age, with a primary inguinal hernia -type 2 or 3 according to Nyhus (23)- were randomly assigned to either Bassini or laparoscopic repair. After obtaining an informed consent, patients were randomized at the outpatient clinic using sealed envelopes.

Patients were admitted the daly before surgery and were routinely discharged one day postoperatively, unless their medical condition indicated otherwise. Postoperative 
morbidity, complications, convalescence, pain and recurrence were assessed. Pain was assessed using a visual analogue scale (VAS). At discharge, patients were explicity instructed there were no restrictions regarding return to routine activities, except if this would cause discomfort and pain. Operating time, postoperative hospital stay and postoperative use of analgesics were recorded.

All operations were performed under general anaesthesia. Bassini repair was performed using interrupted absorbable sutures. The laparoscopic repair was performed using the transabdominal preperitonea. (TAPP) technique. Bassini repairs were performed by all surgeons, or by surgical residents assisted by a surgeon. Laparoscopic repairs were done by three laparoscopic surgeons, or by residents assisted by a laparoscopic surgeon. All laparoscopic surgeons had performed al least 20 laparoscopic repairs before they entered the study.

A recurrence of the hernia was considered as a treatment failure. Recurrence was detined as "a symptomatic or asymptomatic defect in the abdominal wall with herniation of abdominal contents in standing position, exacerbated by a Valsava manoeuvre" To assess recurrence rate, all patients had a physical examination I year postoperatively and will be examined once a year, up to atollollow up of 5 years. Results were analysed according to the 'intention to creat' principle.

The cost analysis was performed from both the hospital-and societal perspective. The hospital perspective included only costs to the hospital. The societal perspective consisted of the hospital costs, plus costs outsicle the health care sector due to postoperative absence from work. Costs to patients and their relatives were assumed to be small and equal in both groups, and were therefore not included in the societal analysis.

All hospital costs were allocated to the activities that are part of the procedure for inguinal hernia repair: a pre-operative outpatient visit, a hospital day, an operation, a recovery-room stay and a postoperative outpatient control-visit. The costs per activity consisted of direct and indirect costs. Direct costs included personnel, material (medical and non-medical) and capacity costs. Indirect costs consisted of the general overhead, which was allocated to activities on the basis of the "costs per square metre" (m2). General overhead consisted of interest, depreciation and maintenance of the building and installations, as well as personnel- and material costs realized on supporting non-medical departments (e.g. Technical department). The non-medical material costs, costs of supporting personnel (e.g., secretaries) and the generai overhead costs of the department of Surgery were made direct by adding them as an overall percentage to the salaries of surgeons and surgical residents. The costs of a particular activity consisted of (wo components: 1) the calculated unit-price per activity (p) and 2 ) the volume of that particular activity ( $q$ ). Costs of medical services (e.g., laboratory test, $X$-ray) and medications were allocated to the activity at which they were ordered or given. All costs from hospital-admission to discharge were defined as "protocol" costs. The protocol costs, plus the additional costs due to 
complications (outpatient visits, medical services, re-admissions, etc.) were defined a hospital costs.

Costs outside the health care sector due to absence from work (productivity loss) wer based on the number of days postoperatively unil paid labour was fully resumed Unpaid labour, like household activities or voluntary work, was not dealt with in th analysis. The friction costs method as described by Koopmanschap et al. (24) wa: used to estimate productivity loss. The costs per friction period were corrected fo: gross wage increases from 1990-1994 (25), assuming that the friction period has remained stable during that period. Friction costs per patient were calculated by dividing the gender and age-specific costs per friction period by the actual number of days a particular patient had been absent from work. All patients were assumed to have an intermediary education (24).

All costs are presented in 1994 Dutch Guilders (1 DA $=0,36$ UKE $=0,55$ US $\$$ average conversion rates 1994 ).

\section{Sratistical analysis}

Recurrence was the primary outcome of the study. A power analysis, based on recurrence rates of $1 \%$ for the laparoscopic repair and $12 \%$ for the Bassini repair, with $\alpha=0,05$ and $\beta=0,1$, set the number of required hernias on 100 per treatment group. To achieve at least the number of required hernias, the number of patients was set at 200. To cortec for possible preoperative withdrawals 220 (10\% extra) envelopes were prepared.

The Kolmogorov-Smimov test was used to test for nomality of the different costcomponents. A Student-t test for unpaired data was performed on normally distributed data. The Chi-square test was used for categorical variables. The nonparametric Mann-Whitney test for unpaired data was performed on skewed data. A wwo-sided Pvalue below 0,05 was considered to indicate statistical significance.

\section{Incremental cost-effectiveness}

Effectiveness of both treatment modalities was expressed as the "proportion of 1 year recurtence-free patients*. Recurrence rates were analysed per patient not per inguinal hernia). Incrementaj effectiveness was calculated as the effectiveness of the laparoscopic repair minus the effectiveness of the Bassini repair. Incremental costs represented the average costs per patient of a laparoscopic repar minus the average costs per patient of a Bassini repar.

\section{Sensiting amalysis}

Sensitivity analysis was performed on selected variables concerning both the hospital and societal perspective. The inputs in the sensitivity analysis were based on onteomes of several reported RCT" $\$$. Laparoscopic operating time ranges from 35 to 87 minutes for unilateral, and from 60 to 124 minutes for bilateral repairs $(2,18,20,21,26,27)$; 
reported short term recurrence rate after laparoscopic repair ranges from $0 \%$ to $4 \%$ (2,17-21,26,28); short term recurrence rate after Bassini repair ranges from $7,5 \%$ to $9,6 \%(7-9,29)$; return to work after laparoscopic repair ranges from 8 days $(2,19)$ to 41 days (26) after laparoscopic repair, the latter which appears to be extremely high as compared to other studies $(2,18-21,27,28,30)$ in which the highest reported number of days off work is 25 days.

Laparoscopic recurrence rate was therefore varied from $0 \%$ to $8 \%$. Laparoscopic operating time was set at 30 minutes, 89 minutes and 120 minutes. The number of days off work after laparoscopic repair was varied from 15 days to 25 days. Recurrence rate after Bassini was held at $7.5 \%$ and $19,5 \%$. Operating time of and return to work after Bassini repair were held constant at respectively 46 minutes and 30,4 days off work (see results).

\section{Results}

From November 1993 to July 1995, 87 patients had 103 Bassini repairs and 88 patients had 114 laparoscopic repairs. Both groups were comparable with regard to age, gender, type of hernia, body mass index and proportion of employed patients (table 1).

One laparoscopic repair was converted to an open repair. According to intention to treat, this patient remained in the laparoscopic group for analysis. Operating times (based on the weighed average of unilateral and bilateral repairs) for Bassini and laparoscopic repair were respectively 46 and 89 minutes $(P<0,001)$. The nean number of days until work was fully resumed amounted to 30,4 (SD=16, range 1-60) days in the Bassini group and 17,3 $(\mathrm{SD}=13$; range 1-58) in the laparoscopic group $(\mathrm{P}<0,001)$. Patients in the Bassini group had significantly more pain during the first week postoperatively compared with the laparoscopic group (mean VAS [SD]:2,9 [1,6] vs $2,0[1,6]$ respectively; $P=0,002$ ).

In the Bassini group half of the patients had inguinal hypatesthesia $(P<0,005$ as compared to laparoscopic group). In the laparoscopic group there were more inguinofemoral ecchymoses ( $\mathrm{P}<0,05$ as compared to Bassini group) and two paticnts were operated for a painful haematoma. After a laparoscopic repair, two patients developed a urinary tract infection and one patient a urinary retention. 
Table 1. Comparability of growps

\begin{tabular}{|c|c|c|c|}
\hline & & Bassini repair & Laparoscopic repair \\
\hline \multicolumn{2}{|l|}{ Men } & $85(98)$ & $88(100)$ \\
\hline \multicolumn{2}{|l|}{ Mean (SD) age (years) } & $54(13)$ & $53(15)$ \\
\hline \multicolumn{2}{|l|}{ Mean (SD) body mass index } & $25(3)$ & $25(3)$ \\
\hline \multicolumn{2}{|l|}{ No. of hernias } & 103 & 114 \\
\hline \multicolumn{2}{|c|}{ Unilateral hernia } & $71(82)$ & $62(70)$ \\
\hline \multirow{2}{*}{\multicolumn{4}{|c|}{$\begin{array}{l}\text { Bilateral hernia } \\
\text { Hernia classification according to Nyhus }\end{array}$}} \\
\hline & & & \\
\hline No. of type 2 hernias & & $23(22)$ & $33(29)$ \\
\hline \multirow{3}{*}{ No of type 3 hernias } & $-\mathrm{A}$ & $54(53)$ & $50(44)$ \\
\hline & $-\mathrm{B}$ & $25(24)$ & $29(25)$ \\
\hline & $-\mathrm{C}$ & $1(1)$ & $2(2)$ \\
\hline Employed patients & & $46(53)$ & $57(65)$ \\
\hline
\end{tabular}

Mean follow up wntil April 1997 is 29 months (range 21-42). The 1-year follow up has been completed in $100 \%$ of the patients from the Bassini group and $98 \%$ of the laparoscopic group. One-year recurrence rates are $19,5 \%$ (17 recurrences in 17 patients) in the Bassini group and $8 \%$ ( 7 recurrences in 7 patients) in the laparoscopic group ( $\mathrm{P}=0,03)$. The 2-year follow up has, up till now, been completed in $44 \%$ of the patients from the Bassini group and $39 \%$ from the laparoscopic group. Two-year recurrence rates amount to $25 \%$ (22 recurrences in 22 patients) after Bassini and $8 \%$ ( 7 recurrences in 7 patients) after a laparoscopic repair ( $\mathrm{P}=0,002)$. Nineteen of the 85 Bassini repairs (22\%) done by surgical residents, and three of the 18 Bassini repairs (17\%) done by senior surgeons resulted in a recurrent herna. Three of 32 laparoscopic repairs $(9 \%)$ done by surgical residents, and 4 of 82 repairs $(5 \%)$ done by senior surgeons resulted in a recurrent hemia. Recurrence rates were not significantly different between surgeons and surgical residents. More detailed information on the results can be found clsewhere (31).

\section{Cost-andysis}

The average costs per activity are listed in table 2. The frequency distributions of the hospital costs for both treatment modalities are presented in figure 1. The average difference in hospital costs amounts to Df 615 at the expense of the Iaparoscopic repair $(\mathrm{P}<0,001)$, which is mainly explained by the difference in operation costs. The higher material costs for the laparoscopic repair are caused by the disposable scissors (which are used twice) and a polypropylene mesh. The average friction costs, based on all patients including those not performing paid labour (friction costs $=0$ ), amount to Df 5.181 in the Bassini group and Dfl 3.637 in the laparoscopic group, which is not significantly different $(P=0,5)$ due to the skewed distribution. Total differential socientl costs amount to DA 928 at the expense of the Bassini repair $(P=0,1)$. 
Table 2. Costs of Bassini and laparoscopic repair

\begin{tabular}{|c|c|c|c|}
\hline Costs & Bassini repair & Laparoscopic repair & P.value \\
\hline Outpadient visit & 52 (n.a.) & $59\left(1 . a_{0}\right)$ & a.a. \\
\hline Hospital stay & $469(90)$ & $497(113)$ & 0,06 \\
\hline Operation: & $738(112)$ & $1272(235)$ & $<0,001$ \\
\hline - personnel & 339 & 598 & na. \\
\hline - material & 235 & 466 & n.a. \\
\hline - capacity & 46 & 90 & n.a. \\
\hline - overhead & 118 & 118 & nat. \\
\hline Recovery & $170(\mathrm{n} . \mathrm{d})$. & $170($ na. $)$ & n.at. \\
\hline Control visit & 45 (n.a.) & 45 (n.a.) & n...A. \\
\hline Protocol costs & $1.472(154)$ & $2.042(275)$ & $<0,001$ \\
\hline Additional services ${ }^{3}$; $*$ & 25 (n.a.) & $71(\mathrm{na})$ & ก.มี. \\
\hline Hospital costs & $1.497(194)$ & $2.112(454)$ & $<0,001$ \\
\hline Friction costs $* * * *$ & $5.1181(5.878)$ & $3.637(4.214)$ & 0,5 \\
\hline Societal costs & $6.678(5.896)$ & $5.750(4164)$ & 0,1 \\
\hline
\end{tabular}

Presented in Dutch guilders as means (SD), n.a. $=$ not applicable, *) different due to slight difference in pre-operative medical services; ***) Fixed per patient; ***; ) Highly skewed, based on a few patients; ******) Mann-Whitney test.

Figure 1. Hospital costs of Bassini (solid bars) versus laparoscopic (shaded bars) repair.

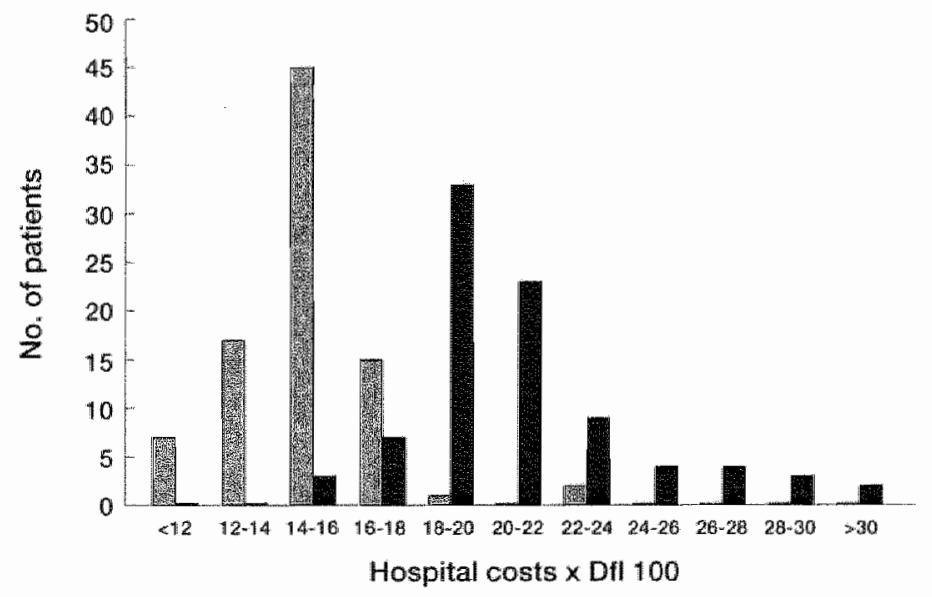




\section{Incremental cost-effectiveness}

Based on 1-year recurrence rates, the laparoscopic repair is more effective as compared to the Bassini repair, but also more expensive. At the hospital level, the incremental costs per additional 1 -year recurrence-free patient amount to Dfl 5.348 (table 3).

The societal perspective results in a change of outcome as compared to the hospital perspective. This is caused by the higher average friction costs in the Bassini group (table 2). As presented in table 3, the Bassini repair is dominated by the laparoscopic repair, the latter being both less costly and more effective.

Table 3. Incremental cost-effectiveness

\begin{tabular}{|c|c|c|c|}
\hline & Costs & Effectiveness & Cost-effectiveness \\
\hline \multicolumn{4}{|l|}{ Hospital perspective } \\
\hline Bassini & 1.497 & 0.805 & 1.860 (average $\mathrm{CE}$ ) \\
\hline Laparoscopic repair & 2.112 & 0,92 & 2.296 (average CE) \\
\hline Increment & 615 & 0,115 & 5.348 \\
\hline \multicolumn{4}{|l|}{ Societal perspective } \\
\hline $\begin{array}{l}\text { Bassint } \\
\text { Laparoscopic repair }\end{array}$ & $\begin{array}{l}0.018 \\
5.750\end{array}$ & $\begin{array}{l}0,805 \\
0,92\end{array}$ & $\begin{array}{l}8.296 \text { (average CE) } \\
6.250 \text { (average CE) }\end{array}$ \\
\hline Increment & -928 & 0,115 & L.d.B* \\
\hline
\end{tabular}

Costs are presented in Dutch guilders (Dfl) as means. Effectiveness is expressed as the proportion of 1 -year recurrence-free patients. $*$ L.d. $B=$ laparoscopic repair dominates Bassini repair.

Sensitivity analysis

Hospital perspective: In an optimistic scenario, in which laparoscopic operating time is 30 minutes and recurrence rate is $0 \%$, the incremental CE-ratio of laparoscopic repair amounts to Df 827 (table 4 ). In a pessimistic scenario, with a laparoscopic operating time of 120 minutes and $8 \%$ recurrence rate, the incremental CE-ratio increases up to Df1 7.449. When recurrence rate after Bassini repair is held at $7,5 \%$, the incremental CE-ratio of laparoscopic repair amounts to Dfl 2.149 in the optimistic scenario. The CE-ratio increases substantially with each additional percentage of recurrence after laparoscopic repair. Beyond 7,5\% laparoscopic recurrence rate, this technique becomes both more costly and less effective as compared to Bassini repair.

Societal perspective: Table 5 shows that laparoscopic repair dominates Bassini repair under many conditions. With laparoscopic operating times of 30,89 and 120 minutes, break-even points $(\triangle C=0)$ are respectively at 23,9 days, 21,8 days and 20,6 days off work after laparoscopic repair. Increasing laparoscopic recurrence rate does not change the break-even points, but only the slope of the CE-ratio. 
Table 4. Incremental CE-ratios (hospital level)

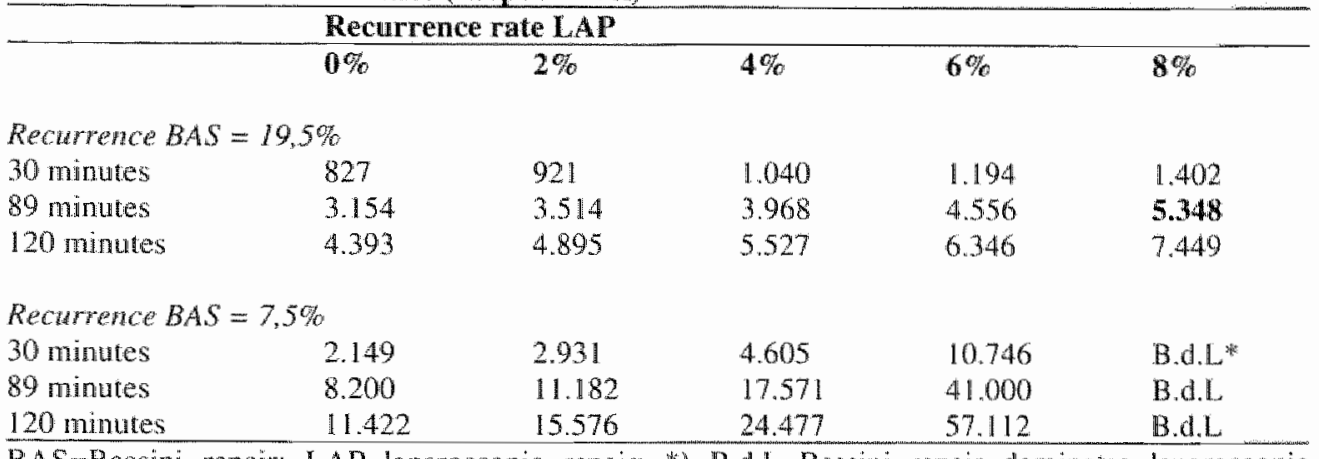

BAS=Bassini repair; LAP=laparoscopic repair; *) B.d.L=Bassini repair dommates laparoscopic repair.

Table 5. Incremental CE-ratios witth $19,5 \%$ recurrence rate alter Bassinil (societal level)

\begin{tabular}{|c|c|c|c|c|c|c|}
\hline Days off work after LAP & 15 & 17 & 19 & 21 & 23 & 25 \\
\hline Recurrence $\angle A P=0 \%$ & & & & & & \\
\hline 30 mimultes & L.d.B* & L.d.B & $\mathbb{L}$.d.B.B & L.d.B & L.d.B & 1.304 \\
\hline 89 minutes & L.d.B & L.d.B & L.d.B & L.d.B & 1.390 & 3.631 \\
\hline 120 minutes & $1 \mathrm{~B}$ & L.d.B & $L d B$ & 393 & 2629 & 4.870 \\
\hline
\end{tabular}

Recurrence $L A P=4 \%$

$\begin{array}{lllllll}30 \text { minutes } & \text { L.d.B } & \text { L.d.B } & \text { L.d.B } & \text { L.d.B } & \text { L.d.B } & 1.640 \\ 89 \text { minutes } & \text { L.d.B } & \text { L.d.B } & \text { L.d.B } & \text { L.d.B } & 1.748 & 4.568 \\ 120 \text { minutes } & \text { L.d.B } & \text { L.d.B } & \text { L.d.B } & 495 & 3.308 & 6.127\end{array}$

Recurrence $1 \mathrm{AP}=8 \%$

$\begin{array}{lllllll}30 \text { minutes } & \text { L.d.B } & \text { L.d.B } & \text { L.d.B } & \text { L.d.B } & \text { L.d.B } & 2.210 \\ 89 \text { minutes } & \text { L.d.B } & \text { L.d.B } & \text { L.d.B } & \text { L.d.B } & 2.356 & 6.156 \\ 120 \text { muinutes } & \text { L.d.B } & \text { L.d.B } & \text { L.d.B } & 667 & 4.458 & 8.258\end{array}$

* $L$. B $=$ laparoscopic repair dominates $B$ assini repair.

Table 6 presents results of the same sensitivity analysis, only with 7,5\% recurrence rate after Bassini repair. At $0 \%$ and $4 \%$ laparoscopic recurrence rate (up to 7,5\%), laparoscopic repair dominates Bassini repair up to the same break-even points as mentioned above. Beyond the break-even points the incremental CE-ratio of laparoscopic repair ranges from Dfl 1.022 (with $0 \%$ recurrence rate) to Df1 27.134 (with $4 \%$ recurrence rate). 
Table 6. Incremental CE watios with 7,5\% recurrence rate after Bassini (societal level)

\begin{tabular}{|c|c|c|c|c|c|c|}
\hline Days off work after LAP & 15 & 17 & 19 & 21 & 23 & 25 \\
\hline \multicolumn{7}{|l|}{ Recurrence $\angle A P=0 \%$} \\
\hline 30 minutes & L.d.B. & L.dB & L.d.B & L.d.B & L.d.B & 3.389 \\
\hline 89 minutes & L.d.B & L.d.B & L.d. B & L.d.B & 3.613 & 9.440 \\
\hline 120 minutes & $L, d B$ & L.d.B & L...C.B & 1.022 & 6.836 & 12.662 \\
\hline \multicolumn{7}{|l|}{ Recurrence $L A P=4 \%$} \\
\hline 30 minutes & L.d.B & $1 . d B$ & L.d.B & L.A.B & L.d.B & 7.263 \\
\hline 89 minutes & L.d.B & L.d. B & L.d.B & L.d.B & 7.743 & 20.229 \\
\hline 120 minutes & L.d.B & $\mathbb{L} \cdot \mathbb{d} \cdot \mathbb{B}$ & L.d.B & 2.191 & 14.648 & 27.134 \\
\hline \multicolumn{7}{|l|}{ Rechrrence LAP $=8 \%$} \\
\hline 30 minutes & $371.162^{* * *}$ & $291.162 *$ & $203.762 *$ & $123.762^{* *}$ & $36.562 *$ & Bad L \\
\hline 89 minutes & $280.400 *$ & $200.400 * *$ & 113.000 氺水 & $33,000^{* * 3}$ & B.d.L & B.d.L \\
\hline 120 minutes & $232.064^{*}$ 隶 & $152.064 * *$ & $64.664^{* 2 *}$ & B.d.LA & B.d.L & B.dL \\
\hline
\end{tabular}

*) L.d.B = Kaparoscopic repair dominates Bassini repair; * CE-ratio of Bassini repair;

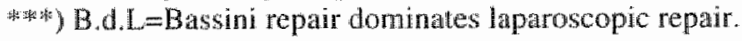

At $8 \%$ laparoscopic recurrence rate, this technique is both less costly and a little less $(0,5 \%)$ effective than Bassini repair. Up to the same break-even points as mentioned above, the incremental CE-ratio of Bassini repair decreases substantially with each additional "day off work" after laparoscopic repair. Beyond the break-even points, laparoscopic repair becomes both more costly and less effective as compared to Bassini repair.

\section{Discussion}

Although QALY's are a common measure of effectiveness in cost-effectiveness studies $(32,33)$, this measure was not used in our analysis. Firstly, the additional gain in survival after a laparoscopic inguinal hernia repair is expected to be zero as compared to survival after a Bassini repair (or other conventional repairs). Secondly, although Quality of Life (QoL) may be an important endpoint to consider, especially when a procedure is aimed primarily at relieving symptoms rather than to increase survival (34), the difference in overall QoL between laparoscopic and Bassini repair is expected to be small and only temporarily $(20,28)$. The calculation of a cost/QALY ratio for a therapy that is only expected to reduce short-term disabilities is not worthwhile, because these disabilities constitute only a small proportion of a person's entire life (35).

A recurrent hernia is the most important clinicall outcome of inguinal hernia repair, which was therefore used as our main outcome measure. This is an intermediate outcome measure, since not all aspects of the outcome of interventions are captured (as in a QALY). Furthermore, the choice of our outcome measure implies that the 
present CE-ratio provides little information on the place of laparoscopic inguinal. hernia repair in relation to other health care programs. The present study is only potentially able to assess laparoscopic inguinal hernia repair within the range of other inguinal hernia repairs.

From the societal perspective laparoscopic repair dominates Bassini repair since it is both less costly and more effective in the short term. In order to benefit society, laparoscopic repair should thus replace Bassini repair.

If the hospital perspective is handled, the laparoscopic repair is both more costly and more effective. Applying the rules of cost-effectiveness analysis, laparoscopic repair should replace Bassini repair when the hospital is willing to pay Dfl 5.348 for one additional 1-year recurrence-free patient. If the cut-off ratio is below DO1 5.348, Bassini repair should not be replaced.

Since there is no cut-off ratio for acceptable cost-effectiveness, interpretation and comparison of the results becomes difficult (36-38). However, the CE-ratio can be put in perspective by considering the consequences of a recurrent hemia. Besides the physical discomfort for the patient and the risk of strangulation, a recurrent hernia can have a social-economic impact. A patient with a recurrent hernia is therefore likely to undergo a re-operation in the future. If one additional recurrence-free patient can be achieved with the laparoscopic repair, than one patient less needs a re-operation for recurrent hernia as compared to the Bassini repair. It can be stated that the maximum cut-off ratio or willingness to pay (WTP) for one additional recurrence-free patient should at least include the hospital costs of repairing a recurrent hernia. Besides the costs of a recurrent hernia repair, the maximum WTP should also include the possible social-economic impact of a recurrent hernia, as well as the patient's disappointment or disutility. The latter components are, however, difficult to express in monetary values. Furthermore, one has to take into account that not all recurrent hernias will be repaired, since asymptomatic recurrences can remain unnoticed for a long time. Furthermore, a discounting factor should also be considered, since not all recurrences are likely to be repaired within the first year postoperatively (31).

The consequences of a recurrent hernia can also be presented in a cost-minimisation analysis. In using this approach, the societal costs of (future) recurrent herniat repairs are added to the societal costs of the primary repair. For a given year $\mathrm{X}$ postoperatively, the chance of having a re-operation for recurrent hernia limes the discounted societal costs of a re-operation can be calculated for both therapies. A disadvantage of this method is, however, that not all effects (id. recurrences) are taken into account ( 39 ).

The diversity in outcomes among the reported studies makes it difficult to draw strong conclusions about the cost-effectiveness of laparoscopic inguinal hernia repair. Firstly, laparoscopic recurrence rates and operating times vary considerably, indicating that laparoscopic inguinal hernia repair may have been in a learning phase when some trials, including the present, were initiated. Increasing experience in laparoscopic 
inguinal hernia repair will probably result in better outcomes, which subsequently leads to subtle changes in the CE-ratio over time. Secondly, results on convalescence after laparoscopic repair, reflected in return to work, also differ considerably. This may indicate that surgeons render different information to patients regarding their resumption of activities, and that different countries may have different policies regarding sick-leave.

The Bassini repair turned out to be a rather cost- "ineffective" comparator for laparoscopic repair. The Bassini repair with absorbable sutures was chosen for two reasons: firstly, it was our standard repair for inguinal hernia, and secondly, a recent Dutch survey has shown that in 1993 the Bassini-type of procedure was still the most popular repair, and absorbable suture material was used most often (5). Our choice of the conventional procedure may have influenced the high recurrence rate, but the results with regard to pain and resumption of activities are valid for all anterior tension-repairs". Furthermore, if the Bassini repair would have been left out of the analysis, surgeons would probably still be performing this technique, with its subsequent high recurrence rate.

Long term cost-effectiveness of the laparoscopic repair can of course not be ignored. Our incomplete 2-years follow up shows that recurrence rates after Bassini repair have increased from $19,5 \%$ to $25 \%$. Recurrence rates after Bassini repair have been noted to rise with continuing follow up (40), which is probably due to further deterioration of the supporting structures of the groin. In laparoscopic hernia repair, the whole inguino-femoral area is reinforced by a prothesis, which makes it difficult to imagine late recurrences. It is therefore expected that laparoscopic inguinal hernia repair becomes even more cost-effective than Bassini repair in the long term. However, whether long term recurrence rates will indeed remain as low as currently reported, will be noted with continuing follow up. In the present study, no special attention was paid to expected long term results, since there were already many uncertainties surrounding the short term cost-effectiveness of laparoscopic repair.

The impact of the present study is that our surgical department has abandoned the Bassini repair due to its disappointing effectiveness. The unacceptably high recurrence rate makes it unethical to continue performing this technique. According to the formal decision rules of societal cost-effectiveness analysis, laparoscopic repair should replace Bassini repair. The laparoscopic repair, however, is not yet accepted as the "new" standard for primary inguinal hernia. The technical difficulty of the laparoscopic repair, which causes the long operating time, makes it difficult for surgeons to justify its routine use. Furthermore, as was mentioned above, the Bassini repair has not been an appropriate control for the laparoscopic repair.

Some authors state that the most suitable comparison is that of laparoscopic inguinal hernia repair with Lichtenstein's tension-free hernioplasty. The Lichtenstein procedure is a relatively simple operation, which can be performed under local anaesthesia. The advocates of the Lichtenstein procedure have stated that 
postoperative pain and recovery period compare favourably with those of laparoscopic repair, while the complication- and recurrence rate, and costs are significantly lower (41). The surgical department is currently exploring this technique.

The authors conclude that the cost-effectiveness of laparoscopic inguinal hernia repair depends on the perspective from which the analysis is performed, the cut-off ratio of acceptable cost-effectiveness and on the comparator chosen. From the societal perspective, laparoscopic repair is more cost-effective than Bassini repair. The present analysis does not provide sufficient information to decide whether laparoscopic inguinal hernia repair is the 'most' cost-effective treatment within the range of other repairs.

\section{References}

1. SIG Health Care Information. Trends in Surgery 1984-1993 (in Dutch). Apeldoom, 1995.

2. Payne, J.H., Grininger, L.M., Izawa, M.T., Podoll, E.F., Lindahl, P.J., Balfour, J. Laparoscopic or Open Inguinal herniorthaphy? A randomized prospective trial. Archives of Surgery 1994:129: 973-981.

3. Kingsnorth, A., Gray, M., Nott, D. Prospective randomised trial comparing the Shouldice technique and plication darn for inguinal hemia. British Joumal of Surgery 1992:79:10681070 .

4. Moschinski,D., Linke, R. Inguinal hemia operations in Germany. Intemational Surgery 1986: $71: 146-147$.

5. Simons, M.P., Hoitsma, H.F.W., Mullan, F.J. Primary inguinal hernia repair in The Netherlands. European Journal of Surgery 1995;161:345-348.

6. Bassini, E. Ueber die Behandlung des Leistenbruches. Anchiv foir Klinische Chirurgie 1890;40: 429-476.

7. Hay, J.M., Boudet, M.J., Fingerhut, A., et al. Shouldice Inguinal herna repair in the male adult: The Gold Standard? A multicenter controlled triall in 1578 pationts. Anmals of Surgery $1995 ; 222: 719-727$.

8. Kux, M., Fuchsjäger, N., Schemper, M. Shouldice is superior to Bassini Inguinal Herniorrhaphy. American Joumal of Surgery 1994;168:15-18.

9. Paul, A. Troidl, H., Williams, J.I., Rixen, D., Langen, R. Randomized trial of modilied Bassini versus Shouldice inguinal hemia repair. British Joumal of Swgery 1994; 81:1531. 1534.

10. Arregui, M.E, Davis, C.D., Yucel, O. Laparoscopic mesh repair of inguiral hernia using a preperitoneal approach: A preliminary report. Surgical Laparoscopy and Endoscopy 1992:2: $53-58$

11. Corbitt, J.D. jr. Transabdominal preperitoneal hemiomthphy. Surgical Laparoscopy and Endoscopy 1993;3:328-332.

12. Dion, Y.M., Morin, J. Laparoscopic ingunal herniormaphy. Canadian Jownal of Surgery 1992,35:209-212.

13. Geis, W.P., Crafton, W.B., Novak. M.J., Malago, M. Laparoscopic hemiornaphy: resulis and technical aspects in 450 consecutive procedures. Surgery 1993;114:765-774.

14. Milkins, R.C., Landsdown, M.J.R. Wedgwood, K.R., Brough, W.A., Royston, M.S. Laparoscopic hemia repari: a prospective study of 409 cases. Minimally twasive Therapy 
$1993: 2: 237-242$

15. Voeller, G.R. Mangiante, E.C., Britt, L.G. Preliminary evaluation of laparoscopic herniorthaphy. Surgical Laparoscopy and Endoscopy 1993;3:100-105.

16. Winchester, D.J., Dawes, L.G., Modelski, D.D., et al. Laparoscopic inguinal hernia repair. A preliminary experience. A rchives of Surgery 1993;128:781-784.

17. Champault, G., Benoit, J., Lauroy, J., Rizk, P. Hernies de l'aine de l'adulte Chirurgie Aaparoscopique vs operation de Shouldice. Eude randomisée contrôlée. Amanales de Chirurgie 1994:48:1003-1008.

18. Maddem, G.J. Ruwkin, G. Bessel, R., Dewit, P., Ponte, L. A comparison of laparoscopic and open thernia repair as a day surgical procedure. Surgical Endoscopy 1994;8:1404-148.

19. Vogt, D.M. Curet, M.J., Pitcher, D.E., Martin, D.T., Zucker, K.A. Preliminary results of a prospective randomized trial of laparoscopic onlay versus conventional inguinal hemiorthaphy. American Jounal of Swgen 1995;169:84-90.

20. Lawrence, K, McWhinnie, D., Goodwin, et al. Randomised controlled trial of laparoscopic versus open repair of inguinal hernia: early resuls. British Medicat Jounal 1995;31 1:981985.

21. Stoker, D.L., Spuegeihalter, D.J., Singh, R., Wellwood, J.M. Laparoscopic versus open inguinal hernia repair: a randomized prospective trial. Lancet 1994;343:1243-1245.

22. Johannesson, M., Jonsson, B., Karlsson. G. Outcome measurement in economic evaluation. Health Econonics 1996:5:279-296.

23. Nyhus, L.M. Iliopubic tract repair of inguinal and femoral hernia. Surgical Clinics of North Amerioa 73:487-499.

24. Koopmanschap, M.A., Rutren, F.F.H., Ineveld van, M., Roijen van, L. The friction cost method for measuring indirect costs of disease. Joumal of Health Economics 1995;14:171189.

25. Statistics Notherlands. Data on labour and wages of employeew, 1994.

26. Schrenk, P., Woisetschlager, R., Rieger, R., Wayand, W. Prospective randomized trial comparing postoperative pain and return to physical activity after transabdominal preperitoneal, total preperitoneal or Shouldice technique for inguinal hernia repair. British Joumal of Surgery 1996; 83:1563-1566.

27. Tschudi, J., Wagner, M., Klaiber, et al. Controlled multicenter trial of laparoscopic transibdominal preperitoneal hemioplasty vs Shouldice hemiormaphy. Early results. Sargical Endoricopy $1996 ; 10: 845-847$.

28. Batkur, J.S., Wexler, MJ., Hinchey, E.J., Thibeault, D., Meakins, I.L. Laparoscopic versus open inguinal herniorthaphy: prelimimary results of a randomized controlyed trial. Sargery $1995 ; 118 ; 703-710$

29. Lien, M.S.L., Vioonhoven van. T.M.V. Laparoscopic inguinal hemia repair. British Joumal of Surgery 1996;83:1197-1204

30. Bessel, I.R. Baxter, P. Riddell, P., Watkin, S., \& Maddern, G.J. A randomized controlled trial of lapatroscopic extraperitoneal hernia repair as a day surgical procedure. Surgtcal Endoscopy $1996 ; 10: 495-500$.

31. Dinksen, C.D., Beets, G.L., Go, P.M.N.Y.H., et al. Open versus laparoscopic repair for prinary inguinal hemia. A randomized controlled trial. European Joumal of Surgery, in

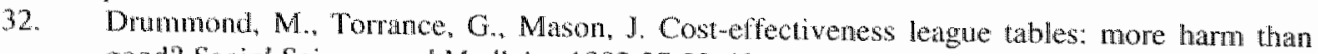
good? Soctal Scrence and Medicine 1993;37:33-40.

33. Gold, M.R., Patrick, D.L., Torrance, G., et al ldentifying and valuing outcomes. In. Gold, M. R. Shegel, I.E, Russell, L.B. Weinstein, M.C. (eds.). Cost-effecriveness in Healh and Medicine, Oxford: University Press 1996:83-123. 
34. Fraser, S.C.A. Quality-of-life measurement in surgical practice. British Jommal of Surgeng 1993:80:163-169.

35. Laupacis, A... Feeny, G., Detsky, A.S., Tugwell, P.X. How attractive does a new technology have to be to warrant adoption and utilization? Tentative guidelines for using clinical and economic evaluations. Canadian Medical Associanon 1992;146:473-481.

36. Detsky, A.S. Naglie. I...G. A clinician's guide to cost-effectiveness. Annals of huternat Medicine 1990;1 13:147-154.

37. Johannesson, M., Weinstein, M.C. On the decision rules of cost-effectiveness analysis. Joumal of Healh Econowics 1993;12:459-467.

38. Phelps, C.E., Mushlin, A.I. On the (near) equivalence of cost-effectiveness and cost-benefit analysis. Internationat Joumal of Technology Assessment in Healh Care 1991;7:12-21.

39. Kald A., Nilsson E., Anderberg B., et al. Reoperation as a surrogate endpoint in hernia surgery. A three year follow up of 1565 hemionhaphies. European Joumal of Surgery $1998 ; 164: 45-50$.

40. Beets, G.L., Oosterhuis, K.J., Go, P.M.N.Y.H., Baetern, C.G.M.I., \& Kootstra, G. Long-term follow up (12-15 years) of a randonized controlled trial comparing Bassini-Stetten, Shoudice and high ligation with narrowing of the internal ring for primary inguinal hemia repair. Joumal of the American College of surgeons 1997:185:352-357.

41. Amid P.K., Shuman A.G., Lichtenstein I.L. An analytic comparison of Latparoscopic Hemia Repair with Open "Tension.Free" Hemioplasty. International Surgery 1995:80:9-17. 



\section{OPEN OR LAPAROSCOPIC PREPERITONEAL MESH REPAIR FOR RECURRENT INGUINAL HERNIA}

A randomized controlled trial

Submitted for publication:

- Beets G.L., Dirksen C.D., Go P.M.N.Y.H., Geisler F.E.A., Baeten C.G.M.I., Kootstra G. Open or laparoscopic preperitoneal mesh repair for recurrent hernia. A randomized controlled trial. 


\section{Introduction}

The traditional anterior approach in the repair of a recurrent hernia carries a high falure rate: from approximately $5 \%$ for the Shouldice technique to more than $30 \%$ for other techniques (1). The use of a large preperitoneal mesh for the repair of recurrent inguinal hernia, as propagated by Stoppa et al., has been shown to be very effective $(2,3)$. In a series of complex recurrent inguinal hernias, our recurrence rate with this "giant prosthetic reinforcement of the visceral sac" technique (GPRVS) was 1\%, and the procedure has become our standard repair for recurrent inguinal hernias (4).

Laparoscopic repair is based on the same principles of a preperitoneal mesh repair. It could combine the low recurrence rate of the open technique with a quick. postoperative recovery. Several randomized trials have addressed this issue in comparing laparoscopic with conventional anterior repair and the Lichtenstein repair in one trial, and including mainly or exclusively primary inguinal hernia patients (5-11). There have been no reports of trials comparing laparoscopic with open preperitoneal mesh repair, or trials for recurrent inguinal hernia.

The aim of this randomized controlled study is to compare morbidity, cost, and recurrence rates of laparoscopic transabdominal preperitoneal mesh repair (TAPP) and open preperitoneal mesh repair (GPRVS) for recurrent inguinal hemia.

\section{Patients and methods}

\section{Study design}

An independent non-clinical investigator was assigned to the project by the Board of Directors of the University Hospital of Maastricht. The randomized controlled trial was approved by the institutional ethical committee and by the scientific committee. All patients eligible for general anesthesia (ASA 1-2-3), between 20 and 80 years of age, with a recurrent inguinal hernia, were randomly assigned to either GPRVS or TAPP repair. Pregnant women, patients with coagulation disorders, advanced carcinoma, history of lower abdominal or other pelvic surgery (except appendicectomy), patients requiring concomitant surgery, and patients with a recurrence after a preperitoneal repair were excluded from randomization. Patients with giant scrotal recurrent hemias were also excluded, because these hemias can be difficult to manage laparoscopically. After obtaining a written informed consent, patients were randomized using the sealed envelope technique.

\section{Outcomes and instruments}

Postoperative morbidity, convalescence, pain, cost, and recurrence were assessed. Hospital stay was standardized: patients were admitted the day before surgery and were discharged the morning after the operation, whenever possible. Operating time, operative findings, postoperative complications and postoperative hospital stay were 
recorded. Postoperative pain was measured with the Visual Analogue Scale (VAS) from 1 to 10 (no pain - intolerable pain) and a Verbal Rating Scale (VRS) with 4 response possibilities (no pain, mild pain, moderate pain, severe pain). At discharge, patients received a questionnaire to report pain levels, amount and type of analgesia use during the first 7 postoperative days. The date of restmption of work and physical activities was recorded. Patients were instructed that there were no restrictions regarding return to routine activities, except if this would cause discomfort or pain.

Two abdominal muscle tests were used as an objective measure of physical performance. These exercises were a modification of a test described by Payne ef al. (5). In the first test the patient crosses the arms on the chest, and performs curled situps. In the second test the patient pulls up his flexed legs. These exercises were performed during 30 seconds, or until the patient felt uncomfortable. Muscle tests were performed before the operation, and 1 day, 10 days, and 6 weeks after the operation. Postoperative performance was expressed as a percentage of preoperative performance.

Follow-up is performed by physical examination by the authors 10 days, 6 weeks, 1 year, 2 years and 5 years after operation. A recurrent hernia is defined as any symptomatic or asymptomatic defect in the abdominal wall with herniation of abdominal contents, exacerbated by a Valsalva manoeuvre.

\section{Anaesthesia}

Premedication, anaesthesia and postoperative pain medication were standardized. Premedication consisted of paracetamol $1000 \mathrm{mg}$. All patients underwent general anaesthesia with thiopentone sodium $4-5 \mathrm{mg} / \mathrm{kg}$, vecuronium $0, \mathbb{1 m g} / \mathrm{kg}$ and fentanyl $1 \mu \mathrm{g} / \mathrm{kg}$. Maintenance of anaesthesia included $\mathrm{N}_{2} \mathrm{O}-\mathrm{O}_{2}$ mixture. Isoflurane up to 1,2 vol\% and iv boli of fentanyl $1 \mu \mathrm{g} / \mathrm{kg}$ were used when required. No opiate anlagonists were used at the end of anaesthesia. Postoperative analgesia consisted of $1000 \mathrm{mg}$ paracetamol 3 times daily, when required.

\section{Operative techniques}

The open repairs were performed by 5 surgeons, or by surgical residents assisted by one of the 5 surgeons. Laparoscopic repairs were performed by 4 laparoscopic surgeons with varying experience in laparoscopic hernia repair, or by surgical residents assisted by a laparoscopic surgeon.

A urinary catheter was introduced to maintain an empty bladder during the operation, and was removed at the end of the procedure. Prophylactic antibiotics were used only for the GPRVS procedure.

The details of the GPRVS have been described previously (4). Through a lower abdominal midline incision access is gained to the preperitoneal and prevesical space. The peritoneal sac is dissected away from the abdominal and pelvic wall, and the hemial sac is reduced. A large polypropylene mesh $(26 \times 18 \mathrm{~cm})\left(\mathbb{M a r l e x}^{*}, \mathrm{C} . \mathrm{R}\right.$. Bard, 
Billerica, MA, USA), with two vertical slits of approximately $10 \mathrm{~cm}$ in the upper border is positioned around the spermatic cords. The vertical slits are closed with a running nonabsorbable suture. The large mesh covers both inguinofemoral areas.

In the laparoscopic transabdominal preperitoneal repair (TAPP), a CO2 pneumoperitoneum is created with a Verres needle. Three cannulas are used for access to the abdominal cavity. The peritoneum is opened at the upper border of the inguinal hernia defect from the medial umbilical ligament to the level of the iliac spine. A direct sac is reduced, an indirect sac is reduced and dissected off the vas deferens and the testicular vessels. When the indirect sac is very large, it is transected. A polypropylene mesh of $10 \times 15 \mathrm{~cm}$ (Prolene ${ }^{\circledR}$, Ethicon, Somerville, N.J., USA) with rounded edges is positioned over the inguino-femoral area, widely overlapping the edges of the hernial defect. The mesh is not anchored by staples or sutures. The peritoneum is closed with a running absorbable suture. An incidentally discovered contralateral hernia is repaired at the same time.

\section{Costs}

The cost analysis was carried out from the hospital perspective. The treatment of an inguinal hernia consisted of 5 activities: outpatient clinic preoperatively, a hospital day, operation, recovery-room stay, and outpatient climic postoperatively. The costs per activity consisted of direct and indirect cost. Direct costs included personnel costs and both medical and non-medical material costs. Indirect costs consisted of the general overhead. Costs of laboratory tests, X-rays, medications, etc. were allocated to the activity in which they were requested or given. Costs of complications (additional outpatient visits, readmissions etc.) were calculated separately. All costs are presented in 1994 Dutch Guilders ( $1 \mathrm{Dfl}=0,36$ UK£ $=0,55$ US\$; average conversion rates 1994).

\section{Staristical analysis}

Results were analyzed according to "intention to treat. The Kolmogorov-Smirnov test was used to lest for normality. The unpaired Student-t test was performed to determine differences between normally distributed variables. The unpaired MannWhitney test was used for differences between non-normally distributed data or ordinal variables. Chi-square test was used to analyze categorical variables, and Fisher's exact test was used when any expected cell value in a $2 \times 2$ table was less than 5 . $P$ values less than 0,05 were considered to indicate statistical significance. 


\section{Results}

From November 93 until March 96, a total of 129 patients aged between 20 and 80 with a unilateral or bilateral recurrent inguinal hernia were treated in our department. Seventy-nine of these patients were randomized. Patient characteristics are given in table 1. The two groups are comparable. Reasons for non-inclusion are: ambulatory treatment: 3, regional anaesthesia: 10, previous lower abdominal surgery: 4, concomitant surgery: 5 , giant scrotall recurrence: 5 , previous preperitoneal repair: 3 , patient refusal: 6 , and unknown: 6 . Eight patients experienced a recurrence while participating in a trial for primary inguinal hernia repair, and were not included in a second trial for ethical reasons.

Table 1. Patient characteristics

\begin{tabular}{lll}
\hline & GPRVS & TAPP \\
\hline Patients (total) & 37 & 42 \\
Female patients & 1 & 1 \\
Working patients & $16(43 \%)$ & $16(38 \%)$ \\
Patients performing physical activities & $29(78 \%)$ & $33(79 \%)$ \\
Mean age \pm SD & $57 \pm 13$ & $58 \pm 12$ \\
Mean Body Mass Index \pm SD & $25,1 \pm 2,8$ & $24,2 \pm 2,9$ \\
Risk factors for recurrence* & $11(30 \%)$ & $10(24 \%)$ \\
Recurrent hernias & 41 & 52 \\
Primary hernas & 11 & 4 \\
\hline
\end{tabular}

Figures are presented as numbers (and percentages) unless otherwise indicated; ${ }^{2}$ prostatism, COPD, obstipation, or strenuous physical labor.

\section{Operative results and hospital stay}

Sixty-five per cent of the GPRVS procedures and $29 \%$ of the laparoscopic repairs were performed by surgical trainees ( $P<0,001)$. One patient assigned to a laparoscopic repair underwent a GPRVS procedure because of laparoscopic equipment supply problems. According to the intention to treat principle, he is retaned for analysis in the laparoscopic group. Operating time (SD) was significantly different: 56 (16) min for GPRVS versus 79 (32) min for laparoscopic repair $(P<0,001)$. Alter a GPRVS, $77 \%$ of patients were discharged within $24 \mathrm{hrs}$, as compared $1092,5 \%$ of patients after a laparoscopic repair $(\mathrm{P}=0,02)$.

\section{Complications}

Complications are listed in table 2. One patient was readmitted 8 days alter a GPRVS with an ileus. At laparotomy small bowel loops were found to be adherent to the mesh through a peritoneal tear. This was easily corrected and the patient had an uneventful recovery. One patient was readmitted with a pulmonary embolus, and was treated with standard anticoagulation therapy. All wound infections were superficial. They were treated on an outpatient basis, and healed without further problems. Two patients 
Chapher

evenually had a scar excision under local anaesthesia for cosmetic reasons.

Table 2. Complications

\begin{tabular}{lll}
\hline & CPRVS & TAPP \\
\hline Vas deferens injury & 0 & 1 \\
Urinary & 1 (retention) & 2 (infection) \\
Chest infection & 0 & 1 \\
Pumonary enbolus & 1 & 0 \\
Ileds/laparotomy & 1 & 0 \\
Wound infection & $4^{\text {th }}$ & $0{ }^{*}$ \\
Hematoma & 5 & 10 \\
Scroma & 7 & 10 \\
Inguind hypesthesial & 0 & 0 \\
Painful testicle (transient) & 1 & 2 \\
Testicular swelling (transient) & 2 & 2 \\
Testicular atrophy & 1 & 0 \\
Chronic neuralgia & 0 & 0 \\
\hline
\end{tabular}

Figures are presenced as numbers; $;) \mathrm{P}=0,04$.

\section{Pain and analgesia use}

The mean VAS scores (SD; range) during the first postoperative week were $2,9(1,5$; 0-7) for GPRVS and 2,2 (1,6;0-7) for the laparoscopic repair $(P=0,005)$. Median (1 st3rd quartile) VRS scores were 1 (1-1) for GPRVS and 1 (1-1) for laparoscopic repair $(P=0,05)$. Ten days and 6 weeks after operation VAS and VRS scores were comparable. The median total analgesia use (range) in the first postoperative week was 3,5 (0-11) tablets in the GPRVS group, and $1(0-6)$ tablets in the laparoscopic group $(\mathrm{P}=0,06)$.

\section{Resumption of activities}

The average disability period for work ( $\mathrm{SD}$; range) was significantly different: 23 $(12,4 ; 1-41)$ days for GPRVS and $13(8,2 ; 1-30)$ days for TAPP $(P=0,03)$. Return to physical activities was after $29(13,4 ; 1-57)$ days for GPRVS and $21(15,5 ; 1-74)$ days for TAPP $(P=0,07)$.

\section{Abdominal muscle tests}

Preoperative absolute performance was comparable in both groups for both muscle tests. The results are presented in figures 1 and 2. Postoperative performance was significantly better in the laparoscopic group at the first and the tenth postoperative days. At six weeks, results were comparable for both groups. 
Figure 1. Sit-up test. Postoperative performance is expressed a percentage of preoperative performance. Black bars: GPRVS: shaded bars: laparoscopic repair; Student-t test.

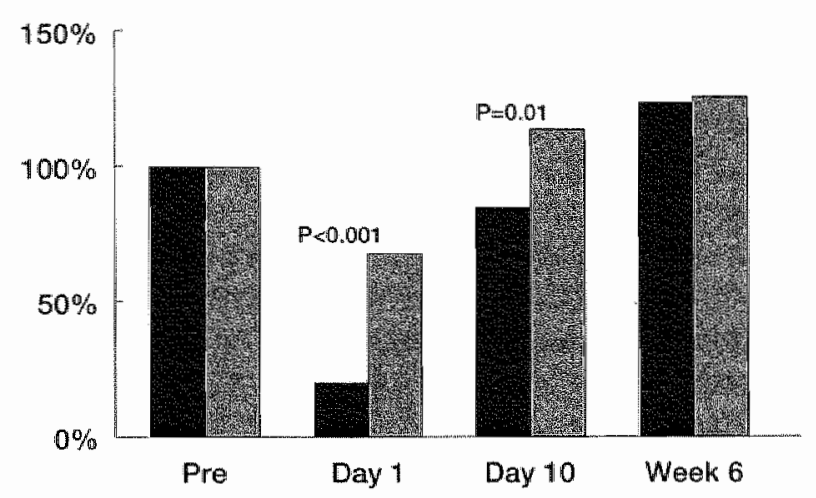

Figure 2. Knees-up test. Postoperative performance is expressed a percentage of preoperative performance. Black bars: GPRVS; shaded bars: laparoscopic repair; Student-t test.

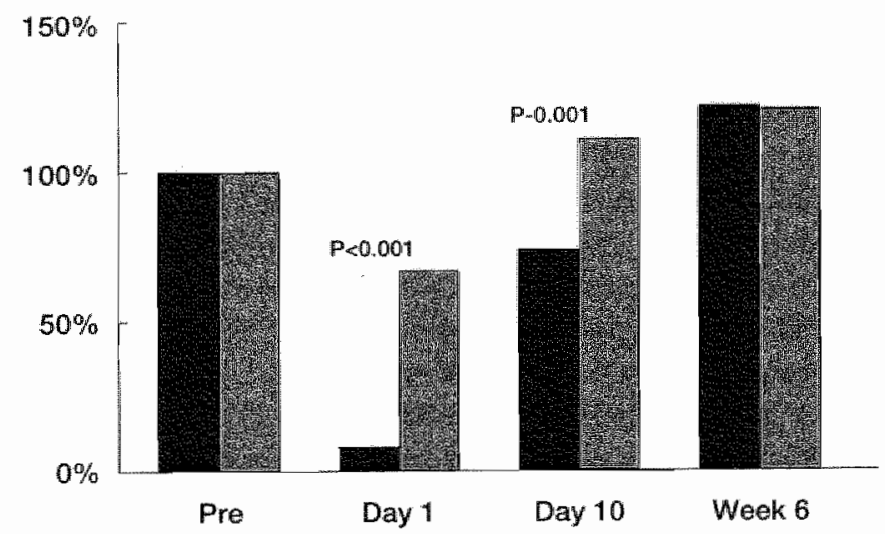


Costs

The costs are presented in table 3. As shown, the difference in theatre costs is mainly caused by the higher personnel costs for the laparoscopic procedure, due to the longer operating time.

Total costs resulting from complications are Df 4.630 for all GPRVS procedures (mean additional cost of Dfl 213), and Dfl 336 for all TAPP procedures (mean additional cost of Dfl 8). When these additional costs are included, GPRVS becomes sligltly more expensive than the laparoscopic repair. Cost of recurrences is not included in the analysis, because it is unclear how many eventually will require a. repair.

Table 3. Hospital costs of GPRVS and laparoscopic repair

\begin{tabular}{cll} 
& GPRYS & TAPP \\
\hline The atre costs (total): & 963 & 1.218 \\
- personnel & 339 & 553 \\
- material & 449 & 467 \\
- capacity & 57 & 80 \\
- overhead & 118 & 118 \\
Oher costs & 869 & 778 \\
Costs of complications & 213 & 8 \\
Total costs & 2.045 & 2.004 \\
\hline
\end{tabular}

*) Outpatient clinic, hospital stay, recovery room

\section{Follow up and recurrences}

The mean follow up time in November 1996 is 21 months (range: 8-36).

In the GPRVS group one patient died of pulmonary disease within the first year after his hernia repair. One patient moved abroad after the 1 year follow up. Thirty-two patients have completed the 1 year follow up, and 15 patients the 2 year follow up.

In the laparoscopic group one patient died of a malignancy 6 months after his hernia repair In the course of his disease, the underwent a laparotomy, on which occasion the hernia repair was found to be intact. Thirty-four patients have been examined after 1 year, and 13 patients after 2 years.

The recurrence rate after GPRVS is $1 / 52$ hernias (1.9\%), or $1 / 37$ patients $(2,7 \%)$. One small asymptomatic recurrence was found at physical examination 1 year after operation. The patient had a postoperative wound infection, for which additional outpatient clinic visits were required. The small recurrence may have gone unnoticed because attention was directed at the wound problem. The asymptomatic recurrence has not been repaired. There were no cases of severe chronic pain. One patient had a persistent minor groin pain.

The recurrence rate after laparoscopic repair is $7 / 56$ hemias $(12,5 \%)$, or $6 / 42$ patients $(14,3 \%)$. Four of the recurrences had been described as 'seroma' or 'bulging" 6 weeks after operation, and were found to be recurrences at the 1 year follow up. One patient with a recurrence diagnosed after one year had not attended the 6 week follow up 
visit. Two recurrences had been noted by the patients, one after 3 months, and one after 5 months. Four of the seven recurrences were asymptomatic at he time of discovery, two of which later became symptomatic. So far, two recurrences have been repaired. They were both medial recurrences, and obviously the prosthetic mesh had not been placed medially enough. The difference in recurrence rates, $1,9 \%$ for GPRVS, and $12,5 \%$ for TAPP, is statistically significant $(\mathrm{P}=0,04)$. There were no patients with severe chronic pain. Two patients had a persistent minor groin pain. Two patients have developed an asymptomatic recurrence from a previously conventionally repaired contralateral hemia.

\section{Discussion}

The $12,5 \%$ recurrence rate after laparoscopic hernia repair is higher than the figure of less than $5 \%$ that is reported in series and randomized trials, summarized in a recent review article (12). Felix et al. report a series of laparoscopic repair of 90 recurrent hernias, in which only one failure was observed (13).

Our strict adherence to physical examination as a follow up method and our definition of recurrence could explain part of our higher recurrence rate. This includes also the small asymptomatic hernias discovered during follow up, some of which might never require a repair. In the present study, only 2 of the 8 recurrences has been repaired so far.

The most important cause for the higher recurrence rate after laparoscopic hernia repair is most likely the technique itself. When property performed, a recurrence should not occur, as in both the open and laparoscopic repair a preperitoneal mesh covers the whole inguinofemoral area. All recurrences are inherently technical failures, and by comparing recurrence rates, we are actually comparing technical difficulty of the procedure. The difference in recurrence rate, $1,9 \%$ for GPRVS and $12,5 \%$ for the laparoscopic repair, indicates that the laparoscopic repair is substantially more difficult.

It has been shown that most recurrences after laparoscopic repair are due to too small a mesh, or not using staples to fix the mesh (14). We have used a large mesh of $10 \mathrm{~cm}$ $x 15 \mathrm{~cm}$ which was not stapled, according to Stoppa's principle. Most of our recurrences after laparoscopic hemia repair have occurred medially, and accordingly, we now place the mesh at least until the midline, and occasionally use hemia-staples when an adequate $(2 \mathrm{~cm})$ overlap cannot be achieved medially. The learning curve effect has been observed by several authors $(15,16)$. In the present study, the laparoscopic repair was performed or assisted by 4 laparoscopic surgeons, with varying experience in laparoscopic hernia repair. The learning curve may have been underestimated. It is reasonable to assume that the recurrence rate of an experienced laparoscopic hernia surgeon will be lower than the $12,5 \%$ presently reported.

The mean follow up is 21 months. For conventional repair, it has been estimated that 


\section{Chapter 5}

only $25 \%$ of recurrences occur within the first postoperative year, whereas $50 \%$ will appear after 5 years (17). For the open preperitoneal mesh repair, the long-term recurrence rate is not substantially different from the short-term recurrence rate (2-4). This is also expected for the laparoscopic repair, as it is based on the same principle. Therefore, we believe that the long-term results of this study will be essentially the same.

Two of the complications after GPRVS, a pulmonary embolus and a mechanic ileus requiring a laparotomy can be considered potentially dangerous, and are indicative of the invasiveness of the procedure. As expected there were less wound problems after a laparoscopic repair than after a GPRVS.

Randomized trials have shown that laparoscopic repair causes less postoperative pain and less postoperative disability than a (conventional) anterior inguinal hernia repair (5-11). In both open and laparoscopic preperitoneal mesh repair, there is no tension on the musculo-aponeurotic groin structures. Goodwin et al have compared, in a prospective non-randomized study, laparoscopic repair with a unilateral preperitoneal mesh repair through a groin incision (18). They found no difference in postoperative pain and disability period. The differences observed in our study, can only be explained by the lower abdominal midline incision in the open repair. It is clear that less pain and disability benefit both individual patients and society. However, when asked for, most patients consider the traditional outcome measure of recurrence more important than the speed of recovery (1.1).

In this study, hospital costs of both procedures were comparable. The two major complications after GPRVS contributed considerable to the costs of the open procedure. Laparoscopic hernia repair can easily be performed in a day-surgery setting, as shown by Evans et al. (19). These authors report, after having performed 300 laparoscopic repairs, operating times of $24 \mathrm{~min}$ for unilateral and $38 \mathrm{~min}$ for bilateral repair. In this selting, laparoscopic repair is substantially less expensive than reported in our study.

Laparoscopic recurrent inguinal hernia repair causes less postoperative pain and disability than GPRVS. Laparoscopic repair is technically more difficult, and the potential for technical failure is higher. When discussing treatment options with a patient, all of the above mentioned items should be addressed. In our opinion, laparoscopic inguinal thernia repair should only be performed by experienced laparoscopic surgeons who assess their personal recurrence rates. With regard to recurrence rates, the open preperitoneal mesh repair remains the best repair for most patients and surgeons alike. 


\section{References}

1. Bendavid, $\mathrm{R}$. The need for mesh. In: Bendavid $\mathrm{R}$, (ed). Prosthesis and abdoninal wall hemias. Austin, Texas: R.G. Landes Company; 1994:116-122.

2. Stoppa, R.E., Rives, J.L., Warlaumont. C.R., at al. The use of Dacron in the repair of hemias of the groin. Surgical Clinics of North America 1984;64:269-285.

3. Wantz, G.E. Giant prosthetic reinforcement of the visceral sac. Surgical Gynecology and Obstemics 1989;169:408-417.

4. Beets, G.L., van Geldere, D., Baeten, C.G.M.I., Go, P.M.N.Y.H. Long-term results of giant prosthetic reinforcement of the visceral sac for complex recurrent inguinal hernia. Brish Joumal of Surgery $1.996 ; 83: 203-206$.

5. Payne, J.H., Grininger, L.M. Lzawa, M.T. et al. Laparoscopic or open inguinal herniorrhaphy? A randomized prospective triat. Archives of Surgery 1994:129:973-979.

6. Stoker, D.L., Spiegehalter, D.J., Singh, R., Wellwood, J.M. Laparoscopic versus open inguinal hernia repair: randomized prospective trial. Lancer 1994:343:1243-1245.

7. Vogt, D.M., Curet, M.J., Pitcher, D.E., et al. Preliminary results of a prospective tandomized trial of laparoscopic onlay versus conventional inguinal hemiorthaphy. American Journal of Surgery 1995; 169:84-89.

8. Maddern, G.J., Rudkin, G., Bessell, J.R., et al. A comparison of laparoscopic and open repair as a day surgical procedure. Surgical Endoscopy 1994;8:1404-1408.

9. Bessell, J.R., Baxter, P., Riddell, P., et al. A randomized controlled trial of laparoscopic extraperitoneal hemia repair as a day surgical procedure. Surgical Endoscopy 1996;10: 495-500.

10. Barkun, J.S., Wexler, M.J., Hinchey, E.J., et al. Laparoscopic versus open ingainal herniorrhaphy: Preliminary results of a randomized controlled trall. Surgery $1995 ; 118: 703-710$.

11. Lawrence, K., McWhinnie, D., Goodwin, A., et al. Randomized controlled trial of laparoscopic versus open repair of inguinal hernia: early results. British Medical Jowmal $1995 ; 311: 981-985$.

12. Liem, M.S.L., Vroonhoven van, T.J.M.V. Laparoscopic inguinal hernia repait. British Joumal of Surgery 1996:83:1197-1204.

13. Felix, E.L., Michas, C.A., McKnight, R.L. Lapearoscopic tepair of recurrent hernias, Surgical Endoscopy 1995:9:135-139.

14. Phillips, E.H., Rosenthal, R., Fallas, M., et al. Reasons for early recurrence following laparoscopic hernioplasty. Surgical Endoscopy 1995; 9:140-5.

15. Lien, M.S.L., Steensel van, C.J., Boelhouwer, R.U. The learning curve for totally extraperitoneal laparoscopic inguinall hernia repair. American Joumat of Surgery $\| 996$; $71: 281-285$.

16. Phillips, E.H., Arregai, M., Carroll, B.ll., elt all. Incidence of complications lollowing laparoscopic hernioplasty. Surgical Endoscopy 1995:9:16-21.

17. Lichtenstein. I.L., Shore, J.M. Exploding the myths of heroia repat. Americam Journal of Surgery: 1976:132:307-315.

18. Goodwin, J.S., Traverso. L.W. A prospective cost and oulcome comparison of ingunal hemia repairs. Laparoscopic transabdominal preperitoneal versus open tension-free preperitoneal. Sargical Endoscopy 1995;9:981-983.

19. Evans, D.S., Ghaneh, P., Kahn, I.M. Day-case lauparoscopic hernia repair. British Joumat of Surgery 1996;83:1361-1363. 
6

\section{DIFFUSION OF SIX SURGICAL ENDOSCOPIC PROCEDURES IN THE NETHERLANDS}

Stimulating and restraining factors

This chapter has originally been published in:

- Dirksen C.D., Ament A.J.H.A., Go P.M.N.Y.H. Diffusion of six surgical endoscopic procedures in the Netherlands. Stimulating and restraining factors. Health Policy 1996; 37: 91 -104. 


\section{Introduction}

In the spring of 1990 , a new technique for the surgical treatment of patients with symptomatic gallstone disease was introduced in the Netherlands, i.e. the laparoscopic cholecystectomy. The conventional operation was the cholecystectomy by laparotomy, i.e. removal of the gallbladder through an approximately $20-\mathrm{cm}$ incision in the abdominal wall. In laparoscopic cholecystectomy the operative area is entered by means of four cannulas or trocars through which a video laparoscope and instruments are conducted. The video laparoscope visualizes the abdominal cavity and projects the images onto a monitor. The instruments, measuring 5-10 $\mathrm{mm}$ in diameter, are used to resect and remove the diseased gallbladder. The laparoscopic operation leaves the patient with four small, 0.5 to $1-\mathrm{cm}$ incisions. Early publications suggested a reduction in operative morbidity after laparoscopic cholecystectomy compared to conventional cholecystectomy. Several practical courses on swine-models and proctoring of surgeons by experienced colleagues induced a rapid dissemination of Japaroscopic cholecystectomy among Dutch surgeons. Close attention by the media stimulated patient demand. At that time, the superiority of this operation compared to conventional treatments had not yet been assessed by means of a randomized controlled trial. Nowadays, this procedure is a well-accepted one that is performed on at least $80 \%$ of all patients with symptomatic gallstone disease, because of its reduced operative trauma, few postoperative complications, short hospitalization period and early convalescence (1-7).

Other surgical endoscopic procedures have evolved in the Netherlands since the introduction of laparoscopic cholecystectomy. These include laparoscopic appendicectorny, treatment of gastro-oesophageal reflux disease with the Nissen fundoplication, large bowel resection, inguinal hernia repair and several thoracoscopic procedures. National surveys among Dutch surgeons in 1991 and 1992 showed different diffusion patterns for these endoscopic techniques compared to laparoscopic cholecystectomy (8). This finding led to a study whose objective was to identify factors that might have an impact on the diffusion of some surgical endoscopic procedures.

Several factors that are related to the diffusion process have been described in publications dealing with various applications of "minimally invasive therapy" (9-12). These studies concluded that the diffusion of a medical technology can be attributed to the influence of 'budget', 'effectiveness', 'conservatism among surgeons', 'patient clemand'. 'media and 'presence of medical innovators'. Another study reported that 'quick recovery", "short convallescence', 'cosmetic results' and 'competition' were important reasons for surgeons to start endoscopic surgery (13). Yet, other authors concluded that the adoption and use of laparoscopic cholecystectomy was related to characteristics of the hospitals and surgeons, such as 'hospital size', 'hospital location', 'type of practise' and 'revenue system' (14-16). One of these studies pointed out that 
'participation in a residency training' was the only independent predictor of the early adoption of laparoscopic cholecystectomy (15).

Nevertheless, little is known about the diffusion curves of laparoscopic cholecystectomy and several related surgical techniques in the Netherlands and about the relative influence of certain pre-defined factors on the adoption of each of these technologies. Better insight into these factors would enable one to exert a better control over the diffusion of a technology in the desired direction. These considerations have led to the development of a comprehensive questionnaire for Dutch surgeons. The aim of the present study was to evaluate the diffusion of six surgical endoscopic procedures among hospitals with and without a surgical training program, i.e. teaching and non-teaching centres, in the Netherlands. The influence of 13 factors on the adoption of each procedure was studied. By means of the results of this study, an ideal diffusion profile was developed.

\section{Methods}

Study design

Hospital-specific information was obtained from the 'Yearbook of the Dutch Surgical Society' (Jaarboek Nederlandse Vereniging voor Heelkunde), the 'Dutch Medical Address Book' (Geneeskundig Adresboek Nederlland) and the "Hospital Yearbook 199 1.' (Jaarboek Ziekenhuizen 1991) (17-19). In the Netherlands there are 139 surgical clinics that can be classified as either teaching hospitals $(n=39)$ with a surgical training program (including 8 University Hospitals), or non-teaching hospitals $(\mathrm{n}=100)$.

In June 1994, questionnaires were sent to 138 general surgeons from all Dutch surgical clinics that perform laparoscopic cholecystectomy. The University Hospital of Maastricht was excluded from the mailing list, since this centre originated the survey. The database consisted of surgeons who had registered for training programs and courses or who had co-operated in earlier surveys on laparoscopic cholecystectomy. These surgeons were considered "representatives" of their hospital with regard to the introduction of surgical endoscopic procedures, although they were not representing the opinions of other surgeons in their partnership. The reason we preferred surgeons to be the target population of this survey was that the introduction of a 'medium technology' like endoscopic surgery does not require extensive capital investments or specific governmental regulation. Adoption, therefore, is mainly initiated by the surgeons themselves with only limited control from the hospital management or from the government (20-22).

In the survey, surgeons were asked about 6 endoscopic procedures and 13 pre-defined factors. The laparoscopic procedures included: cholecystectomy, appendicectomy, inguinal hernia repair, Nissen fundoplication, large bowel resection and thoracoscopic operations. The factors are listed and defined in table 1. 
Table 1. Definition of the factors

\begin{tabular}{|c|c|}
\hline Factor & Definition \\
\hline Budget & Available budget for endoscopic equipment and instruments. \\
\hline Competition & Concurence between surgeons regarding performance and prestige. \\
\hline Conference/meeting & $\begin{array}{l}\text { Information on conferences and meetings about aspects of the endoscopic } \\
\text { procedure. }\end{array}$ \\
\hline Extrabenefit & $\begin{array}{l}\text { Value of the endoscopic procedure with respect to (clinical) effectiveness, } \\
\text { morbidity, cost-effectiveness, etc. }\end{array}$ \\
\hline Medía & Information by journals, tellevision, newspapers, etc. \\
\hline Nature of technology & $\begin{array}{l}\text { Characteristics of endoscopic surgery: e.g. a two-dimensional perspective, } \\
\text { use of instruments, camera, etc. }\end{array}$ \\
\hline Patient demand & Explicit demand for the endoscopic procedure by patients. \\
\hline Planning/logistics & $\begin{array}{l}\text { Preparation of the operating theatre, availability of equipmentinstruments, } \\
\text { duration of the operation, etc. }\end{array}$ \\
\hline Reimbursement & Surgeon's fee for the endoscopic procedure. \\
\hline Service industry & $\begin{array}{l}\text { Service with respect to delivery and repair of equipment and (reusable) } \\
\text { instruments. }\end{array}$ \\
\hline Support industry & $\begin{array}{l}\text { Sponsoring of conferences/courses and try-outs of equipment and } \\
\text { instruments. }\end{array}$ \\
\hline Surgio & Specific surgicall performances during the endoscopic operation. \\
\hline Training/courses & $\begin{array}{l}\text { Supply/content of training and courses with respect to an endoscopic } \\
\text { procedure. }\end{array}$ \\
\hline
\end{tabular}

In the survey the following questions were posed: (1) Which of the six endoscopic procedures are being performed in your hospital now? (2) Since when (month and year) are they being performed? Subsequently, for each procedure the surgeon was asked to give an opinion about the influence that each of the 13 factors had on adoption All factors had to be marked as 'stimulating', 'neutral' or 'restraining' on a 7point scale. Surgeons who had not, or not yet, adopted the particular procedure (called 'non-adopters") were asked to express their expectations regarding the factors. For the purpose of this study 'diffusion' was defined as 'adoption of the technology"; it should not be interpreted in the broader sense of 'adoption and volume of utilization' $(20,23)$. Some factors defined in this study are closely related to the organisation and financing of health care in the Netherlands (i.e. budget and reimbursement). Due to a costcontainment policy of the Dutch government, all hospitals receive an annual budget with which all care must be provided. The costs that are generated by providing health care services are compensated by the revenues based on charges. The total costs are bound to a maximum, which is the budget. If this maximum is exceeded, the hospital is liable for the excess costs. The introduction of a "new" medical technology is often accompanied by higher costs for the hospital. These additional costs need to be financed by internal budget shifts, something which forces hospitals and units to make choices among different (levels of) services (24).

The reimbursement system is regulated by the 'Law of Health Care Tariffs' (Wet Tarieven Gezondheidszorg). Technologies that are considered to be experimental are 
not reimbursed by public health insurance (Ziekenfonds). A new diagnostic tool or treatment must be proven safe, (cost-)effective and beneficial to be admitted to the health insurance package. It may take some time before hospitals and surgeons receive an adjusted tariff for a new medical technology. The factors 'budget' and 'reimbursement' therefore are not universal concepts but rather need to be considered within the context of the Dutch health care system.

\section{Statistical analysis}

Results of the factor assessment are presented as median values with 10 th and 90 th percentiles to provide information about the distribution. For statistical analysis, respondents were divided in non-adopters and adopters. Hospitals were stratified according to hospital type (teaching or non-teaching). The non-parametric MannWhitney test was used to analyse differences in factor assessment between adopters and non-adopters, differences in time of adoption between teaching and non-teaching hospitals and for differences in the number of endoscopic procedures adopted between these hospital types. A Chi-square test was performed to test for an association between adoption and hospital type. For all tests, a two-sided $\mathrm{P}$ value below 0.05 was considered statistically significant.

\section{Results}

\section{Adoption rates}

Of the 138 questionnaires sent out, 7 were returned uncompleted. Four of these were returned by surgeons from co-operating hospitals, two centres did not have indications for laparoscopic surgery, and one surgeon was retired. The response rate based on 131 questionnaires was $82 \%(\mathrm{n}=108)$. Among the respondents were $32(82 \%)$ teaching hospitals, including $6(86 \%)$ University Hospitals, and $76(77 \%)$ non-teaching hospitals. According to the surgeons" responses, the numbers of centres that pertormed endoscopic procedures in 1994 were 108 (100\%) for cholecystectomy, 69 (64\%) for appendicectomy, $56(52 \%)$ for thorax operations, $46(43 \%)$ for inguinal hernia repair, $21(19 \%)$ for Nissen fundoplication and $20(19 \%)$ for large bowel resection.

In table 2 the numbers of adopted procedures and the times of adoption are listed for teaching and non-teaching hospitals. Except for cholecystectomy, endoscopic procedures were adopted more by surgeons from teaching hospitals than by those from non-teaching hospitals. This was significantly different for the thorax operations, inguinal hernia repair and Nissen fundoplication. Surgeons from teaching hospitals adopted a median of four procedures, which is significantly higher than the median of two procedures in non-teaching hospitals. All procedures were adopted earlier by surgeons from teaching hospitals than by those from non-teaching hospitals, which was significantly different for cholecystectomy, thorax operations and large bowel 
Chaper 6

resection.

Table 2, Hosplifil type and adoption

\begin{tabular}{|c|c|c|c|c|c|c|}
\hline \multirow[b]{2}{*}{ Procedures } & \multicolumn{3}{|c|}{ Numbers of hospiltals $(\%)$} & \multicolumn{3}{|c|}{ Median time of adoption } \\
\hline & Teaching* & Nonteaching & $x^{2}$ & Teaching & Nonteaching & M-Wh。 \\
\hline Cholecystectomy & $32(100 \%)$ & $76(100 \%)$ & -...- & Feb'91 & Junt 91 & $P=0,04$ \\
\hline Appendicectomy & $24(75 \%)$ & $45(59 \%)$ & $P=0,1$ & $\operatorname{Jan} 92$ & $\operatorname{Jun} 92$ & $P=0,4$ \\
\hline Thonax operations & $28(88 \%)$ & $28(37 \%)$ & $<0,001$ & Jun 92 & $\tan 93$ & $P=0,007$ \\
\hline Inguinal hernia & $19(61 \%)$ & $27(35 \%)$ & $P=0,01$ & Jun 93 & Sep 93 & $P=0.4$ \\
\hline Nissen fundlopl. & $12(38 \%)$ & $9(12 \%)$ & $P=0,002$ & May 92 & Nov' 93 & $P=0,2$ \\
\hline Large bowel & $8(25 \%)$ & $12(1.6 \%)$ & $P=0,3$ & Nov 91 & Mar 93 & $P=0,02$ \\
\hline
\end{tabular}

No. of procedures $4(2-6) \quad 2(1-4) \quad P<0,001$

* Teaching hospitals include University Hospitals. 8 Presented as medians with 10th and 90 th percentiles within parentheses. \#ann-Whitney test.

Figure 1 presents the aggregated adoption curves for the six procedures based on the dates of adoption indicated by the respondents.

Figure 1. Diffusion of endoscopic surgery in the Netherlands in the period 1990-mid 1994.

$t=$ cholecystectomy, $\Delta=$ appendicectomy, $0=$ thorax-operation, $+=$ inguinal hemia repair, = large bowel resection, $=$ = Nissen fundoplication. $M=$ first six months of the year; $\mathrm{E}=$ last six months of the year.

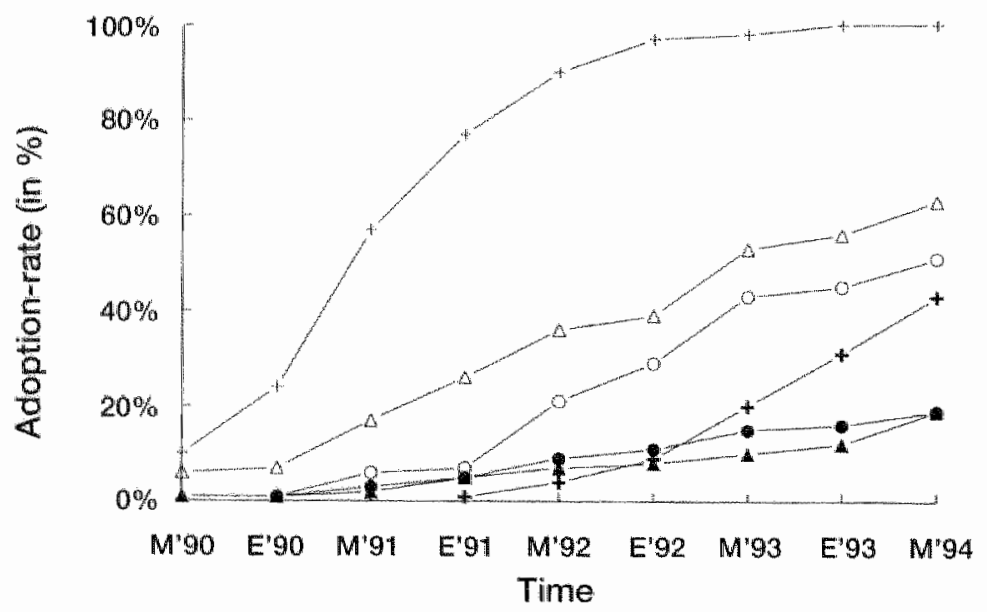




\section{Factor assessment}

Table 3 shows the influence of the 13 factors on the adoption of each procedure. Results are presented for all respondents and, subsequently, for adopters and nonadopters. Based on the median values, the factors could be subdivided into those that were predominantly 'stimulating', 'neutral' or 'restraining'. The factors 'conference, 'extra benefit', 'support by the industry' and 'training' stimulated the introduction of most procedures. A noteworthy finding was that these factors were all assessed as "neutral" for laparoscopic appendicectomy. Furthermore, the factor 'extra benefit' was assessed as 'neutral' for large bowel resection. Extra benefit was the only factor with both restraining and stimulating assessments. Appendicectomy and large bowel resection showed Jarge dispersions on this factor.

'Competition', 'media', 'nature of the technology', 'patient demand', 'reimbursement' and 'surgical technique' were found to be predominantly neutral factors in all but two procedures. The adoption of laparoscopic cholecystectomy, for example, was stimulated by all of these factors except 'reimbursement'. Thoracoscopic procedures were stimulated by the factors 'nature of the technology' and 'surgical technique'. 'The dispersions of the factors (table 3 ) show that 'reimbursement' tends to be a restraining factor with a distribution that is skewed to the left, whereas 'competition', 'patient demand' and 'media' tend to be stimulating. "Service of the industry' has an ambiguous influence on adoption but seems stimulating if the dispersion is considered. 'Nature of technology" and 'surgical technique' have 'normal' distributions with both 'restraining' and 'stimulating' influences. The factors 'planning' and 'budget' were assessed as 'restraining' with no exceptions for any of the procedures. The distributions of these factors are all skewed to the left.

It can be concluded that the factors defined were generally more 'stimulating' or less 'restraining' for adopters than for non-adopters. We tested to what extent these differences between sub-groups were significant to find the factors that distinguished adopters from non-adopters. The Mann-Whitney test was used for each procedure except laparoscopic cholecystectomy. The most obvious results were found for the factor 'extra benefit'. This was the only factor that was assessed significantly differently by adopters and non-adopters for all five procedures. 'Nature of the technology' and 'surgical technique' were assessed differently for all procedures except inguinal hernia repair. The factor 'conference' was assessed differently for all procedures except appendicectomy. 'Training', 'support by the industry' and 'service by the industry" were assessed differently for three procedures. The other factors either did not indicate, or only occasionally indicated significant differences between adopters and non-adopters.

Table 2 showed that surgeons who practise in teaching hospitals adopt more of the endoscopic procedures than their colleagues in non-teaching hospitalls. Furthermore, this group tends to adopt these procedures earlier. We performed Mann-Whitney tests 
to compare the factor assessment of surgeons from teaching hospitals with surgeons from non-teaching hospitals. For none of the procedures were significant differences found.

Table 3 . Factor assessment

\begin{tabular}{|c|c|c|c|c|c|c|}
\hline $\begin{array}{l}\text { Treatments - } \\
\text { Factors }\end{array}$ & $\begin{array}{l}\text { Cholecys- } \\
\text { tectomy }\end{array}$ & $\begin{array}{l}\text { Appen- } \\
\text { dicedony }\end{array}$ & $\begin{array}{l}\text { Thoras- } \\
\text { operation }\end{array}$ & $\begin{array}{l}\text { Inguimal } \\
\text { hemia rep. }\end{array}$ & $\begin{array}{l}\text { Nissen } \\
\text { fundoplic. }\end{array}$ & $\begin{array}{l}\text { Bowel } \\
\text { resect. }\end{array}$ \\
\hline \multirow[t]{2}{*}{ Budger } & $3(1-5)$ & $3(1-4)$ & $3(1-4)$ & $2(1-4)$ & $2(1-4)$ & $2(1-4)$ \\
\hline & & $2 \cdot 3$ & $2 \cdot 3$ & $2-3^{*}$ & $2-3$ & $2-1$ \\
\hline \multirow[t]{2}{*}{ Competition } & $5(4-6)$ & $4(4-5)$ & $4(4-5)$ & $4(4-6)$ & $4(4-6)$ & $4(4-5)$ \\
\hline & & $4-4 *$ & $4-4$ & $4-4$ & $4-4^{*}$ & $4-4$ \\
\hline \multirow[t]{2}{*}{ Conference } & $6(5-7)$ & $4(4-6)$ & $5(4-7)$ & $5(4-6)$ & $5(4-6)$ & $5(4-6)$ \\
\hline & & $4-4$ & $5-5^{\text {粰 }}$ & $5-6^{k}$ & $5-5 *$ & $4-5$ 源 \\
\hline \multirow[t]{2}{*}{ Extra benefit } & $6(5-7)$ & $4(1-6)$ & $6(4-7)$ & $5(3-6)$ & $5(3-6)$ & $4(1-6)$ \\
\hline & & $4-5^{2}$ & $5-6$ & $4-6+$ & $5-5^{*}$ & $4-5$ \\
\hline \multirow[t]{2}{*}{ Media } & $5(4-6)$ & $4(4-5)$ & $4(4-5)$ & $4(4-5)$ & $4(4-5)$ & $4(4-5)$ \\
\hline & & $4-4$ & $4-4$ & $4-4$ & $4-4$ & $4-4$ \\
\hline \multirow[t]{2}{*}{ Nature tedplnology } & $5(3-7)$ & $4(3-6)$ & $5(3-6)$ & $4(3-7)$ & $4(3-6)$ & $4(2-6)$ \\
\hline & & $4-4.4$ & $4-5^{*}$ & $4-4$ & $4-5^{2}$ & $4-5^{*}$ \\
\hline \multirow[t]{2}{*}{ Patient demand } & $5(4-7)$ & $4(4-5)$ & $4(4-5)$ & $4(4-6)$ & $4(4-5)$ & $4(4-4)$ \\
\hline & & $4-4$ & $4-4$ & $4-5^{*}$ & $4-4$ & $4-4$ \\
\hline \multirow[t]{2}{*}{ Planning } & $4(2-5)$ & $2(1-4)$ & $4(1-5)$ & $3(1-4)$ & $3(1-4)$ & $2(1-4)$ \\
\hline & & $2-2$ & $3-4$ & $3-3$ & $3-3$ & $2-2$ \\
\hline \multirow[t]{2}{*}{ Reimbursement } & $4(2-4)$ & $4(2-4)$ & $4(2-4)$ & $4(2-4)$ & $4(2-4)$ & $4(1-4)$ \\
\hline & & $4-4$ & $4-4$ & $4-4$ & $4-4$ & $4-4$ \\
\hline \multirow[t]{2}{*}{ Service } & $5(3-7)$ & $4(4-6)$ & $5(4-6)$ & $5(4-6)$ & $4(4-6)$ & $4(4-6)$ \\
\hline & & $4-4$ & $4-5 *$ & $5-5$ & $4-5$ & $4-5 *$ \\
\hline \multirow[t]{2}{*}{ Support } & $5(4-7)$ & $4(1-5)$ & $5(4-6)$ & $5(4-6)$ & $5(4-6)$ & $5(4-6)$ \\
\hline & & $4-4$ & $4-5$ ** & $5-5 *$ & $4-5$ & $4-5 * *$ \\
\hline \multirow[t]{2}{*}{ Surgical technope } & $5(3-7)$ & $4(3-6)$ & $5(3-7)$ & $4(2-7)$ & $4(2-7)$ & $4(2-6)$ \\
\hline & & $4-5$ *s & $5-5 \%$ & $4-5$ & $4-5^{36}$ & $3-5^{2 *}$ \\
\hline \multirow[t]{2}{*}{ Traning } & $6(5-7)$ & $4(4-6)$ & $5(4-6)$ & $5(4-6)$ & $5(3-6)$ & $5(4-6)$ \\
\hline & & $4-4$ & $5-5 *$ & $5-5$ & $5-6 *$ & $5-5 *$ \\
\hline
\end{tabular}

Every first row presents results for all respondents, as medians with loth and 90 th percentilles within parcntheses. In the second rows median values for respectively non-adopters and adopters are preschicd. I=very restraining, $2=$ restraning, $3=$ little restraining, $4=$ neutral, $5=$ little stimulating, $6=$ stimulating, $7=$ wery stimulating. * $P<0,05 ; * * 0,005$.

\section{Discussion}

The conclusions of this study need to be interpreted with caution. First, in this study the idea of "diffusion" does not refer to 'volume of utilization', which would provide complete information about the process. In this context, however, the extent of use is not relevant because the objective was to study factors that might influence the surgeons" decision to adopt a given procedure. Secondly, these findings specifically 
refer to surgical endoscopic procedures and cannot be generalized to other medical technologies. 'High technologies' like transplantation surgery (kidney, heart, liver. lung) or magnetic resonance imaging (MRI) are more specialized and expensive than laparoscopic surgery; the diffusion of these technologies in the Netherlands is primarily controlled by the government and not by physicians themselves. Furthermore, the aim of this study was not to explain, but rather to describe the diffusion of endoscopic surgery on the basis of certain factors. We are well aware that the degree and swifness of the diffusion of a medical technology depend on a complex combination of economical, organizational, political, institutional, medical, social-demographic and cognitive factors, and this combination varies in time $(12,15,16,20,22,24,25)$. All of these factors have been identified and described by several authors. Until now, however, no explanatory model exists in which all determinants of diffusion are represented.

The first conclusion of this study is based on objective information on the type of hospital in which the respondents are practising. The results indicate that the surgeons" behaviour with regard to adoption differed between teaching and non-teaching hospitals. Surgeons from hospitals with a surgical training program had adopted more of the endoscopic techniques being studied. Based on the median times of adoption, they tended to adopt them earlier than their non-teaching counterparts. Of course, this finding does not imply that teaching hospitals are always the first ones to introduce a procedure. The first laparoscopic cholecystectomy, for example, was performed by a surgeon from a non-teaching hospital. In addition, the results show that surgeons from teaching hospitals were not more positively influenced by the factors than surgeons from non-teaching hospitals. Therefore, the finding merely suggests that the conditions for the adoption of new medical technologies can be more favourable in teaching hospitals. Surgeons from teaching hospitals must be skilled in order to train residents who must deal with more advanced surgical endoscopic techniques in the future. In the Netherlands, but also in most of the surgical clinics in Europe, laparoscopic cholecystectomy and other endoscopic applications are now part of the surgical training program (13,26). Another reason for adoption is that surgens from University Hospilals have to keep up with recent developments in surgery, in order to compete scientifically (16).

In the subjective part of this study, the surgeons' opinions with respect to the influence of 13 predefined factors on the adoption of the endoscopic procedures were studied. The factors 'budget" and "planning", for example, were found to have a genenal restraining effect on the adoption of surgical endoscopic procedures. The introduction and use of endoscopic technology require an investment in specific equipment (i.c. an endoscope, a monitor and disposable or reusable endoscopic instruments). In the operating theatre some adjustments need to be made regarding the purchase, planning and maintenance of the equipment and instruments. Moreover, endoscopic surgery implies a change in the planning of personnel and time. Assisting personnel have to be 
trained to operate the camera and must have knowledge of the instruments (27). An endoscopic procedure is more time-consuming than a conventional procedure, especially for surgeons in their 'learning curve' $(28,29)$. Furthermore, most endoscopic procedures are technically more difficult than conventional operations. These characteristics of endoscopic surgery have a cost increasing effect and imply some changes in the planning of surgical interventions. However, one must expect such difficulties in the early adoption phase.

The factor 'reimbursement' was generally assessed as a 'neutral' factor, based on the median values. However, this factor tended to be restraining when the dispersion was considered. In 1994 surgeons began receiving adjusted fees for laparoscopic cholecystectomies. Other surgical endoscopic procedures, however, are not yet reimbursed differently from conventional procedures by public health insurance. It is, therefore, not surprising that at the time of this survey the factor 'reimbursement' was not one that stimulated adoption. The reason is that these new applications of endoscopic surgery have not, or not yet, proven to be cost-effective.

The factors 'budget', 'planning' and 'reimbursement' have a similar effect for adopters and non-adopters, that is, an impeding influence. Yet, the overall negative assessment of these factors did not keep surgeons from adopting endoscopic techniques. This finding suggests that the influence of these factors is perhaps not important enough to guide the decision to adopt a procedure or not. A similar conclusion can be drawn regarding the factors 'media', 'competition' and 'patient demand'. Although these factors stimulated the adoption of laparoscopic cholecystectomy, they seemed of little importance in the introduction of the other surgical endoscopic procedures.

"Training", 'support by the industry' and "service by the industry' were assessed differently by adopters and nonadopters with regard to three procedures. These factors may occasionally have supported the decision to adopt or not to adopt the technology, but the results are too diverse to draw general conclusions.

The factors 'surgical technique', 'nature of the technology' and 'conference' were assessed differently with regard to four procedures but, according to the non-adopters, they did not impede the adoption of any of the procedures. However, the technical aspects and characteristics of several surgical endoscopic applications were evidently more appealing to adopters than to non-adopters. Surgical conferences and meetings offer opportunities for discussion and exchange of information on these issues. Adopters were obviously more positively influenced by this factor.

The strongest conclusion can be drawn from the factor 'extra benefit'. Although the non-adopters were not restrained by this factor, adopters had significantly more positive perceptions about the additional benefits of the endoscopic approach, and this applied to all procedures. This finding shows that a considerable proportion of the surgeons seems cautious regarding other endoscopic procedures, despite the fact that all, possibly 'biased', respondents have adopted laparoscopic cholecystectomy. Discussions about the value of several endoscopic procedures continue. Some 
international trials have been, and are still being performed to collect scientific proof of the short- and long-term effectiveness, costs and (dis)advantages of endoscopic surgery. Apparently, none of the other endoscopic applications have yet proven themselves to surgeons to be as effective as laparoscopic cholecystectomy $(30,31)$.

\section{A Diffusion profile}

The factors in this study have an unambiguous, marginal or conflicting influence on adoption of medical technology. But in which phase of the diffusion process, how and by whom can these factors be applied or allowed to influence the diffusion of a surgical endoscopic procedure, or a surgical procedure in general, in the desined direction?

\section{Phase 1. Testing/experimening on human subjects.}

The diffusion process starts when the technology is tested or used on human subjects (32). Early international publications, presentations by "opinion leaders" and personal communications mostly offer the first scientific information on the technique. Usually, only a few "innovative" surgeons with special interest will perform the technique on selected patients to test whether the procedure is (technically) feasible and safe. In this early phase information is gathered on the possible effectiveness and (technical) complexity of the procedure. Valuable developments may emerge in this phase and control is neither possible nor desired. The experience of these first patients will influence the surgeon in his personal perception of the benefits, or 'extra benefit" of the tectunique.

\section{Phase 2. Early adoption: conduction of clinical trials.}

In the ideal situation, the widespread diffusion of a new surgical procedure is preceded by a medical technology assessment in the early phase, preferably in academic centres, to decide whether or not the technique is valuable. In practise, extensive research can be very costly and is not always necessary. The need for a medical technology assessment depends, among other things, on the prevalence and incidence of the disease, the proportion of patients who will profit from the procedure, the expected benefic (health gain) and costs of the technique, as well as on the avalability of other (cost-)effective techniques. If a medical technology is expected to generate considerable effects (clinical, ethical, social) or costs, early evaluation is desired and should serve as a prerequisite for widespread diffusion.

The Dutch Health Council (Gezondheidsraad) closely monitors the "stute of science", including medical technologies, and serves as an early waming system by identifying potentially valuable developments. However, before top-down research guidelines are presented in the annual report of the Health Council, technologies may already be in widespread use. By maintaining more informal contacts with, and providing direct 
guidelines to, surgical associations or study groups, the Health Council may better be able to stimulate research in the early phase. This research can be supported by the government through the "Fund for Investigational Medicine". The laparoscopic inguinal hernia repair, for example, is under evaluation in a 3-year multi centre study with the support of this fund. This usually means that all research-related costs (personnel and material) are compensated. However, not all evaluations have to take 3 years. Less extensive studies can be performed in a shorter period with funding, for example, only for additional personnel. This will enhance the flexibility of a medical technology assessment. Furthermore, funding is not always obligatory to perform research. An increasing number of professionals are taking initiatives towards medical. technology assessment without any financial support.

It is important to realise that an early evaluation of a "new" surgical procedure with a possible impact on health care (cost) can be advantageous for both professionals and decision-makers. With a coordinated approach to assessment, the government can monitor the early phase of a medical technology and be better informed about its progress. The advantage for the physicians is that the decision-makers can decide quickly whether or not to cover the procedure in the health care insurance package and to reimburse it accordingly.

In the course of doing research, it becomes clear whether or not a technique seems beneficial. If so, training courses, allong with scientific meetings and conferences aimed at consensus development, may serve as important means of transferring information. It is said that not only scientific literature, but more often informal contacts and subjective feelings will influence a clinician's practise. Another way to stimulate late adopters of a procedure, is by having experienced surgeons proctor interested colleagues in order to become sufficiently familiar with the technique. These activities can be coordinated by surgeons involved in the investigation. Medical companies can sponsor these activities and can simultaneously improve their products through close co-operation with the surgeons.

\section{Phase 3 : Strmulate diffusion or abandon the technique?}

There is a considerable time-lag between the need for and the availability of "reliable' scientific literature. Before results are published in a scientific journal, the information is more or less "classified". However, in order to influence the diffusion in the desired direction, it is important that study results be distributed as soon as possible. Therefore, meetings need to be organized aimed at possible users of the technique, even if the technique is ineffective. Furthermore, a report with information on clinical parameters, technical aspects, indications for use and cost should reach the decisionmakers.

If the prerequisite of 'extra benefit' of the technique is evident, then diffusion can be stimulated by other factors. Cooperation between the hospital's admissions department, surgeons, operating theatre personnel, anaesthesiologists and other 
specialists using endoscopic materials will improve the logistics and planning regarding endoscopic surgery in the hospital. This will ultimately imply cost reductions and budgetary advantages. Manufacturers can stimulate the adoption of an endoscopic procedure and optimize the use of their products by providing an adequate supply, delivery, repair and pricing of equipment and instruments.

The influence of the 'media', 'patient demand' and 'competition' on the diffusion of a medical technology, is desirable if the technique is valuable. An example is the recent attention given to "dynamic graciloplasty". This technology has recently proven to be an effective treatment for patients with faecal incontinence (33), and it received much attention in the media only after the results were published. The media has stimulated patient demand considerably, and the waiting list for this treatment is now growing. These same factors have contributed to a rapid adoption of laparoscopic cholecystectomy before its value was proven. Patient demand, however, was not based on valid information and might easily have led to adverse outcomes. On the other hand, treatments that have been proven ineffective receive little or no attention in the media. The physician is probably not very enger to display 'negative' information to the public. However, if patients will refuse a treatment due to a television program or newspaper report, the media might be an effective means to impede the diffusion. It is primarily the responsibility of the physicians as to when and how to inform the media about developments in health care.

Despite the 'reimbursement', laparoscopic cholecystectomy was very rapidly adopted by Dutch surgeons, which indicates that this factor was neither a major driving force, nor an inhibitor of adoption. However, if a technique is (cost-)effective and indicated for many patients, the government can encourage surgeons to adopt and perform the appropriate technique by adjusting the tariff. This seems reasonable, for example, if the new procedure is more time-consuming, and thus more costly, than the traditional procedure. If the technique is not beneficial, it will be kept out of the insurance package. To forbid the adoption and use of an ineffective procedure does not seem possible with the current governmental regulations regarding low and medium technologies. However, "peer control' and budgetary pressures within a department will discourage surgeons from performing that particular procedure.

\section{Conclusion}

This study has contributed to our knowledge about the diffusion of several surgical endoscopic procedures in the Netherlands. Of the factors studied, the surgeon's perception of the additional benefits of an endoscopic technique over the conventional operation is that which is the most important in deciding whether it will be adopted or not. This factor should serve as a prerequisite and must be proven before other factors are allowed to stimulate the diffusion of a medical technology. 


\section{References}

1. The Southern Surgeons Club. A prospective analysis of 1518 laparoscopic cholecystectomies. Now England Jownal of Medicine 1991;324:1073-1078.

2. Holohan T.V. Laparoscopic cholecystectomy. Lancet 1991;338:801 -803.

3. Kunz, R., Orth, K.. Steinacker, J.M., et al. Laparoskopische Cholecystektomie wersus MiniLap-Cholecystektomie. Der Chirurg 1992;63:291-295

4. Barkun, J.S., Barkun, A.N., Sampalis, J.S., et al Randomised controlled trial of laparoscopic versus mini cholecystectomy. Lancet 1992;340:1116-1119

5. Trondsen, E., Reiertsen, O. Andersen, O.K. Kjaersgaard, P. Laparoscopic and open cholecystectomy. A prospective randomized study. European Jourhat of Surgery 1993:159:217221.

6. McMahon, A.J., Russell, LT., Baxter, J.N., et al Laparoscopic versus minilaparotony cholecystectomy: a randomised trial. Lancet $1994 ; 343: 135-138$.

7. Go, P.M.N.Y.H., Schol. F.P.G., Gouma, D.I. Laparoscopic cholecystectomy in the Netherlands. British Jourwal of Strgery 1993;80:1180-1183.

8. Go, P.M.N.Y.H. Enquête Endoscopische Chirurgie in Nederland. Chirurgendagen, $13-14$ of May 1993, Amsterdam, the Wetherlands.

9. Vondeling. H., Haterkens. E., Wit de, A., Bos, M., Banta, H.D. Diffusion of Minimally Inwasive Therapy in the Netherlands. Healh Policy 1993;23:67-81.

10. Banta, H.D. Vondeling, H., Diffusion of Minimally Invasive Therapy in Europe. Health Policy 1993:23:125-133.

11. Banta, H.D. The cost-effectiweness of 10 selected applications in Minimally Invasive Therapy. Health Policy 1993;23:135-151.

12. Gelijns, A.C., Fendrick, A.M. The dynamies of innovation in Minimally Invasive Therapy. Healh Policy 1993:23:153-166.

13. Jakimowicz, J.J. Practice of endoscopic surgery in Europe. Current State. Surgical Endoscopy $199377: 393-397$.

14. Steiner, C.A., Bass, E.B., Talami, M.A., Pitt, H.A., Steinberg, E.P. Surgical rates and operative mortality for open and laparoscopic cholecystectomy in Maryland. New England

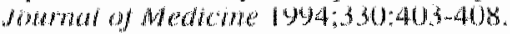

15. Fendrick. A.M. Escarce, J.J., McLane, C., Shea, J.A., Schwark. I.S. Hospital acloption of Laparoscopic Cholceystectomy. Medical Care 1994:10:1058-1063.

16. Escarce, J.J. Bloon, B.S., Hillman, A.L., Shea, J.A., Schwartz, J.S. Diffusion of Laparoscopic Cholecystectony Among General Surgeons in the United Suates. Medical Care $1095: 11: 256-271$.

17. Nederlandse wereniging voor Heelkunde. Jaraboek 1994/1995.

18. Geneeskundig Adresbok Nederland 93/94. Deel 2: Algemene Gegevens. Nijgh periodieken. Schicdam.

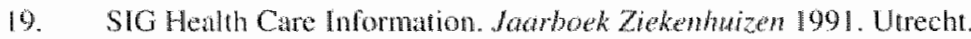

20. Battista, R.N. Innovation and diffusion of health-related rechnologies, A conceptual framework. Intermational Jownal of Technology Assessment in Health Care 1989;5:227-248.

21. Bos, M. Health care techology in the Netherlands. Heath Policy 1994;30:207-255.

22. Kazanjian, A., Friesen, K. Defusing technology. Technology diffusion in British Colombia, International Joumal of Technology Assessment in Health Care 1993;9:46-61.

23. Bana. H.D., Behney. C.J., Willens, J.S. Toward rational technology in medicine. Considerations for health policy. New York. Springer Verlag. 1981.

24. Neuhauser. D. Budgeting incentives for the appropriate use of medical technology. 
International Joumal of Technology Assessment in Healh Care 1987:3:173-185.

25. Dixon, A.S. The evolution of Clinical Policies. Medical Care 1990,6201 220 .

26. Schol, F.P G., Go, P.M.N.Y.H., Gouma, D.J., Kootstra, G. Laparoscopic cholecysteetomy in a surgical training program. European Journal of Surgery 1996;162:193-197.

27. Go, P.M.N.Y.H., Froeling, F.M.J.A., Cilissen, L.A.M., Mzerman, A. (eds.) Endoscopische chirurgie. Utrecht: Wetenschappelijke uitgeverij Bunge, 1995.

28. Kesteloot, K., Penninck, F. The costs and effects of open versus laparoscopic cholecystectomies. Health Economics 1993;2:303-312.

29. Cook, J., Richardson, J., Street, A. A cost utility analysis for treatment options for gallstone disease. Methodological issues and results. Healh Economic 1994;3:157-168.

30. Soper, N.J., Brunt, L.M., Kerbl, K. Laparoscopic General Surgery. Now England Journal of Medicine 1994;330:409-419.

31. Warshaw, A.L. Reflections on laparoscopic surgery. Surgery 1993;114:629-630.

32. Banta, H.D., Luce, B.R. Healnh care technology and its assessment. An international perspective. Oxford: Oxford University Press. 1993.

33. Baeten, C.G.M.I., Geerdes, B.P., Adang, E.M.M., et al. Anal dynamic graciloplasty in the treatment of intractable fecal incontinence. New England Joumal of Medicine 1995;332:1600. 1605. 
7

DISCUSSION, CONCLUSIONS AND RECOMMENDATIONS 


\section{Laparoscopic cholecystectomy}

In order to obtain an unbiased evaluation of a new trearment's value one usually needs to assign each patient randomly to either new or standard treatment. It is now generally accepted that the randomized controlled trial is the most reliable method of conducting clinical research (1). Since laparoscopic cholecystectomy was compared to both ESWL and conventional cholecystectomy in a retrospective study, some issues need to be considered.

Selection bias is one of the shortcomings in non-randomized studies. Although the same in- and exclusion criteria were used for both conventional- and laparoscopic cholecystectomy, the surgeon's choice of patients for the laparoscopic treatment may, subconsciously, have been more restrictive. Patient preference for the laparoscopic treatment has probably been minimal, since the present study was performed in the initial phase of laparoscopic cholecystectomy. The ESWL group consists of different patients as compared to both cholecystectomy groups, since they were admitted on the basis of more stringent criteria. Furthermore, a higher proportion of the ESWL patients performed paid labour compared with both cholecystectomy groups. This may indicate an explicit choice of these patients for ESWL because of the expected quick recovery.

Another general shortcoming of a retrospective study is information bias. For example, no information was available on the preoperative situation of the patients regarding the type of work, full-time or part-time employment, or the level of complaints. The postoperative comparison may therefore have been affected by other than only treatment-related factors. Also the preciseness of the results can be argued. Objective health outcomes were determined by review of patient charts, which may have led to incomplete observations. Subjective health outcomes were determined by means of a written questionnaire. Since patients from the laparoscopic cholecystectomy group were the most recently treated, their response may have been more reliable as compared to that of the conventional cholecystectomy- and ESWL. group. Finally, hospital costs were probably underestimated in all three groups.

In this retrospective study no complete economic evaluation was performed. Learning effects for example, were not embodied in this study. Specialisation in laparoscopic cholecystectomy is known to decrease the conversion rate, operating time and postoperative hospital stay (2), which may subsequently lead to lower costs. Also the risk for bile duct injuries, although not present in our study, decreases with the a growing experience of the surgeon (3).

In the present study most of the laparoscopic equipment and instruments used were reusable; however, no sensitivity analysis was performed to investigate whether our conclusions would change if, for example, disposable trocars were used. One study has calculated that the costs of a laparoscopic cholecystectomy procedure using disposables are at least 7,5 times higher than the costs per procedure with reusable 
instruments (4).

The present study also lacks a long term follow up with regard to stone recurrence rate after ESWL, which vary from $13-22 \%(5,6)$ after 19 months of follow up to $31 \%$ after 5 years (7) in the literature. Patients with recurrent stones after ESWL are therefore likely to undergo additional treatment in the future, which was not captured in our analysis.

The methodology and shortcomings of the present study hinders us to draw strong conclusions regarding the (cost-)effectiveness of laparoscopic cholecystectomy. However, no randomized controlled trial (RCT) has yet been reported in which laparoscopic cholecystectomy is compared with both ESWL and conventional cholecystectomy.

Most RCT's have compared laparoscopic cholecystectomy with 'mini-laparotomy' cholecystectomy (8-14). The majority of these studies have revealed that laparoscopic cholecystectomy is the preferred treatment in terms of pain and analgesia use, complication rates, quality of life, hospitalization time and resumption of activities. Two of these studies have presented conflicting costs outcomes $(10,12)$. Prospective comparative cost-studies have all demonstrated that hospital costs of laparoscopic cholecystectomy are either comparable or lower as compared to conventional cholecystectomy (15-19). From the point of view of society, two studies have revealed that laparoscopic cholecystectomy is a cost-saving strategy compared to conventional cholecystectomy, provided that a certain number of laparoscopic procedures are performed annually $(2,20)$.

Others have compared conventional cholecystectomy with ESWL. One author found that open cholecystectomy is preferred to ESWL in terms of symptom relief and quality of life $(21,22)$. In this RCT $48 \%$ of the patients were free of stones after ESWL within 18 months follow up, and results were better for patients with a solitary stone. Another RCT has shown that cholecystectomy patients had belter results regarding symptom relief, and that hospital costs were higher for ESWL (23). Sione clearance rate after ESWL was $24,3 \%$ at 12 months follow up, and results were comparable for patients with small-and large-bulk $(>4 \mathrm{~cm})$ gallstones.

Only one RCT has compared laparoscopic cholecystectomy with ESWL (24). In this study $72 \%$ of all patients assessed were excluded from the study because they were found not to be eligible for ESWL. Stone disappearance rate was $38 \%$ after ESWL with a stone recurrence rate of $3 \%$ after a median of 15 months follow up. The mean total disability duration was significantly shorter in the ESWL group, although hospital costs were substantially lower for laparoscopic cholecystectomy. The authors mentioned that gallbladder stone ESWL is of limited applicability, and that perhapss only a subgroup of patients should be offered any treatment.

The results of our retrospective study compare well with the results of most RCT's 
and comparative (cost) studies. It is therefore concluded that:

\section{Conclusions - laparoscopic cholecystectomy}

- Laparoscopic cholecystectomy is a safe and effective treatment for most patients with symptomatic gallbladder stones.

- The laparoscopic cholecystectomy procedure is more expensive compared with the conventional procedure.

- Laparoscopic cholecystectomy is associated with a reduction in postoperative inpatient days and recovery time.

- From the societal perspective, the laparoscopic procedure is the preferred treatment for most patients with symptomatic gallbladder stones.

- ESWL can be a cost-effective procedure in selected patients with a solitary, completely radiolucent stone.

\section{Laparoscopic inguinal hernia repair}

\section{Primary inguinal hernia}

In a well performed cost-effectiveness analysis all relevant alternatives are included. When the optimal design is not achieved or chosen, the intervention under study should at least be compared with the 'best' alternative intervention, which is usually also the standard treatment. When the present study was initiated, Bassini repair was the most performed operation for primary inguinal hernia in the Netherlands. Other traditional 'tension' repairs, like Shouldice, McVay and related techniques were less, though also frequently performed by Dutch surgeons (25).

In our study, the Bassini repair has turned out to be a rather cost. 'ineffective' comparator, which resulted in the high incremental effectiveness of laparoscopic repair in the denumerator of the cost-effectiveness ratio. The above indicates that another technique with a more acceptable recurrence rate might have been a more appropriate control.

The use of a prosthetic mesh in primary inguinal hernia repair has not been common in The Netherlands (25). Some authors state, however, that the most suitable comparison is that of laparoscopic inguinal hernia repair with Lichtenstein"s tensionfree hernioplasty. The Lichtenstein procedure is a relatively simple operation, which can be performed under local anaesthesia. The advocates of the Lichtenstein procedure have stated that postoperative pain and recovery period compare favourably with those of laparoscopic repair, while the complication- and recurrence rate, and 
costs are significantly lower (26). Two RCT's have compared laparoscopic repair with open tension-free repair. One study found that short term recurrence rates, operativeand hospitalization times were comparable. Operating costs were higher, and recovery and return to work seemed faster in the laparoscopic group (27). Another RCT revealed that operative times and hospital costs of the laparoscopic repair were higher, whereas postoperative pain and use of analgesia were less, and total societal costs were lower in the laparoscopic group (28).

\section{Recurrent inguinal hernia}

In the original design of the RCT comparing the laparoscopic repair with Giant Prosthetic Reinforcement of the Visceral Sac (GPRVS), or Stoppa's repair for recurrent hernias, 60 patients were required in each treatment group, in order to demonstrate a significant difference of $20 \%$ in postoperative morbidity and complications (29). Patient inclusion, however, went slower than expected and was ended after 2,5 years. The number of patients in the study was therefore small: 37 patients were ultimately included in the GPRVS group and 42 patients in the laparoscopic group. A possible consequence is that the difference of $20 \%$ in morbidity was not found, although there were evidently more wound problems and complications in the GPRVS group. In addition, the results with respect to pain and resumption of activities do not differ significantly between both groups. The conclusions therefore need to be interpreted with caution.

In the present study no cost-effectiveness analysis was performed. From the hospital perspective GPRVS probably dominates the laparoscopic repair, because of the higher effectiveness of GPRVS (a higher proportion of recurrence-free patients) and comparable costs. Although the laparoscopic operation is more expensive than GPRVS, the two major complications after GPRVS contributed considerably to the costs of the procedure.

Based on the present results regarding the postoperative "return to work", the costs outside the hospital due to postoperative sick-leave are lower in the laparoscopic group. From the societal point of view GPRVS therefore appears to be a more effective, but also more expensive alternative than laparoscopic repair.

A Dutch multicenter RCT has recently compared the totally extraperitoneal laparoscopic repair with a representative "mixture" of conventional techniques for unilateral primary or first recurrent hernia (30). This study, which was financially supported by the "Fund for Investigational Medicine" (Fonds Ontwikkelingsgeneeskunde), has revealed that the laparoscopic procedure is more effective than conventional techniques, in terms of short term recurrence rate, postoperative pain, resumption of sport-and daily activities, and work. From the societal perspective, the laparoscopic repair was Dfl 251 more expensive as compared to conventional repairs, which resulted in an incremental cost-effectiveness ratio of more 
than Df1 9.500 per (second) recurrence averted (31). The higher costs of laparoscopic repair were largely determined by the use of an expensive, especially designed disposable kit which included, among others, a dissection balloon and disposable trocars. The authors recognized that the laparoscopic equipment costs were slightly overestimated, since most hospitals already had reusable trocars at their disposal.

\section{Conclusions - primary inguinal hernia}

- Laparoscopic (TAPP) repair for primary inguinal hernia is a safe operation, which is associated with lower short term recurrence rates, less pain and a reduced recovery time as compared to the Bassini repair.

- A disadvantage of the laparoscopic repair is that general anaesthesia is required.

- From the hospital perspective, the laparoscopic inguinal hernia repair is more expensive than the Bassini repair.

- From the societal perspective, the laparoscopic repair is more cost-effective than Bassini repair at the short term.

- The question whether the laparoscopic repair is the most cost-effective repair among all available techniques cannot be answered on the basis of the present scientific evidence.

- The cost-effectiveness of laparoscopic repair is influenced by the surgeon's expertise.

\section{Conclusions - recurrent inguinal hernia}

- Laparoscopic (TAPP) repair for recurrent hernia is a safe operation, associated with less postoperative complications, less pain and a reduced recovery time as compared to GPRVS.

GPRVS is preferred to the laparoscopic repair with regard to recurrence rate.

- The laparoscopic repair is a difficult procedure, and the potential for technical failure is higher.

- The hospital costs of both procedures are comparable. 


\section{The diffusion of endoscopic surgery and MTA}

The surgeon"s perception of the additional benefits of an endoscopic technique over the conventional operation is the most important factor in deciding to adopt it. In an ideal diffusion process, this factor should serve as at prerequisite and must be proven before other factors are allowed to stimulate the diffusion of a medical technology. Most assessments, however, are - if when - performed when the technology is already in (widespread) use. Before evaluations are completed and reported, patterns of use are often already established. The above indicates that, in practice, the ideal diffusion process is often not followed.

In 1992, two years after its introduction in the Netherlands, laparoscopic cholecystectomy was adopted by $90 \%$ of the laparoscopic surgeons, whereas the first RCT's comparing laparoscopic with conventional- or mini-cholecystectomy were published in $1992(8,9)$. The surgeons" decision to adopt this procedure was, besides its expected 'extra benefit', mainly guided by the influence of 'conferences', and "training-programmes/courses". Laparoscopic cholecystectomy is by now internationally accepted as the standard treatment for most patients with symptomatic gallstone disease.

The diffusion of laparoscopic inguinal hernia repair has been more modest. In The Netherlands the first laparoscopic repair was performed at the end of 1991. In 1994, approximately $2 \frac{1 / 2}{2}$ years after its introduction, laparoscopic inguinal hernia repair was adopted by $43 \%$ of the laparoscopic surgeons. In the same year the first results of randomized controlled trials became available. $(27,32)$. The adopters of laparoscopic repair were especially influenced by the expected 'extra benefit' of the procedure, and 'conferences'. Most of the laparoscopic surgeons (the 'non'-adopters) however, had neither a positive, nor a negative perception of the advantages of this technique. Apparently this technique was not as appealing compared with laparoscopic cholecystectomy.

Laparoscopic cholecystectomy has evidently diffused into widespread use before it was adequately evaluated, whereas the adoption process of laparoscopic inguinal hernia repair seems to take place in a more modest way. Based on the current knowledge regarding the adoption rates and (cost-)effectiveness of both laparoscopic procedures, the question is whether the diffusion at this point should either be stimulated or restrained.

Since laparoscopic cholecystectomy is already fully established, further stimulation of the diffusion seems superfluous. In 1993 the procedure was placed on the Health Insurance Council"s "List of 126", which contains 126 existing health care programs and technologies that should be considered for further investigation (33). With regard to laparoscopic cholecystectomy there were silll some questions concerning the (dis)advantages, indications for use and required expertise. Despite these reservations, 
the reimbursement for laparoscopic cholecystectomy has been adapted, indicating that this procedure is considered established and accepted. Up till now laparoscopic cholecystectomy has not been formally investigated in the Netherlands, and it probably never will be. There seems, however, to be some discussion about the change in the spectrum of patients undergoing the procedure and in the threshold for performing it (34-36). This relates well to one of the questions stated earlier by the Health Insurance Council, and might be interesting for further investigation.

Laparoscopic inguinal hernia repair appears to be a cost-effective technique, based on the present scientific "state of the art". Because of the technical difficulty of the procedure, it is expected that not all laparoscopic surgeons will ultimately use this technique in daily practice. Before diffusion-stimulating initiatives are therefore to be considered, further research into the present adoption rate and (indications for) use of laparoscopic inguinal hernia repair is desired. Restraining the diffusion process at this point does not seem necessary, considering the current critical approach of the surgical community towards this technique (37-39).

Besides whether the diffusion of a medical technology should be either stimulated or restrained, the question how this could be achieved is also important.

One way to distinguish medical technologies is in: 1) drugs and biological substances, 2) medical devices and 3) medical services. For each of these technologies different regulative and control mechanisms exist with regard to the "admission to the market", 'admission to the benefit package', and (efficient) 'application within the benefit package'. Surgical endoscopic procedures can be considered as medical services.

Medical services are regulated and controlled by 'article 18' of the Hospital Provisions Act, the benefit package and the global budgeting system. Article 18 regulation has proven to be an effective means to control the diffusion and use of supra-regional 'high-tech' facillites. Most (candidates for) article 18 procedures have been assessed formally and some facililies are restricted to specific indications. Only hospitals that have official approval are allowed to provide the particular treatment, and the extra costs are compensated by an increase in the hospital budget. With regard to "low- and medium-tech" medical technologies, however, no such instrument is available.

The statutory supply of medical technologies is reflected in the health insurance benefit package. However, most medical services are so-called 'open benefits' Specialist care, for example, is often globally described. New techniques and/or other indications for use are automatically reimbursed once they are used by the medical profession. Only when the reimbursement is adapted, as for laparoscopic cholecystectomy, the particular procedure is explicated in the benefit package.

Finally, the hospital budget is not always an effective instrument to control the ditfusion of a new medical technology. Although, for example, the initial investments in equipment and disposable instruments for laparoscopic surgery have been 
substantial, the technique was relatively easy introduced in most hospitals. Once the equipment was obtained and laparoscopic cholecystectomy introduced, other endoscopic procedures soon followed. Although the hospital budget has proven to be effective in containing costs at the macro-level, it is not always an explicit instrument to guide and control the introduction and use of a specific technology at the meso- and micro-level.

As has become obvious, the medical profession has an important role in the diffusion of most medical services, among which surgical endoscopic procedures. This group is also primarily responsible for the conduction of MTA studies. However, it may not be surprising that their primary interest concerns the safety, efficacy and effectiveness of a new medical technology. It is therefore important that the aspects as regards content and organisation of MTA be sufficiently supported.

In order to guide and control the process from introduction to widespread use of "lowand medium-tech' medical services in The Netherlands, the following is recommended:

\section{Recommendations}

- Important new developments should emerge as a result from cooperation between the Health Council and medical societies and/or working groups.

- Formal assessment, preferably in a multi-centre setting when a clinical trial is being performed, should always be the criterion for admitting new significant procedures to established medical practice.

- The central question and design of MTA studies need to be altuned to information that is required and/or already available.

- The central question and design of MTA studies should be endorsed by the specific medical society or working group, in order to stimulate implementation of the knowledge afterwards.

- Reports of formal MTA studies should reach medical professionals, medical societies and working-groups in order to become an explicit and formal part of consensus activities and clinical guidelines.

- The medical profession is primarilly responsible for consensus activities and the drawing up of clinical guidelines with regard to a particular medical technology; indications for use should be explicated. 
The benefit package should include indications for use when necessary.

When a technology has proven to be (cost-)effective, formal assessments should be followed by national questionnaires or comparable activities, in order to determine the actual extent of - and indications for use of that particular medical technology.

- Appropriate incentives should be created for hospitals when a medical technology has proven to be cost-effective at the societal level. When, for example, the reimbursement of a cost-effective medical service is adjusted, this should also be reflected in the hospital budget.

The government and medical insurance companies have to continue the support of MTA studies with regard to significant developments, and they should support the activities surrounding the process of MTA.

\section{References}

1. Pocock, 5.J. Clinical Trials. A pracrical approach. John Wiley \& sons, Chichester, 1989.

2. Kesteloot, K. Penninckx F. The costs and effects of open versus laparoscopic cholecystectomies. Healh Economics 1993;2:303-312.

3. Schol, F.P.G., Go P.M.N.Y.H., Gouma D.J. Risk factors for bile duct injuries in laparoscopic cholecystectomy; analysis of 49 cases. British Jounal of Surgery 1994:81:1786-1788.

4. Demoulin, L.. Kesteloot K., Penninckx. A cost comparison of disposable vs reusable instruments in laparoscopic cholecystectomy. Surgical Endoscopy 1996;10:520-525.

5. Adamek, H.E., Sorg S., Bachor A., Riemann J.F. Symptoms of Post-Extracorporeal Shock Wave Lithotripsy: Long- term analysis of Gallstone Patients before and after Successful Shock Wave Lithotripsy. American Jownal of Gastroenterology 1995;90:1125-1129.

6. Schneider. HT, Benninger J., Rabes U., el al. Recurrent Gallstone Formation after Successful Extracorporcal Shock-Wave Lithotripsy. American Joumal of Gastroenterology $1993 ; 88: 1399-1404$.

7. Sackmann, M., Niller H.. Klueppelberg U., et al. Gallstone recurrence after shock-wave therapy. Gasmonterology 1994; 106:225-30.

8. Kunz. K. Orth K... Vogel J., at al Laparoskopische cholecystectomie versus Mini-Lap Cholecystectomie. Ergebnisse einer prospectiven randomisienten Sudie. Der Chirug $1992 ; 63: 291-295$.

9. Barkun, J.S.. Barkun A.N., Sampalis J., et al Randomised controlled trial of laparoscopic versus mini cholecystectomy. The Lancet 1992:340:1116-1119.

10. Barkun, J.S., Caro J.J. Barkun A.N. et al. Cost-effectiveness of laparoscopic and mimicholecystectomy in a prospective randomized trial. Surgical Endoscopy 1995;9:1221-1224.

11. MeMnibon, A.J., Russel I.T., Ramsay G., el al. Laparoscopic and minilaparotomy cholecystectomy: a randomized trial comparing postoperative pain and pulmonary function. Surgery 1994: 115:533-539.

12. McMahon, A.J., Russell I.T., Baxter J.N., el al. Laparoscopic versus minilaparotomy cholecystectomy: a randomised trial. The Lancet 1994:343:135-138. 
13. MoGinn, F.P., Miles A.J.G., Uglow M., et al. Randonized trial of laparoscopic cholecystectomy and mini-cholecystectomy, British Joumat of Surgery 1995;82:1374-1377.

14. Majeed. A.W. Troy G., Nicholl J.P., et al. Randomised, prospective single blind comparison of laparoscopic versus snall-incision cholecystectomy. The Lancet 1996:347:989-994.

15. Constant, E., Janssen P., Nys J.M. et al. Prospective analysis of 192 consecutive cholecystectomies: a comparative study between laparoscopy and laparoromy. Acha Chirurgica Belgia 1995: 95:254-260.

16. Fullarton, G.M., Darling K... Williams J., MacMillan R. Bell G. Evaluation of the cost of laparoscopic and open cholecystectomy, British Jowmal of Swgery 1994:81:124-126.

17. Hardy, K.J., Miller H., Fleteher D.R. Jones R.M., Shulkes A., MoNeil J.J. An evaluation of laparoscopic versus open cholecystectomy. Medical Youmal of Assiratia 1994:160:58-62.

18. Kelley, J.E., Burrus R.G., Burns R.P., Graham L.D., Chandler K.E. Safety, efficacy. costs and morbidity of laparoscopic versus open cholecystectomy: a prospective analysis of 228 consecutive patients. American Surgeon 1993;59:23-27.

19. Pouvourville de, G., Ribet-Reinhart N., Fendrick M., et al. A prospective comparison of cost and morbidity of laparoscopic versus open cholecystectomy. Hepatogastroenterology 1997;44:35-39.

20. Berggren, U., Zethraeus N, Arvisson D.s Haglund U., Jonsson B. A cosi-minimization analysis of laparoscopic cholecystectomy versus open cholecystectomy. Americam Journal of Surgery 1996;172:305-310.

21. Plaisier, P.W., Hull van der R.L. Nijs H.G., Toon der R., Terpstra O.T., Bruining H.A. Quality of Life after treatment of gallstones: results of at randomised study of lithotripsy and open cholecystectomy. Europeam Joumal of Surgery 1994;160:613-617.

22. Plaisier, P.W., Hul van der R.L., Nijs H.G., Toom der R., Terpstra O.T., Bruining H.A. The course of biliary and gastrointestinal symptoms after treatment of uncomplicated symptomatic gallstones: results of a randomised study comparing extracorporeal shock wave lithotripsy with conventional cholecystectomy. American Journal of Gastroenterology 1994;89:739-744.

23. Nicholl, J.P., Brazier J.E., Milner P.C., et al. Randomised controlled trial of cost-effectiveness of lithotripsy and open cholecystectomy as treatments for gallbladder stones. The Lancet 1992; 340:801-807.

24. Barkun, AN, Barkun IS, Sampalis JS, et al. Costs and effectiveness of extracorporeal gallbladder stone shock wave lithoripsy versus laparoscopic cholecystectomy. Intemational Journal of Technology Assessment in Health Care 1998; 13:589.601.

Simons, M.P. Hoitsma H.F.W. Mullan F.J. Primary Inguinal hernia repair in The Netheriands. European Journal of Surgery 1995; $161: 345-348$.

26. Amid, P.K., Shuman A.G., Lichenstein I.L. An analytic comparison of Laparoscopic Hemia Repair with Open "Tension-Free" Hernioplasty. Internationat Surgery 1995:80:9.17.

27. Payne, J.H., Grininger L.M., Izawa M.T., Podoll E.F., Lindahl P.J. Balfour J. Laparoscopic or open hemiorhaphy? A randomized Prospective Triat. Archives of Surgery 1994;129:973981.

28. Heikkinen, T., Haukipuro K., Leppala J.. Hulkko A. Toul cosis of laparoscopic and Lichtenstein inguinal hemia repairs; a randomized prospective study. Surgical Laparoscopy dendoscopy 1997;7:1-5.

29. Dirksen, C.D. Kosten en effecten wan liesbreuk chinurgie in het academsich riekenhus Maastricht. Eindrapportage t.b.w. Profileringsfonds az M, maart 1997.

30. Liem. M.S. Graf van der I., Steensel van C.I., et al. Comparison of eonventional anterior surgery and laparoscopic surgery for inguinal hemia reparr. New England Joumal of Medicine $1997 ; 336: 1541-1547$.

31. Liem, M.S.L. Inguinal hernia: Modern insights in treament and epidemiology. Academisch 
proefsehrift, Universileit Utrecht, 1997.

32. Stoker, D.L., Spiegelhalter D.J., Singh R., Wellwood J.M. Laparoscopic versus open inguinal hernia repair: randomised prospective trial. The Lancet 1994:343:1243-1245.

33. Zickentondsraad. Kosten-effectiviteitsanalyse bestande versirekkingen (advies), 1993.

34. Stemer, C.A., Bass E.B., Talami M.A., Pitt H.A., Stemberg E.P. Surgical rates and operative mortality for open and laparoscopic cholecystectony in Maryland. New England Journal of Medicine 1994:330:403-408.

35. Legoretta, A.P., Silber J.H. Constantino G.N., Kobylinski R.W., ZatZ S.L. Increased cholecystectomy rate after the introduction of laparoscopic cholecystectomy. Jowrnal of the American Medical Association 1993;27:1429-1432.

36. Schellekens, P.C., Bijnen A.B., Honing M., Lourens J., Ruiter de P. Gevolgen van de introductie van laparoscopische cholecystectomie op morbiditeit en sterfe door galblaasoperaties in een groot regionaal ziekenhuis. Nederlands Tijdsch rift voor Geneeskunde 1995;139:723-727.

37. Hirsch, $N$, Hailey D. The evolution of laparoscopic surgery in routine health care. International Journal of Technology Assessment in Health Care 1995;4:779-785.

38. Mellinger J.D., Ponsky J.L. Recent publications in laparoscopic Surgery: an overview. Endoscopy 1996:28:441-451.

39. Hunter, J.G. Advanced laparoscopic Surgery. American Jownal of Surgery 1997:173:14:18. 


\section{Summary}

The aim of this thesis is twofold. First, the costs and effects of two surgical endoscopic procedures are evaluated. Laparoscopic cholecystectomy is compared to both conventional cholecystectomy and Extra Corporeal Shock-wave Lithotripsy (ESWL). Laparoscopic inguinal hernia repair is compared to Bassini repair, and to Stoppa's Giant Prosthetic Reinforcement of the Visceral Sac (GPRVS) for respectively primary and recurrent inguinal hernias.

Secondly, the adoption rates of six surgical endoscopic procedures, and the influence of several health-care related factors on the adoption of these procedures are investigated. Based on the results of this study, an ideal diffusion profile is described.

In chapter 1 the concept of Medical Technology Assessment (MTA) is presented. The organisation of MTA in the Netherlands, and its relation to the diffusion of medical technology are shortly described. The introduction of laparoscopic cholecystectomy and laparoscopic inguinal hernia repair in the University Hospital of Maastricht is delineated, which went together with the design of MTA studies.

In chapter 2 a retrospective analysis of the costs and effects of three alternative strategies for the treatment of gallbladder stones is presented. The study included 55 patients treated by Extra Corporeal Shock-Wave Lithotripsy (ESWL), 45 patients who had a conventional cholecystectomy (CC) and 47 patients who had a laparoscopic cholecystectomy (LC). Clinical effectiveness and costs of the different modes of gallstone treatment were determined.

After ESWL, 35\% were free of stones, $23 \%$ had residual fragments $\leq 5 \mathrm{~mm}$ and $42 \%$ had fragments $>5 \mathrm{~mm}$, the latter category indicating treatment failure. Ten patients underwent cholecystectomy. Two patients underwent additional treatment. Three patients with initial complete stone dissolution had stone recurrence with I year follow up. In the CC group one patient had to be re-operated because of an incisional hernia. All patients were free of symptomatic residual or recurrent bille duct stones after follow up of at least 1 year. In one patient the laparoscopic procedure was converted to an open procedure, and two patients had a laparotomy within 24 hours of the laparoscopic procedure. All patients from the LC group were free of symptomatic residual or recurrent bile duct stones after follow up of at least 6 monihs. Persistent complaints were most reported by patients from the ESWL group, which was related to the presence of stones. Patient appreciation score was significantly higher in the LC group compared with CC and ESWL. Hospital costs were highest for ESWL. From the financial perspective $\mathrm{CC}$ is the most expensive. The societal costs, expressed as numbers of days until activities are fully resumed, are significantly higher in the CC group as compared to both ESWL and LC. 
In chapter 3 the effectiveness of open and laparoscopic primary inguinal hernia repair is compared by means of a randomized controlled triall. Between November 1993 and July 1995,87 patients with 103 open repairs and 88 patients with 114 laparoscopic repairs were included in the study. Laparoscopic repair was performed using the transabdominal preperitoneal (TAPP) technique. Open hernia repair was performed using the Bassini technique. Outcome measures were: operating time, morbidity and complications, pain, convalescence and recurrence. Operating time was longer for the laparoscopic repair as compared to Bassini repair. The rate and severity of complications was similar in both groups. Patients from the Bassini group had higher postoperative pain scores, used more analgesics, and needed a longer convalescence lime. With a mean follow-up of 24 months, recurrence rates are $21,4 \%$ after Bassini and $6,1 \%$ after laparoscopic repair.

In chapter 4 an incremental cost-effectiveness analysis is presented, comparing the Bassini repair with laparoscopic repair for primary inguinal hernia. The analysis was performed from both the societal- and hospital perspective. The cost-effectiveness ratio was based on the incremental costs per additional 1 -year recurrence-free patient. Results of several reported randomized controlled trials were used as inputs in sensitivity analysis. From the societal perspective, Bassini repair is dominated by the laparoscopic repair, the latter which is both more effective and less costly. From the hospital perspective, the incremental CE-ratio of laparoscopic repair amounts to Dfl 5.348. Results were highly sensitive to assumptions about recurrence rate of Bassiniand laparoscopic repair, laparoscopic operating time and 'return to work'.

In chapter 5 open and laparoscopic preperitoneal mesh repair for recurrent inguinal hernia are compared in a randomized controlled trial. From November 1993 to March 1996. 37 patients (with 41 recurrent and 11 primary inguinal hernias) and 42 patients (with 52 recurrent and 4 primary hernias) were respectively randomized to either open preperitoneal mesh repair or laparoscopic repair. Open mesh repair was performed using Stoppa's Giant Prosthetic Reinforcement of the Visceral Sac (GPRVS). Laparoscopic repair was performed using the transabdominal preperitoneal (TAPP) technique. Operating time, complications, pain, analgesia use, convalescence, recurrences and hospital costs were recorded. Mean operating time was longer for the laparoscopic repair as compared to GPRVS. Most complications were minor, except for a pulmonary embolus and an ileus, both after GPRVS. Wound problems were recorded in $11 \%$ of the patients from the GPRVS group. Patients from the GPRVS group had higher postoperative pain scores, used more analgesics, and needed a longer convalescence time. With a mean follow-up of 21 months, recurrence rates are $1,9 \%$ after GPRVS and $12,5 \%$ after laparosicopic repair. Hospital costs were comparable: Df 2.045 for GPRVS and Dfl 2.004 for laparoscopic repair. 
In chapter 6 the diffusion of six surgical endoscopic procedures in the Netherlands is investigated. Questionnaires were sent to 138 laparoscopic surgeons. They were asked which of the following endoscopic procedures they had adopted in their hospital: cholecystectomy, appendicectomy, Nissen fundoplication, inguinal hemia repair, large bowel resection and thoracoscopic procedures. Furthermore, they were asked to indicate the influence of 13 pre-defined factors: 'budget', 'competition', 'conference', 'extra benefit", 'media', 'nature of the technology', "patient demand', 'planning/logistics", 'reimbursement', "service industry', 'support industry', 'surgical technique' and 'training/course' on the adoption of those procedures.

The adoption rates for the above procedures were: $100 \%, 69 \%, 19 \%, 43 \%, 19 \%$ and $52 \%$, respectively. In general, factors were assessed more positively by adopters than by non-adopters. Significant differences were mainly found for 'extra benefit', 'nature of the technology', 'surgical technique' and 'conference'. The surgeon's perception of the additional benefits of an endoscopic technique and, to a lesser degree, of its technical aspects were the most important factors in deciding whether or not to adopt a procedure.

In an ideal diffusion model, a description is given of when and how the 13 factors can influence the diffusion of an endoscopic procedure in the desired direction. It is outlined that new technology should not be controlled in the experimental phase, since valuable developments can emerge in this phase. If the technology is expected to generate considerable effects or costs, early evaluation is desired during the initial adoption phase. During research, training courses, scientific meetings and conferences serve as important means for information transfer. Such activities can be supported by medical companies. When assessments are finished it is important that results be distributed among possible users. If the prerequisite of 'extra benefit' is evident then diffusion can be stimulated by other factors like the media, patient demand, competition and reimbursement.

In chapter 7, some methodological issues of the clinical studies are considered, and results are placed into a broader (international) perspective. The general condusions of these studies are explicated. In addition, the diffusion of both laparoscopic cholecystectomy and laparoscopic inguinal hemia repair is related 10 MTA. It is discussed whether and how the diffusion of these technologies should be influenced. Finally, general recommendations are given with respect to MTA in relation to the diffusion of medical services. 



\section{Samenvatting}

Het doel van dit proefschrift is tweeledig. Ten eerste worden de kosten en effecten van twee chirurgisch-endoscopische procedures geevalweerd. De laparoscopische galblaas verwijdering wordt vergeleken met de conventionele galblaasverwijdering en de "extracorporale schokgolf lithotripsie" (ESWL). De laparoscopische liesbreukoperatie wordt vergeleken met het Bassini herstel en de operatie volgens Stoppa, voor respectievelijk primaire- en recidief liesbreuken.

Ten tweede wordt een inventarisatie gemaakt van de adoptie-percentages van zes chirurgisch-endoscopische verrichtingen in Nederland. Daarbij wordt de invloed van verschillende factoren op de adoptie onderzocht. Op basis van de resultaten wan deze studie wordt beschreven op welke wijze de diffusie van een medische technologie idealiter zou moeten plaatsvinden.

In hoofdstuk 1 wordt het concept van "Medical Technology Assessment"(MTA) beschreven. De organisatie van MTA in Nederland, alsmede de relatie van MTA met de diffusie van medische technologieën wordt kort gepresenteerd. Vervolgens wordt beschreven dat de introductie van de laparoscopische galblaasverwijdering, en vervolgens de laparoscopische liesbreukoperatie, in het academisch ziekenhuis Maastricht vrijwel direct aanleiding is geweest tot het schrijven van onderzoeksprojecten, met het doel de laparoscopische techniek te vergelijken met de gebruikelijke therapieèn.

In hoofdstuk 2 worden de resultaten van een retrospectieve studie gepresenteerd. De studie omvat 55 patiënten die zijn behandeld met "Extracorporele Schokgolf Lithotripsie" (ESWL), 45 patiënten die een conventionele galblaasoperatie (CC) hebben ondergaan en 47 patiënten die middels de laparoscopische galblaasoperatie (LC) zijn geopereerd. De eindpunten van de studic zijn: steenvijheid, klachtenvrijheid, tevredenheid over de behandeling en kosten. Na de ESWL procedure is $35 \%$ van de patiënten steen-vrij (succesvol), $23 \%$ heeft restustenen $\leq 5 \mathrm{~mm}$ (technisch geslaagd) en $42 \%$ heeft restwstenen $>5 \mathrm{~mm}$ (niet succesvol). Tien patiërnten ondergaan na ESWL alsnog een cholecystectomie en 2 patiènten krijgen additionele behandeling. Drie patiënten bij wie de vergruizing in eerste instantie succesvol was, krijgen recidief-stenen binnen én jaar follow up. In de $\mathrm{CC}$ groep ondergaat sén patiënt een re-operatie vanwege een littekenbreuk. Bij geen van de patiènten zijn na eén jaar follow up symptomatische rest-stenen of recidief-galwegstenen aanwezig. In de LC groep vindt één conversie plaats naar de open procedure. Twee patiënten ondergaan binnen 24 uur na de operatie een laparotomie. Bij geen van de patiënten zijn na ten minste 6 maanden follow up symptomatische rest-stenen of recidiefgalwegstenen aanwezig. Blijvende klachten worden het meest gerapporteerd in de ESWL groep, hetgeen gerelateerd is aan de aanwezigheid van stenen. Patiẻnten uit de 
LC groep zijn het meest tevreden over de behandeling, vergeleken met beide andere groepen. De ziekenhuiskosten zijn het hoogst voor de ESWL procedure. Vanuit het perspectief van de ziektekostenverzekeraar is conventionele cholecystectomie het duurst. Ook de indirecte kosten, uitgedrukt in het aantal dagen totdat de activiteiten weer volledig zijn hervat, zijn het hoogst in de CC groep.

In hoofdstuk 3 worden de resultaten van een gerandomiseerde studie beschreven, waarin de standaard Bassini operatie wordt vergeleken met het laparoscopische transabdominaal preperitoneaal prosthetisch herstel, voor de behandeling van primaire liesbreuken. De Bassini groep bestat uit 87 patiënten, die 103 liesbreuk-operaties ondergaan. De laparoscopie groep bestaat uit 88 patiénten met 114 liesbreukoperaties. De belangrijkste eindpunten van de studie zijn: operatieduur, morbiditeit en complicaties, pijn, herstelperiode en het optreden van een recidief. De operatieduur is langer voor het laparoscopische herstel. Beide ingrepen zijn nagenoeg vergelijkbaar wat de hoeveelheid en ernst van de complicaties betreft. Patiënten die een Bassini operatie hebben ondergaan ervaren na de operatie meer pijn, gebruiken meer pijnstillers, en hebben een langere herstelperiode nodig, vergeleken met patiënten uit de laparoscopie groep. Met een gemiddelde follow up van 24 maanden bedraagt het recidiefpercentage $21,4 \%$ in de Bassini groep en $6,1 \%$ in de laparoscopie groep.

In hoofdstuk 4 wordt een incrementele kosten-effectiviteitsanalyse gepresenteerd. Uitgangspunt van deze analyse vormt de in hoofdstuk 3 beschreven gerandomiseerde studie. De resultaten worden zowel vanuit het maatschappelijke perspectief als het ziekenhuis-perspectief beschreven. De kosten-effectiviteitsratio is gebaseerd op de incrementele kosten per additionele recidief-vrije patiënt, binnen een follow-up van I jaar. De resultaten van verschillende studies worden als input gebruikt voor gevoeligheidsanalyses. Vanuit het maatschappelijke perspectief wordt de Bassini operatie gedomineerd door het laparoscopische herstel, ondat laatstgenoemde zowel effectiever als goedkoper is. Vanuit het ziekenhuisperspectief bedraagt de incrementele kosten-effectiviteitsratio van de laparoscopische liesbreukoperatie Dfl 5.348 per recidief-vrije patiènt. De resultaten blijken zeer gevoelig voor de hoogte van de recidief-percentages, de laparoscopische operatieduur en het 'aantal dagen tot volledige werkhervatting".

In hoofdstuk 5 worden twee technieken voor de behandeling van recidief liesbreuken in een gerandomiseerde studie met elkaar vergeleken. Zevenendertig patiënten (met 41 recidief- en 11 primaire breuken) en 42 patiënten (met 52 recidief-en 4 primaire breuken) worden gerandomiseerd voor respectievelijk het open preperitoneaal prosthetische herstel volgens Stoppa en het laparoscopische transabdominaal preperitonealal prosthetisch herstel. Als eindpunten van de studie zijn gedefinieerd: operatieduur, morbiditeit en complicaties, operatieduur, pijn, herstelperiode, het 
optreden van een recidief, alsmede de kosten voor het ziekenhuis. De gemiddelde operatieduur is langer voor de laparoscopische procedure, vergeleken met het open herstel. $\mathrm{Na}$ het open herstel heeft $11 \%$ van de patiênten wondproblemen, en treden er 2 ernstige complicaties op. Patiënten uit deze groep ervaren tevens meer pijn, gebruiken meer pijnstillers en hebben een langere herstelperiode nodig. Met een gemiddelde follow up van 21 maanden bedragt het recidiefpercentage $1,9 \%$ na het open herstel en 12,5\% na een laparoscopisch herstel. De gemiddelde kosten per patient zijn voor het ziekenhuis nagenoeg vergelijkbaar: Df 2.045 voor het open preperitoneale herstel en Df1 2.004 voor het laparoscopische herstel.

In hoofdstuk 6 wordt verslag gedaan van een onderzoek naar de diffusie van 6 chirurgisch-endoscopische ingrepen in Nederland. Vragenlijsten zijn verstuurd naar 138 laparoscopische chirurgen. Aan de chirurgen wordt gevraagd on aan te geven of en, indien ja, wanneer de volgende endoscopische ingrepen in hun betreffende ziekenhuis zijn geïntroduceerd of geadopteend cholecystectomie, appendectomie, Nissen fundoplicatie, hernia inguinalis herstel, colon operatie, thoracoscopische procedures. Vervolgens wordt gevraagd om de invloed van de volgende 13, vooraf gedefinieerde factoren op de adoptie van betreffende procedures aan te geven: 'budget', 'competitieve factoren', 'congressen/symposia', 'meerwarde van de behandeling', 'media', 'aard van de technologie', 'patiünt-vraag', 'planning/logistiek', 'vergoeding", "service van de industrie", 'ondersteuning door de industrie', 'chirurgische techniek' en 'training/cursus'. De adoptie-percentages van bovengenoemde procedures bedragen respectievelijk: $100 \%, 69 \%, 19 \%, 43 \%, 19 \%$ en $52 \%$. In het algemeen worden de factoren positiever beoordeeld door chirurgen die een techniek wél hebben geintroduceerd, dan chirurgen die betreffende techniek (nog) niet hebben geintroduceerd. Dit geldt met name voor de factor "meerwaarde", en in mindere mate voor de factoren 'aard van de lechnologie', "chirurgische lechniek", en "congressen/symposia".

Op basis van bovenstande resultaten wordt beschreven op welke manier betreffende factoren de diffusie van een medische technologie in de gewenste richting zouden kunnen beïnvloeden. Gesteld wordt dat de experimentele fase van een technologic 'ongecontroleerd' dient plaats te vinden, aangezien mogelijk waardevolle ontwikkelingen daardoor afgerend zouden kumnen worden. Indien ha de eerste ervaringen met de techniek verwacht wordt dat deze een aanzienlijke verschuiving in kosten en/of effecten teweeg kan brengen, dient deze in een zo vroeg mogelijk stadium van de diffusie geevalueerd te worden. Tijdens de evaluatie kunnen trainingen, cursussen en wetenschappelijke bijeenkomsten een belangrijke bijdrage leveren aan de informatie overdracht. De resultaten van (kosten-)effectiviteits studies dienen bij mogelijke gebruikers terecht te komen, opdat deze ook daadwerkelijk worden geïmplementeerd. Pas indien een technologie een bewezen meerwarde heeft, mogen andere factoren bijdragen aan een optimale diffusie van betreffende 
technologie.

In hoofdstuk 7 worden een aantal methodologische aspecten van de klinische studies aan de orde gesteld, waarbij de resultaten van betreffende studies in een breder (internationaal) kader worden geplaatst. De algemene conclusies ten aanzien van deze studies worden nog eens naar voren gehaald. Vervolgens wordt cle relatie gelegd tussen MTA en de diffusie van de laparoscopische galblaasverwijdering en liesbreukoperatie. Bediscussieerd wordt óf en op welke wijze de diffusie van beide ingrepen beïnvloed zou kunnen worden. Tenslotte worden algemene aanbevelingen gedaan, waarin de relatie wordt gelegd tussen MTA en de diffusie van medische procedures. 


\section{Dankwoord}

Graag wil ik iedereen bedanken die direct of indirect een bijdrage heeft geleverd aan de totstandkoming van dit proefschrift. Een aantal mensen wil ik met name noemen.

Professor dr. G. Kootstra, hoofd vakgroep Algemene Chirurgie en promotor. Professor Kootstra, met name het afgelopen jaar bent u zeer betrokken geweest bij mijn proefschrift én volhoudend ten aanzien van de afronding ervan. $I k$ dank u hartelijk voor het getoonde vertrouwen, en voor die latste duw in de goede richting die ik nodig had.

Peter Go, chirurg en co-promotor. Beste Peter, onze eerste ontmoeting waarbij ik letterlijk achter jou aan rende op weg naar je kantoor, kenmerkt precies de wijze waarop jij te werk gaat. In de loop der jaren ben ik jouw tempo enigscins gaan bijhouden, maar ik zal je nooit inhalen. Zeer hartelijk bedankt voor jouw stimulerende rol bij de totstandkoming van dit proefschrift.

André Ament, econoom en co-promotor. Beste André, hoewel ik in de eerste periode van onze samenwerking jouw kalme vastberadenheid wel eens verwarde met ongelijk hebben -koppig als ik kan zijn- ben ik daar zeer snel op teruggekomen. Jouw bijdragen aan dit proefschrift zijn zeer waardevol geweest, bedankt daarvoor.

Geerard Beets, chirurg en collega-onderzoeker bij de "liesbreuk studie". Beste Geerard, bedankt voor de leuke samenwerking gedurende de afgelopen jaren. Hoewel jouw agenda zonder twijfel voller stond dan die van mij en jij zelf ook druk was met je eigen proefschrift, kon ik met vragen altijd bij je terecht. Ik hoop dat jij met "economische vragen" nog eens bij mij langskomt.

Cor Baeten, chirurg. Beste Cor, hoewel we niet dagelijks hebben samengewerkt heb je als projectmedewerker toch altijd zijdelings een oog gehouden op het onderzoek. Dank voor je commentaren en inbreng bij de artikelen die hieruit zijn voortgekomen. Eddy Adang, econoom en collega van de research kamer Chirurgie. Besle Eddy, jij hebt mij in de beginperiode bij Chirurgie wegwijs gemaakt in het reilen en zeilen op de afdeling én, zeker niet onbelangrijk, in "De Research". Onze discussies waren dikwijls fel, maar hebben tot een aantal leuke resultaten geleid. Bedank voor jouw enthousiaste en kritische samenwerking.

Bernadette van Acker. Frans Dekker, Marius Kemler en Henk Pietersen, ook collega's van de research kamer Chirurgie. Vijf onderzoekers in Cén kamer is niet altijd een productieve formule gebleken, maar wel een gezellige. Inmiddels zijn we, op ěén na, allemaal van de kamer verdwenen, maar de gezelligheid zetten we tegenwoordig onder culinaire ornstandigheden voort aan "De Tafel van Vijp". Dank voor jullie collegialiteit en vriendschap.

Gerard Engel, voormalig secretaris Raad van Bestuur azM. Beste Gerard, hoewel je niet direct bij mijn proesschrift betrokken bent geweest, heb je altijd een kritische interesse getoond in mijn werkzaamheden. Mijn onderzoek heeft tot veel leuke 
gesprekken met jou geleid die het geheel zeker ten goede zijn gekomen. Mijn dank daarvoor.

Jean Vranken, voormalig beheerder Chirurgie en Marjan Siep, office manager Chirurgie, beiden bedankt voor alle praktische ondersteuning die jullie mij hebben geboden tijdens en ook na mijn aanstelling bij Chirurgie.

Yvonne Bormans, Claudia Driehuys en Wilma Domen, bedankt voor de secretariële ondersteuning. Yvonne en Claudia, hoewel ik officieel eigenlijk geen beroep op jullie mocht doen, hebben jullie me bij veel klussen geholpen. Bedankt voor jullie enthousiaste steun. Wilma, bedankt voor je vriendelijke hulp met name in de laatste fase.

Alle medewerkers van de KVA2, polikliniek Chirurgie en Bureau Opname wil ik bedanken yoor hun inzet tijdens de studie. Dankzij jullie informatie en telefoontjes heb ik bijna geen patiënt "gemist" en bovendien heel wat gezonde kilometers in het ziekenhuis afgelegd.

Alle laparoscopische chirurgen in Nederland wil ik bedanken, die met het invullen van de "Enquëte Laparoscopische Chirurgie" een bijdrage hebben geleverd aan éen van de publikaties van dit proefschrift.

De leden van de beoordelingscommissie, prof. dr. H. Maarse (voorzitter), prof. dr. J. de Haan, prof. dr. R. Stockbrügger, prof. dr. F. Rutten (Erasmus Universiteit Rotterdam) en prof. dr. K. Kesteloot (Katholieke Universiteit Leuven, België) dank ik voor de beoordeling van dit proefschrift en de voorgestelde verbeteringen.

Mijn huidige collega's van de Onderzoeksgroep, Jack Bibo, Annemie Courtens, Brigitte Essers, Fred Nieman en Gemma Voss wil ik bedanken voor hun belangstelling en steun in die laatste drukke maanden voor "de dag".

Mijn lieve vriendin en paranimf Danielle, jou wil ik bedanken voor je vriendschap en hartelijkheid gedurende de afgelopen 10 jaar. Onze studie Gezondheidswetenschappen hebben we gezamenlijk afgesloten met een stage bij Chirurgie. Wie had ooit gedacht dat deze stage uiteindelijk tot een proefschrift zou leiden!

Lieve pap en mam, dank voor jullie steun en vertrouwen. Ondanks het feit dat de afgelopen jaren voor jullie zeer ingrijpend zijn geweest, hebben jullie altijd interesse getoond in mijn activiteiten. Mijn dank daarvoor en hél véél liefs.

Mijn lieve zus(je) Ingrid, jou wil ik bedanken voor al die gezellige en ontspannende dagen die we samen in Maastricht of in Utrecht hebben doorgebracht. Een weekendje stappen met jou leidde mij altijd weer met frisse moed -doch niet zo"n fris gezichtnatr een nueuwe week.

Lieve Marcel, mijn beste vriend en partner, jouw rustige manier van relativeren van woor mij - stressvolle zaken, en jouw rotsvaste vertrouwen in mijn kunnen, heeft mijn zelfvertrouwen altijd gesterkt. Ik hoop dat je deze invloed ook op me zal hebben tijdens de verdediging, wanneer jij als paranimf aan mijn zijde staat. Dankjewel voor alles. 


\section{List of Publications}

- De diffusie van endoscopische chirurgie. Economisch Statistische Berichten 1994; 79: 82-85. Dirksen C.D., Ament A.J.H.A., Go P.M.N.Y.H., Hupkens van der Elst D.

- Budgettering van ziekenhuizen: géén doeltreffend instrument voor efficięntie. Nederlands tijdschrift voor Heelkunde 1994; 3: 54-55. Dirksen C.D. Go P.M.N.Y.H.

- Cost-effectiveness of treatment with extracorporeal shock-wave lithotripsy, conventional and laparoscopic cholecystectomy. Go P.M.N.Y.H., Stolk M.F.J., Obertop H., Dirksen C.D., Hupkens van der Elst D., Ament A.J.H.A., Erpecum van K.J., Berge Henegouwen van G.P., Gouma D.J. Surgical Endoscopy 1995; 9: $37-41$.

- Medical Technology Assessment: economic evaluation of new technologies. Adang E.M.M., Dirksen C.D., Engel G.L., Baeten C.G.M.I. British Jounal of Hospital Medicine 1995; 53: 562-566.

- Five years of laparoscopic cholecystectomy in the Netherlands. Go P.M.N.Y.H., Dirksen C.D. International Surgery 1995; 80: 304-306.

- Diffusion of six surgical endoscopic procedures in the Netherlands. Dirksen C.D., Ament A.J.H.A., Go P.M.N.Y.H. Stimulating and restraining factors. Health Policy 1996;37:91-104.

Medical technology assessment and the role of economic evaluation in health care. Adang E.M.M., Ament A.J.H.A. Dirksen C.D. Joumal of Evaluation in Clinical Practice 1996;2:287-294.

- Technologie afgewogen. Dirksen C.D., Adang E.M.M. Medisch Nieaws (maandelijkse column januari-december 1996).

- Eindrapportage t.b.v. het Profileringsfonds azM. Kosten en effecten van liesbreuk chirurgie in het academisch ziekenhuis Maastricht. Dirksen C.D., Beets G.L., Go P.M.N.Y.H., Geisler F.E.A., Baeten C.G.M.I., Kootstra G. (rapport, maart 1997). 
- Eindrapportage t.b.v. psychotherapeutisch centrum "De Viersprong". Patiënten-populatie psychotherapeutisch centrum "De Viersprong". Dirksen C.D. (rapport, oktober 1997 ).

- Chirurgische patiëntenstroom geanalyseerd. Een retrospectief onderzoek in het Academisch Ziekenhuis Maastricht. Dirksen C.D., Wildenberg van de F., Merode van F., Vranken J., Boumans R. Medisch Contact 1998; 53: 390-394.

- Bassini repair versus laparoscopic repair for primary inguinal hernia. A randomized controlled trial. Dirksen C.D., Beets G.L., Go P.M.N.Y.H., Baeten C.G.M.I, Geisler F.E.A., Kootstra G. European Journal of Surgery. (In press).

- Cost-effectiveness of open versus laparoscopic repair for primary inguinal hernia. Dirksen C.D., Ament A.J.H.A., Adang E.M.M., Beets G.L., Go P.M.N.Y.H., Baeten C.G.M.I., Kootstra G. International Joumal of Technology Assessment in Health Care. (In press).

- Open versus laparoscopic preperitoneal mesh repair for recurrent inguinal hernia. A randomized controlled trial. Beets G.L., Dirksen C.D., Go P.M.N.Y.H., Geisler F.E.A., Baeten C.G.M.I., Kootstra G. (Submitted). 


\section{Curriculum Vitae}

Carmen Dirksen was born on December $8^{\text {th }} 1967$ in Sneek, The Netherlands. In 1986 she graduated from the Corderius Coliege in Amersfoort. From 1986101987 she attended the first year of physiotherapy at the Tim van der Laan Academy for Physiotherapy in Utrecht, where she took her propaedeutics. In September 1987 she started studying at the Faculty of Health Sciences from the University of Limburg, and graduated in August 1992. From December 1992 to March 1997 she worked as a researcher at the Department of Surgery from the University Hospital of Maastricht. From March 1997 to September 1997 she worked as a researcher at the department of Heaith Organisation, Policy and Economics (HOPE) from the Faculty of Health Sciences, University of Maastricht. In September 1997 she started working at the Research Unit Patient Care from the University Hospital of Maastricht. 
Financial support for the publication of this thesis was provided by Drukkerij Schrijen-Lippertz Voerendaal bv. 